\title{
Reducing Poverty AND Hunger IN AsIA
}

The Role of Agricultural and Rural DeVelopment

EDITED BY

NURUL ISLAM 


\section{Introduction}

After 30 years of dynamic growth and substantial poverty reduction in Asia, do agriculture and rural development still have a role to play in that region? The policy briefs in this collection provide abundant evidence that they do. Although the incidence of people living in poverty fell from more than 50 percent in the mid-1970s to 18 percent in 2004, and the incidence of hunger fell to 16 percent,Asia is still home to more than half of the world's poor, most of whom live in rural areas. Agriculture and rural development are thus still key to reducing poverty and hunger in the region.

These policy briefs explore how agriculture and rural development can play this vital role. The authors examine the scale and nature of poverty and hunger in rural Asia and explore growth and structural changes in Asian agriculture and rural nonfarm activities. They discuss strategies for economy-wide and trade policies to encourage inclusive rural growth, key emerging risks such as climate change, and instruments for mitigating and managing risks.

These briefs arise out of a high-level policy forum, "Agricultural and Rural Development for Reducing Poverty and Hunger in Asia: In Pursuit of Inclusive and Sustainable Growth," organized by the International Food Policy Research Institute (IFPRI) and the Asian Development Bank (ADB) in Manila in August 2007. The forum brought together about 100 leaders and stakeholders from the public and private sectors, academia, and civil society from all over Asia and around the world. This forum was part of a wider consultation process leading up to the IFPRI-facilitated conference "Taking Action for the World's Poor and Hungry People," held in Beijing in October 2007.

We are very grateful to Nurul Islam for conceptualizing the policy forum and editing this collection, and to the contributors for their insightful briefs. We also thank Ruth Vargas Hill for the key role she played throughout this process. We deeply appreciate the collaborative partnership with ADB in organizing the forum. We hope that the findings and recommendations presented here will contribute to a broader consensus on the role of agricultural and rural development in reaching and going beyond the Millennium Development Goals and in achieving inclusive and sustainable growth in Asia.

Joachim von Braun
Director General
Rajul Pandya-Lorch

Head, 2020 Vision Initiative

The International Food Policy Research Institute (IFPRI) is one of several international research centers supported by the Consultative Group on International Agricultural Research (CGIAR). "A 2020 Vision for Food, Agriculture, and the Environment" is an initiative of IFPRI to develop a shared vision and consensus for action on how to meet future world food needs while reducing poverty and protecting the environment. These briefs are based on a policy consultation process coordinated by IFPRI's 2020 Vision Initiative that focused on the world's poor and hungry people. IFPRI gratefully acknowledges the contributions of: Asian Development Bank (ADB) www.adb.org, Bill and Melinda Gates Foundation www.gatesfoundation. org, Canadian International Development Agency (CIDA) www.acdi-cida.gc.ca, Deutsche Welthungerhilfe (German Agro Action) www.welthungerhilfe.de, European Commission ec.europa.eu, and German Federal Ministry for Economic Cooperation and Development www.bmz.de, with Deutsche Gesellschaft für Technische Zusammenarbeit www.gtz.de (BMZ/GTZ), International Development Research Centre (IDRC) Canada www.idrc.ca, and Irish Aid www.irishaid.gov.ie.

The views expressed in these Focus briefs are those of the author(s) and are not necessarily endorsed by or representative of IFPRI or of the cosponsoring or supporting organizations. 
NURUL ISLAM AND JOACHIM VON BRAUN

Focus I5 • BRIEF I OF I5 • MARCH 2008

I n the past 30 years Asia has experienced dynamic growth and structural transformation and achieved substantial poverty reduction. The extension of current trends will create a dramatically transformed Asia by 2015. The incidence of people living in poverty in the region has fallen from more than 50 percent in the mid-1970s to 18 percent in 2004, and the incidence of hunger from more than 30 percent to 16 percent. Currently the region is home to 520 million hungry people (as defined by the Food and Agriculture Organization of the United Nations [FA0]) and 600 million poor people (as defined by the World Bank).

By 2015 Asia's share of global gross domestic product (GDP) will approach 42 percent, but Asia will still be home to half of the world's poor, and projections show that three-quarters of these poor will live in rural areas. Currently 85 percent of those who live on less than a dollar a day live in rural areas. Generating productivity increases in agriculture and nonfarm rural industries is critical in a region in which 60 percent of the population will still live in rural areas in 2015. Solving rural poverty in Asia is thus essential to facilitating the participation of the poorest in the region's growth.

\section{ACHIEVEMENTS TO DATE}

In 1975 agriculture accounted for between 30 and 40 percent of GDP and 49-94 percent of the workforce across the region, so growth in this sector was a major source of overall economic growth well into the late 1980s (Table 1). Agricultural growth was driven by productivity increases in agriculture resulting from higher yields, expansion of irrigation, higher agricultural labor productivity, and scientific and technological advances.

In South Asia these productivity increases were in large part due to the Green Revolution, whereas in other countries they were driven mainly by agricultural policy reform. Although early growth in agricultural income in China was accelerated by Green Revolution effects, later growth resulted from the break-up of collective farms, the introduction of the household responsibility system, reforms to the procurement system, and the liberalization of agricultural prices. Picking the "low-hanging fruits" of agricultural reform not only resulted in a one-time gain to agricultural growth, but also triggered a monumental expansion of the Chinese economy.

Because poverty is concentrated in rural areas and many poor people depend on the farm sector for their incomes, agricultural growth had a substantial impact on poverty reduction, regardless of agriculture's share in overall GDP. This impact is shown in the experiences of both China and India: Indian states that saw the largest poverty reductions also experienced the highest agricultural growth, and the periods of greatest poverty reduction in China were the ones when agricultural incomes increased the most. Agricultural growth contributed most to poverty reduction when land was equitably distributed (as in Indonesia), new technologies could be profitably adopted on farms of all sizes (such as Green Revolution technology), rural infrastructure connected villages to local markets (as in the lowland areas of Vietnam), and farmers were able to diversify into the rural nonfarm economy (such as in Bangladesh).

Agricultural growth affects rural poverty reduction not only by increasing farm incomes, but also by stimulating the nonfarm economic sector in rural areas and small towns. Studies in the 1980s showed that the impact of a US\$1 increase in agricultural value added in the region resulted in an increase in nonfarm value added of between US\$0.50 and US\$1. Nonfarm incomewhich includes rural trade, services, transportation, handicrafts, transfers of remittances, and small-scale manufacturing-now accounts for 51 percent of rural income in Asia. The contribution of the rural nonfarm economy to reductions in rural poverty has resulted as much from indirect effects-the tightening of rural labor markets and increases in agricultural wages-as from direct increases in income-earning opportunities.

Table I-Share of Agriculture in GDP and Growth, and Trends in Poverty

\begin{tabular}{|c|c|c|c|c|c|c|}
\hline \multirow[b]{2}{*}{ Region/Country } & \multicolumn{2}{|c|}{$\begin{array}{l}\text { Share of Agriculture } \\
\text { in GDP (\%) }\end{array}$} & \multicolumn{2}{|c|}{$\begin{array}{c}\text { Share of Agricultural Growth in } \\
\text { Overall Growth (\%) }\end{array}$} & \multicolumn{2}{|c|}{$\begin{array}{l}\text { US\$I a Day } \\
\text { Poverty (\%) }\end{array}$} \\
\hline & 1975 & 2005 & $1975-1985$ & $1995-2005$ & $|98|-\mid 983$ & 2004 \\
\hline East Asia and the Pacific & 32 & 13 & 20 & 7 & 58 & 9 \\
\hline China & 32 & 13 & 21 & 6 & 64 & 10 \\
\hline South Asia & 40 & 19 & 18 & 10 & 50 & 31 \\
\hline India & 41 & 18 & 17 & 9 & 48 & 34 \\
\hline
\end{tabular}

Source:World Bank, World Development Report 2008 (Washington, DC: 2007). 
The rate of progress has not been uniform, however. In East Asia and the Pacific, the value added in agriculture grew at about 4.7 percent during the $1980 \mathrm{~s}, 3.5$ percent during the 1990s, and 3.4 percent during 2000-2004, whereas in South Asia the respective rates of growth during these periods were 4.4, 3.2, and 2.1 percent. Within countries, regional disparities have also been stark. In India, for instance, half of the poor are found in just three states. The most disadvantaged regions often suffer from poor agroecological conditions and limited market access, although their poorer record on poverty reduction could also be due to public policies or poor governance. Thus there are in fact many "Asias" today, and policies to deal with poverty and rural development must be tailored accordingly.

Specific groups within the region have benefited less from growth. Ethnic minorities located in mountainous regions in Southeast Asia (such as in Laos and Vietnam), tribal peoples in South Asia (such as in Bangladesh and India), and members of scheduled castes in India are examples of these excluded groups. The situation of women in Asia varies from country to country, but in general gender inequality remains a cause for concern. Inclusive agricultural and rural development strategies that offer real opportunities for improvements in well-being for these groups are needed.

\section{CURRENT AND FUTURE CHALLENGES AND OPPORTUNITIES}

The continued concentration of the Asian population, particularly the poorest, in rural areas implies that productivity increases in agriculture and nonfarm rural industries remain a critical component of an inclusive growth strategy for the region. It takes time for growth in urban-based manufacturing and service activities to pull and absorb the increasing labor force from the rural sector and for small-scale farming to shift toward a mix of increased-scale, efficient part-time farming arrangements and nonfarm work.

Because accelerating rural growth is a key way to reduce rural poverty, the primary challenge before policymakers is to strengthen incentives, technology, and institutions designed to promote rural growth. Second, measures must be taken to ensure that rural poor farmers and the landless can participate in the fruits of rural economic growth.

The components of a pro-poor development strategy include

- improved access to markets, land, and credit for the poor;

- land markets and land reforms to increase tenure security and access for smallholders;

- the effective use of new and increasingly sophisticated technologies in agriculture and communications, and efforts to make these technologies available to small farmers and rural communities;

- innovations to bring small farmers into the orbit of microfinance and insurance institutions through intermediaries, if appropriate;

- public-sector investment in crop technologies and biotechnology that have high social benefits for the poor; and

- decentralization of extension services to encourage bottom- up flow of information from farmers about their needs, combined with adaptive, location-specific research.

Encouraging agricultural and rural growth will not be enough to ensure that the poor are included. Investments in education, health, and nutrition are also required. Social protection and safety nets must supplement incomes and provide employment when incomes are jeopardized. Different countries have tried a wide variety of social assistance measures, such as labor-intensive public employment schemes, conditional or unconditional cash or food transfer or subsidy programs, as well as nutritional intervention programs. The lessons learned need to be monitored and analyzed so that improved cost-effective and povertyalleviating schemes can be devised and shared.

Asia also faces different challenges and opportunities than in the past. Current conditions call for a broader concept of agriculture that encompasses the whole supply chain (production, processing, and retailing) and incorporates the growing role of ecosystem services (such as biomass production for energy, carbon sequestration, and watershed management). Also, a pro-poor rural growth strategy must adopt a concept of nutritional deficiency that goes beyond calories. In particular, rural development strategies need to adapt to a number of new realities.

\section{The Changing Nature of Agriculture}

Food markets and agricultural production are rapidly changing in Asia. Cropping patterns are diversifying from traditional cereals and export crops toward newer and higher-value products such as fruits, vegetables, and flowers-all facing rising demand in response to income growth in domestic and export markets. Livestock and dairy production is also increasing in response to rising demand. Food safety and animal health in extended food chains have become increasingly important, and production systems have changed as a result. Consumers are increasingly willing to pay a premium for quality and food safety, and a larger share of consumer food purchases are now made through supermarkets that can meet these demands.

Agricultural energy (biofuel) production presents an opportunity for farmers by increasing demand for agricultural products, including for biomass products. A modern biofuel industry could also provide farmers in parts of Asia with a use for crop residues and marginal land. Because biofuel production can be labor intensive, it may also generate additional employment in rural areas.

Enabling smallholder farmers to connect to these new markets is a challenge for the public and private sector in the region. The productivity advantage of small farms is thought to be derived from lower labor costs, but the new markets often entail higher capital intensity in production, pose greater risks (perceived and real), and demand new skills. Ensuring that new crops and technologies are scale-neutral, training farmers in new crops and markets, improving access to credit for farmers without collateral, and investing in supportive infrastructure such as cold storage facilities are all important points of entry for policy. The benefits can be large because the diversification of small farmers' output raises the value added per capita and helps them escape from poverty.

Information and communication technologies are increasingly used to provide farmers with timely access to information on input and output markets. Institutional 
innovations are also under way in credit markets. Small farmers acting individually often cannot achieve economies of scale in supplying value chains and meeting required quality and safety standards for high-value products. Producers' organizations can help small farmers overcome high transaction costs in factor and product markets, achieve economies of scale in input procurement and output marketing, and gain market power in integrated distribution and marketing chains.

\section{The Increasing Role of Nonfarm Income}

Nonfarm activities make up a substantial share of the income of farm households in today's Asia. But poor households have difficulty establishing and expanding these businesses, which thus operate on a small scale (rarely employing any nonfamily members) and remain undercapitalized. Many of these businesses suffer from lack of infrastructure, especially electricity and telecommunications services. Strategies are needed to help the poorest farmers invest in and develop these businesses. Improved access to credit and policies that provide reliable, affordable electricity and telecommunications services would support these businesses. Reforms that encourage the formalization of these businesses are also important in enabling the nonfarm sector to play a larger role in markets that are increasingly quality driven.

\section{Liberalized Trade Environment}

The agricultural and rural sector in Asia has recently been adjusting to the external forces of competition unleashed by agricultural trade liberalization. As countries deal with the evolving world trading regime, they need to liberalize their own trade while exploiting opportunities for trade within regional organizations and with the rest of the world. For foodexporting countries, export trade liberalization would raise export prices and help small farmers by lifting their incomes and expanding production. But a rise in food prices in these countries could adversely affect poor consumers. The spread of trade liberalization and domestic market reforms may have to be gradual, subject to close monitoring of results and to short-term adjustments.

\section{Lagging Regions}

The mountainous regions of Asia require specific attention in economic strategies. Whereas the majority of a country's poor frequently live in the high-potential areas, in the low-potential, low-density areas, most people are poor. This situation poses an important dilemma for policy choices on poverty alleviation. Although promoting growth in the more-favored regions with high agricultural potential and better market access may raise the greatest number of people out of poverty, the extreme poor in the marginal areas (often ethnic minorities) are very vulnerable. Until these people migrate, policymakers face the daunting challenge of improving the productivity, stability, and resilience of their farming systems.

Marginal areas with low agricultural potential may be able to develop nonfarm activities with linkages to urban and industrial areas. Policies can help promote this process by emphasizing the development of human capital-training and skills appropriate to nonfarm activities as well as useful for eventual migration to urban areas.

Investing in infrastructure can also reduce spatial disparities and foster rural-urban linkages. This option must be balanced, however, against the policy of transferring income in the short run from the more-favored areas to the poor in the lessfavored regions, supplemented by measures in the medium term to facilitate migration through investment in education and subsidized resettlement.

\section{Water and Irrigation}

The decreasing potential for meeting rising demand for water supplies and quality is a serious challenge in developing Asia. Because much of the future water requirement must be met from existing supplies, the institutional and legal contexts of water supply and use will need to change. Essential components of an agenda for action on water include the removal of subsidies and taxes that lead to the misuse of water, the establishment of property rights, greater participation of water users in management, and the development of water markets whenever possible to send correct signals about the real value of this basic resource.

\section{Climate Change}

Climate change in the next decade and beyond poses a serious risk to Asia. The impacts will get progressively more severe as mean temperatures rise and climate becomes more variable.

Adaptation to climate change includes a broad range of policies-changes in land use and timing of farming operations, adaptive breeding and technologies, risk management techniques including catastrophic or weather-risk insurance, climate forecast information, irrigation infrastructure, water storage, and water management. Poor farmers in particular may need special help in adapting to climate change. Some steps, like long-term weather forecasting and the dissemination of technology and droughtand flood-resistant crop varieties, will require national and international planning and investment.

Agriculture's contribution to greenhouse gas emissions may be reduced by new crop and livestock breeding and planting technologies. In addition, the emerging market for carbon emissions trading offers new opportunities for farmers to benefit from land uses that sequester carbon. But the cost of reducing greenhouse gas emissions from farming may be much higher than the costs in the transport and power sectors. Little work has been done thus far to assess mitigation potential in agriculture.

\section{Risk and Insurance}

Agriculture is subject to a variety of risks-from output and price fluctuations caused by weather variations and pest outbreaks to changes in demand and world markets-and new markets can be characterized by increased risk (as in the case of perishable fruit and vegetable production) or at least higher perceived risk (perhaps as a result of new production techniques or marketing unknowns). Building innovative insurance markets around risks that directly and indirectly affect Asia's rural poor is a real opportunity. Information and communication technology and institutional innovations provide the means for change. Poor people's use of savings to cope with these risks is hindered by the limited development of rural savings instruments and institutions for the poor, a situation being gradually remedied by microfinance institutions. Some of them have started to establish insurance schemes of their own, including health and life insurance, which are particularly important for the rural poor. More-formal insurance mechanisms related to crop futures, 
including those organized or subsidized by the government, are currently underdeveloped in Asia and require careful assessment.

\section{Increased Focus on People and Human Resources}

The main source of rural change in the future will be healthy, well-nourished, trained, and educated people. The human resources agenda for rural poverty reduction should include increased attention to micronutrient malnutrition and food safety as well as to agriculture-health linkages, including linkages between animal health and human health. Development of the food system to improve food security and nutrition is thus part of pro-poor agriculture and rural development.

\section{Increased Need for Transparent Institutions}

Access to information about the functions, policies, and decisions of local government, rural development institutions and agencies, and organizations of poor farmers, workers, and small businesses is vital. The latter groups need to have clear oversight and monitoring functions in order to protect and preserve their own interests against the capture of power by vested interest groups.

\section{CONCLUSION}

Agricultural and rural development strategies are a critical component of an inclusive growth strategy for Asia, where poverty remains predominantly rural. In developing these strategies for today's Asia, policymakers can learn from the region's experiences of the past 30 years, but trends cannot be simply projected. The challenge is to determine where these lessons can and cannot serve as a guide, and this challenge is partly country- and location-specific.
In the context of the new realities described in this brief, priority action areas for achieving inclusive agricultural and rural development include

- using technological innovations in new agricultural supply chains;

- investing in infrastructure and communications systems to reduce spatial disparities and foster rural-urban linkages;

- developing ecosystem services through public-private cooperation to meet the challenges of water scarcity and climate change;

- encouraging development of finance and insurance interventions for the poorest; and

- providing effective safety nets and nutritional improvement in rural areas.

Effective and equitable implementation of these priority actions and other components of an inclusive rural development strategy require strong institutional and organizational arrangements and good governance. The rural poor need to participate in developing and implementing policies and programs. Decentralized rural political systems are an important instrument, as are innovations in institutions that ensure gender equity, inclusion of minorities, and participation of the poorest in markets and the provision of services. The priority action areas listed provide broad guidance but will have different weights in the different regions and countries of Asia. What is needed is a fresh initiative to identify the appropriate actions for inclusive agricultural and rural development in those regions of Asia where most of the poor live, and where the poorest live. 
$\mathbf{T}$ here are three basic ways to reduce poverty: redistribute productive assets (especially land) to the poor; provide direct income supplements or subsidies to the poor; and connect the poor to rapid, sustained economic growth. Over the past century, Asia has tried all three approaches to reducing poverty. The historical record suggests that only economic growth in which the poor participate can lift large numbers of the population out of poverty and keep them and subsequent generations above the poverty line. Creating the technologies, infrastructure, and environment for such growth requires active government policy.

This policy brief reviews the historical lessons from the Asian experience with reductions in poverty and hunger, then examines current issues and the challenges ahead. The focus is on the role of government policy in enhancing food security at both the household and national level, because achieving and sustaining food security is the end result of reductions in poverty and hunger. Thus there is an inevitable need to address the underlying political economy that explains why some governments have been more successful than others in providing and sustaining food security for their citizens.

The main lesson from Asia's economic history is that poverty reduction succeeds only when there is a basic political commitment to an economic growth process that includes the poor. This commitment has three key components:

1. Rapid growth is necessary for sustained poverty reduction, and this growth requires

a. macroeconomic stability, including relatively stable food prices;

b. a reasonably open trade policy for goods and services; and

c. a competitive market economy that generates laborintensive growth with rising real wages and greater participation in the formal sector.

\section{Efficient government investments and policies} are needed to connect the poor to this growth. These investments and policies include

a. rural infrastructure, especially farm-to-market roads and communications;

b. public health and education facilities that are accessible to the poor;

c. technologies that have substantial public-good dimensions to them, especially for agriculture and health; and

d. a smooth interface between rural and urban economies, including easy opportunities for rural-tourban migration.
3. Effective public-private partnerships provide the political dynamic for pro-poor growth. Such partnerships require

a. integrating macro-level (market-level) with microlevel (household-level) food security,

b. rural-urban financial intermediation for market integration, and

c. local leadership to improve the rural investment climate.

Asia's dramatic poverty reduction in the past was driven by pro-poor economic growth. This growth was made possible by a successful Green Revolution, led by high-yielding rice varieties (and wheat in South Asia and north China); massive investments in rural infrastructure, including irrigation; and the ready availability of fertilizer. The resulting economic growth was the most pro-poor in history and led to the most rapid and widespread reduction in poverty over four decades that has ever been witnessed.

There is also an argument that Asia's success has been significantly conditioned by the key role that rice plays in its food systems. As a commodity, rice is different, and the difference has powerfully influenced economics and politics throughout much of East and Southeast Asia (the wheat-growing areas of South Asia face somewhat different problems). The difference is manifested in three ways.

First, rice is the dominant food staple throughout the region, often accounting for more than half of normal food energy intake, even as diets begin to diversify among the middle and upper classes. Daily access to rice is essential for survival, especially for the poor.

Second, rice is grown predominately by smallholders who have been adept at adopting new technologies when market signals were favorable. In many countries, rice farmers are the single largest identifiable voting group, and catering to their interests has been important even in non-democratic societies. As in their response to market signals, small farmers throughout Asia are also adept at responding to (and sending) political signals.

Third, international rice markets have been historically thin and unstable, causing all Asian countries to buffer their own farmers and consumers from fluctuating world prices (and thus making the world price fluctuations worse in an even thinner market). Historically, this buffering required governments to control the flow of rice across their borders. Since the mid-1980s world rice prices have not shown the sharp fluctuations seen in earlier decades, and there is hope that in the future world rice markets will be as stable as wheat and maize markets. That possibility has not yet sunk in among policymakers. 
These characteristics of rice-based food systems forge a strong link between politics and economics, a link that policymakers, elected or not, see as a public mandate to deliver food security in the form of stable access to rice. Without understanding this link, it is impossible to understand Asia's record of economic growth-driven historically by dynamic rural economies-and the subsequent, seemingly inevitable, rise of agricultural protection and high-priced food staples, even in societies that remain quite poor. Although some of the forces driving this protection are similar to those in Europe and the United States, the speed, level, and early onset are unique to Asia.

\section{GROWTH, POVERTY,AND STABILITY}

The close historical connection seen in much of East and Southeast Asia between improvements in food security and reduction of poverty has been a result of government efforts to link market-led economic growth to interventions that improve food security at both the household and national levels. This strategic connection was driven to a large extent by the special nature of smallholder agriculture in Asia, and especially by particular characteristics of Asian rice economies.

A coherently designed macro-level food policy couples a strategy for food security with a strategy for growth that reaches the poor. Establishing this link to food security allows a country to capture growth opportunities, some quite subtle, that are missed otherwise. Such a macro-level food policy has three components, which, in turn, reinforce the country's food security: rapid economic growth, poverty reduction through growth in rural productivity, and stability of the food system. Agriculture, especially the rice sector, and a dynamic rural economy are the keys to integrating all three components.

This macro-level perspective on the food economy helps integrate a country's food security at the household level with national food markets. In turn, food security at both levels enhances the prospects for rapid economic growth, poverty reduction, and broad-based participation by citizens in higher living standards. The complexity for food policy arises because the achievement of each of these goals depends on the simultaneous pursuit of the other two strategies, which interact through market and behavioral mechanisms. For example, rapid economic growth must be designed to reach the poor. Otherwise, poverty reduction is delayed. Likewise, more direct interventions to reach the poor, such as a targeted food distribution program, cannot be sustained if many rural households are poor. Similarly, raising poor households above the poverty line does not guarantee their food security if food supplies disappear from markets or if prices rise beyond their means.

\section{REACHING THE POOR}

Very rapid declines in poverty rates were achieved in China, Indonesia, and Vietnam beginning in the 1970s, and starting earlier in Malaysia, Thailand, and Northeast Asia. Income distribution tended to be stable, or even improve somewhat, during periods of extremely rapid growth in average incomes per capita. Despite this long-run stability in income distribution, there is considerable short-run variance in how well the poor connected to economic growth. This variance tends to be explained by initial conditions-especially land distribution-and by the sector of economic growth. In most of Asia, agricultural growth, especially driven by higher productivity in the foodgrain sector, has tended to be much more pro-poor than growth in the modern industrial or service sectors. Food prices are also influential in explaining changes in income distribution, with sharply rising food prices especially bad for the poor.

\section{STABILIZING FOOD PRICES}

All government leaders recognize the impact of rice prices on the poor, and most countries stabilize their rice economy by keeping domestic rice prices more constant than border prices. Economic growth, poverty reduction, and stability are linked to each other through a set of "virtuous circles." Greater stability of the food economy contributes to faster economic growth by reducing signal extraction problems, lengthening the investment horizon, and reducing political instability. In the other direction, stability contributes to equity and poverty reduction by reducing the vulnerability of the poor to sudden shocks in food prices or availability. Greater equity also stimulates investment in human capital, especially in rural areas, thus speeding up economic growth, at least in the long run.

From 1970 to 1995, Indonesia managed this stabilization process while not deviating far from the long-run trend of prices in the world market. More-developed countries in the region, from Japan to Malaysia, kept their rice prices stable at levels that became progressively higher in relation to the price of rice in world markets. Much of this divergence, however, was not due to a conscious policy of raising the real price of rice domestically, but because the world price of rice declined almost continuously from the mid-1970s to the mid-2000s. Most of these economies also had appreciating currencies relative to the U.S. dollar, the currency in which world rice prices are quoted.

By implementing a simple policy objective of stabilizing the real domestic price of rice-the operational definition of food security in these societies-most Asian countries saw the level of protection of their rice farmers rise sharply from the 1970s to the mid-1990s. Pro-poor economic growth and stable rice prices were the recipe for food security in East and Southeast Asia. High levels of agricultural protection, and failure to diversify and modernize their agricultural sectors, were largely unanticipated side effects of the strategy of growth with stability. Efforts to reduce these high levels of agricultural protection, especially for rice farmers, by directly confronting the political forces defending this "Asian" approach to food security, have been repeatedly rebuffed since the 1980s.

Integrating all three components of the strategy for food security-rapid growth in the macroeconomy, poverty reduction through rural economic growth, and stability of the food systemis greatly complicated by the changing relationship between the rural and urban economies during the process of industrialization. In all successful economies, incomes earned from farming tend to lag behind those earned in other occupations. Rural labor productivity can increase in two ways: directly in agricultural activities, through the application of new technologies, and indirectly, as workers shift from agriculture to manufacturing or the modern service sector. Both processes are part of the structural transformation, but the productivity of urban workers tends to run ahead of rural productivity, causing a pronounced structural lag.

In most of Asia, from China to Indonesia to India, there has been a growing spread between the wages earned by unskilled agricultural workers and new entrants into labor-intensive manufacturing sectors, such as garments and electronics. 
At the same time, rice (and wheat) growing has been kept profitable through subsidies, virtually free irrigation water, price support and stabilization programs, and a well-developed rural infrastructure that ensures low marketing margins. Investments in rural education and health have helped build human capital, but accumulation of other assets by farmers has been limited.

\section{MANAGING FOOD POLICY DURING THE STRUCTURAL TRANSFORMATION}

The challenge throughout Asia is to modernize agriculture, reduce its heavy dependence on rice through diversification, integrate the entire rural economy more fully into the industrial sector, especially through greater processing activities, and keep rural incomes high enough to avoid rapid migration of workers to cities. Much of this challenge is not unique to Asia (although rice economies really do face different challenges than wheat- or corn-based economies). It is at the heart of the tension generated by all successful structural transformations. But the political pressures to resolve the tension can quickly distort policymaking and cause massive budget losses, burdens on consumers, and conflicts with trading partners. In particular, efforts to reduce the incomes of rice farmers by bringing domestic prices closer to world prices are seen by policymakers as worsening the situation, not helping it. A food policy that helps smooth the transition from a poor and rural economy to a rich and urban economy would pay very high dividends, but it must be formulated with a clear understanding of why the structural lag exists and its political link to food security.

Managing policy during the structural transformation thus becomes the organizing framework for food policy analysis. The advantage (but also the challenge) of this perspective is the need to keep long-run objectives and economic forces in focus at the same time that short-run crises receive urgent attention. For example, even as governments in the region attempt to cope with the problem for rice farmers of low prices in world markets, the structural transformation has reduced the significance of rice to national economies, to consumers, and even to rural incomes. Throughout Asia, most rice-producing families now earn more income from nonrice sources, including nonfarm sources, than they do from producing and selling rice. Growing rice is a source of income that is competitive with nonfarm wages for only a small share of rural households, and the proportion will continue to fall in the future. If efforts to raise incomes of rice farmers are not consistent with these longer-run forces, the efforts will at best be expensive palliatives that slow down the movement of resources to more highly paid alternatives.

\section{THE POLITICAL ECONOMY OF AGRICULTURAL PROTECTION}

It is one sign of progress that policymakers throughout Asia have come to worry more about keeping rice prices high than about keeping them low. Historically, in those societies in which poverty has remained untouched or even deepened, the agricultural sector has been seriously undervalued by both the public and private sectors. In addition to an urban bias in most domestic policies, the root cause of this undervaluation was a set of market failures. Commodity prices, by not valuing reduced hunger or progress against poverty, failed to send signals with appropriate incentives to decisionmakers. These inappropriate signals tend to cause several problems.
First, low values for agricultural commodities in the marketplace are reflected in low political commitments. But political commitments to rural growth are needed to generate a more balanced economy. The developing world has already seen a notable reduction in the macroeconomic biases against agriculture, such as overvalued currencies, repression of financial systems, and exploitive terms of trade. Further progress might be expected as democracy spreads and empowers the rural population in poor countries (although agricultural policies in most democracies make economists cringe).

The second problem with low valuation of agricultural commodities is that rural labor is also undervalued, a point stressed by Arthur Lewis more than a half century ago. This undervaluation weakens the link between urban and rural labor markets (by creating surplus labor in rural areas), a link which is usually manifested in the form of seasonal migration and remittances. There is no hope of reducing rural poverty unless real wages for rural workers rise. Rising wages (in both rural and urban sectors) have a demand and a supply dimension, and migration can affect both in ways that support higher living standards in both parts of the economy. Migration of workers from rural to urban areas raises other issues, of course, but those issues depend fundamentally on whether this migration is driven by the push of rural poverty or the pull of urban jobs. Whatever the cause of migration, the implications for food security are clear: a greater share of food consumption will be sourced from urban markets. Whether these urban markets are supplied by domestic farmers or international trade is one of the key food security debates under way in most Asian countries.

So far, policymakers' typical response to both of these problems has been to address them with trade and subsidy policies that increasingly protect farmers, especially rice farmers, from foreign competition. How does urban bias turn so quickly to agricultural protection? The question has fascinated political scientists and economists for some time. Building on theories of rent seeking and collective action, researchers have made several attempts to explain the rapid rise of agricultural protection in Asia in terms of the changing role of agriculture in the structural transformation and the costs of free-riding in political coalitions. In broad terms, this approach is now formalized as "positive political economy." Actors in both economic and political spheres make rational (personal) choices with respect to policies, using political action, lobbying, and even bribery as mechanisms of influence.

These "rational choice" models of agricultural protection, while illuminating, are not entirely satisfactory. An alternative model that builds on Asian societies' deep desire for food security, manifested as stable rice prices, does a much better job of explaining changes in the nominal degree of protection of rice farmers in Asia. It is this deep-seated desire for food security that explains the rapid flip from urban bias to high protection. Newly well-off urban workers no longer need cheap rice to survive, but they still must buy all of their rice in local markets. They want to be certain rice is available. For societies deeply distrustful of the world market as a source of reliable supplies, it is a very short step to protecting their own rice farmers as the surest vehicle to ensure the availability of rice.

But food security for the poor does not come from protecting farmers. The historical lesson from Asia is clear: the only way to sustain food security is through pro- 
poor economic growth. No country has been able to generate such growth decade after decade without reasonably open engagement in the world economy for its manufacturing sector. Rice has lost much of its significance to Asian macroeconomies, but the poor still rely on stable access to rice in rural and urban markets. Keeping those markets stable and accessible will be far easier and cheaper if Asia's agricultural economies, including its rice economies, also participate openly in world markets.

The way forward is to make rice less "different" to consumers, farmers, and the world market by making it more of an economic commodity and less of a political commodity. Much progress has actually been made in this direction since the 1980s, mostly as a by-product of Asia's rapid structural transformation, the product (and cause) of economic growth and rapid urbanization. But that progress has not been clearly recognized or understood, especially in political circles. Without this understanding, the potential for rice to be an "economic" commodity has not been incorporated into new, politically viable strategies for food security in Asia.

Still, the ingredients of such a strategy are clear: greater investment in rural human capital to improve labor productivity and mobility; more diversified and higher-valued rural economies that provide the commodities needed by modern supply chains and domestic supermarkets; more efficient rural financial markets to facilitate farm consolidation and even rural exit; and coordinated international efforts to open the world rice market to freer trade in order to deepen and stabilize price formation. This is a big agenda, to be sure, but implementing it-even gradually-will ensure a more prosperous and equitable future for Asia's farmers and greater food security for its consumers.

C. PeterTimmer (ptimmer@cgdev.org) is a visiting professor in the Program on Food Security and Environment, Stanford University, and a non-resident fellow at the Center for Global Development, Washington, DC. The author thanks Wally Falcon and Nurul Islam for comments on this policy brief and for extended conversations over the years on the general topic. 


\section{Focus I5 • Brief 3 OF I5 • March 2008}

A Ithough Asia has made remarkable progress in poverty reduction in the past decade, millions of people across the continent are still solely preoccupied with survival, and hunger is a reality in their everyday life. Today, around 600 million people in Asia subsist on less than $\$ 1$ a day and many live well below that: 240 million in the region live on less than 75 cents a day. The most unfortunate consequence of widespread poverty is that more than 520 million people cannot afford an adequate diet.

Where do Asia's poorest and hungry live, and who among them will be likely to move out of poverty and hunger and who will remain left behind? This brief addresses these questions so as to better understand the characteristics of Asia's poorest and hungry and assess the progress in reducing poverty among the poorest of the poor.

\section{ASIA'S POOREST}

Asia has enjoyed substantial reductions in poverty rates since 1990. In 1990, 33 percent of the population-nearly one billion peoplelived on less than $\$ 1$ a day (the World Bank defines the extreme poor as those living on less than $\$ 1.08$ international dollars per person, per day, measured at the 1993 purchasing power parity exchange rates for consumption.) In 2004, less than 18 percent lived on a $\$ 1$ a day, representing a reduction of 323 million people.

Not only did the number of poor people fall during this 14-year period, but the regional composition of Asia's poor also changed dramatically (see Figure 1). In 1990, about half of Asia's poor lived in South Asia, and 40 percent lived in East Asia. Today, almost three-quarters of the continent's poor live in South Asia and only 21 percent live in East Asia. The difference in trends in the number of poor between the East and the Pacific (East Asia and Southeast Asia combined) and South Asia is remarkable. While both regions had about the same number of poor in 1990, East Asia and the Pacific had 277 million fewer people in poverty in 2004 than did South Asia. In Middle and Central Asia, the share of the region's poor more than tripled, from 0.3 percent in 1990 to 1 percent in 2004.

In many countries in Asia, those living below $\$ 1$ a day are already the poorest of the poor. However, in some countries large portions of the population live below $\$ 1$ a day (for example, 34 percent of the population in India), and so the poorest of the poor are those who live well below the dollar-a-day line. It is of some concern that those who have benefited the most from increases in the region's growth are those who are closest to the poverty line. What, then, can be said about the poorest of the poor and about changes in the welfare of those who live well below the poverty line?

This question can be answered by disaggregating those living on less than $\$ 1$ a day into three groups according to their location below the dollar-a-day poverty line (note that, although the poverty gap ratio and the distribution-sensitive squared poverty gap ratio could be used to measure the depth and the severity of poverty, respectively, the head-count measure of poverty was used here because its interpretation is straightforward):

- Subjacent poor: those living on between $\$ 0.75$ and $\$ 1$ a day

- Medial poor: those living on between $\$ 0.50$ and $\$ 0.75$ a day

- Ultra poor: those living on less than $\$ 0.50$ a day.

Disaggregating dollar-a-day poverty into these groups provides a simple way of looking below the dollar-a-day line to see where people in each group live and how each group has fared over time. Of the 614 million people living on less than \$1 a day in 2004 in

\section{Figure I-Dollar-a-Day Poverty in Asia, 1990 and 2004}

\section{7 million in 1990}

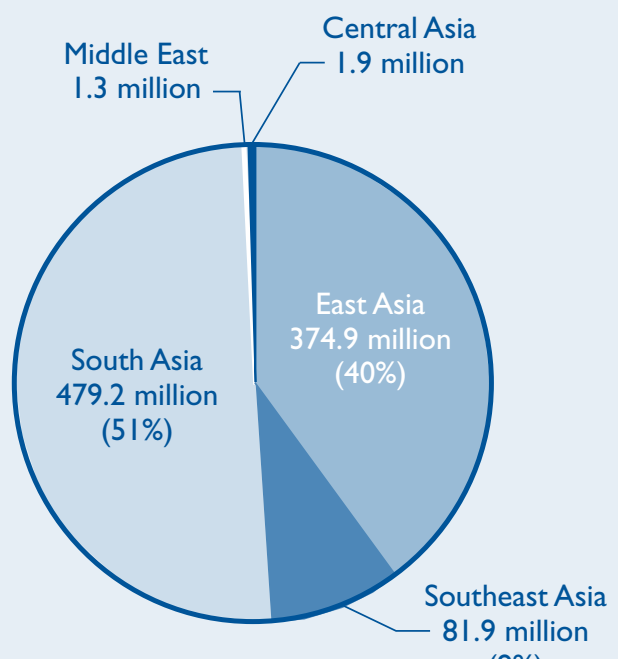

614 million in 2004

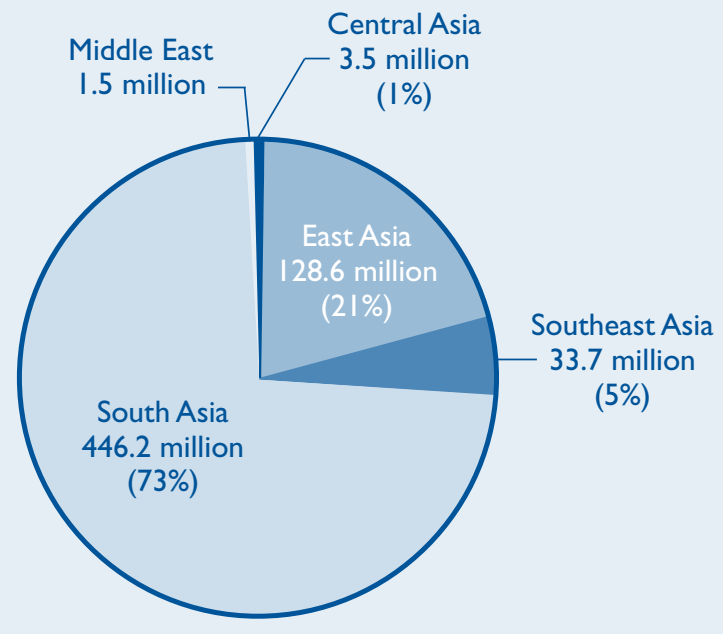

(9\%) 
Asia, 61 percent were subjacent poor, 35 percent were medial poor, and 5 percent were ultra poor. At each level of poverty, South Asia accounts for the highest share of the region's poor (between 70 and 77 percent). Figure 2 shows the trends in each of these groups over time for Asia, East Asia and the Pacific, and South Asia.

While panel data are needed to confirm whether those in ultra poverty have fared better or worse than those closer to the line, it is

Figure 2-Trends in Subjacent, Medial, and Ultra Poverty Rates, 1990-2004
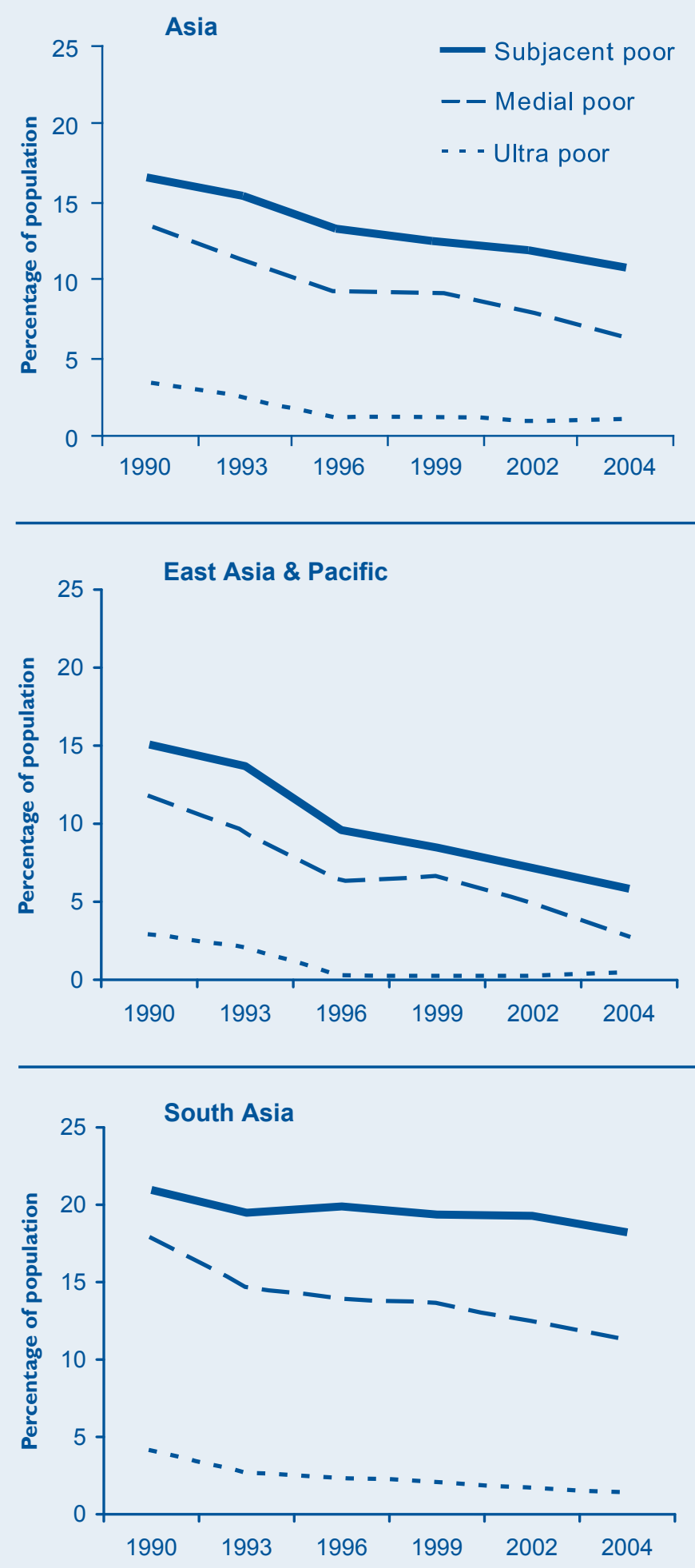

Source: Devised by authors using data from the World Bank's PovcalNet <http://iresearch.worldbank.org/PovcalNet/jsp/index.jsp>. possible to get an indication from national poverty data by calculating the amount that subjacent, medial, and ultra poverty would have decreased if poverty reduction had come from everyone's income growing by the same amount (with the underlying income distribution remaining unchanged). This "equal-growth scenario" poverty reduction is then compared with the amount of poverty reduction that actually took place. For example, if the 15.6-percentage-point decrease in poverty in Asia had come from everyone's income increasing by the same amount, there would have been a fall in subjacent poverty of 5.6 percentage points, a fall in medial poverty of 6.7 percentage points, and a fall in ultra poverty of 3.2 percentage points. In reality, the subjacent and medial poverty rates fell more than that at the expense of ultra poverty rates. The "equal-growth scenario" poverty reduction is shown as a white bar next to the actual change in each poverty rate in Figure 3.

\section{HUNGER IN ASIA}

Progress in reducing hunger was examined by using the Global Hunger Index (GHI), an index designed to capture three dimensions of hunger: insufficient food availability, shortfalls in the nutritional status of children, and child mortality. Accordingly, the Index includes the following three equally weighted indicators: the proportion of people who are food-energy deficient, the prevalence of underweight in children under the age of five, and the under-five mortality rate. An Index value greater than 10 indicates a serious problem, a value greater than 20 is alarming, and one exceeding 30 is extremely alarming.

Figure 4 presents the GHI for East Asia and the Pacific, South Asia, the Middle East and North Africa, and Eastern Europe and Central Asia, and shows that South Asia is a current hot spot of hunger and undernutrition. Although South Asia made large strides in combating hunger and undernutrition in the 1990s, the region still has the highest prevalence of underweight in children in the world.

A more in-depth look at hunger was obtained from household surveys conducted in several Asian countries. As with the poor, the hungry were also disaggregated into three groups:

Figure 3-Percentage-Point Change in Poverty from Changes in Subjacent, Medial, and Ultra Poverty, 1990-2004

Asia

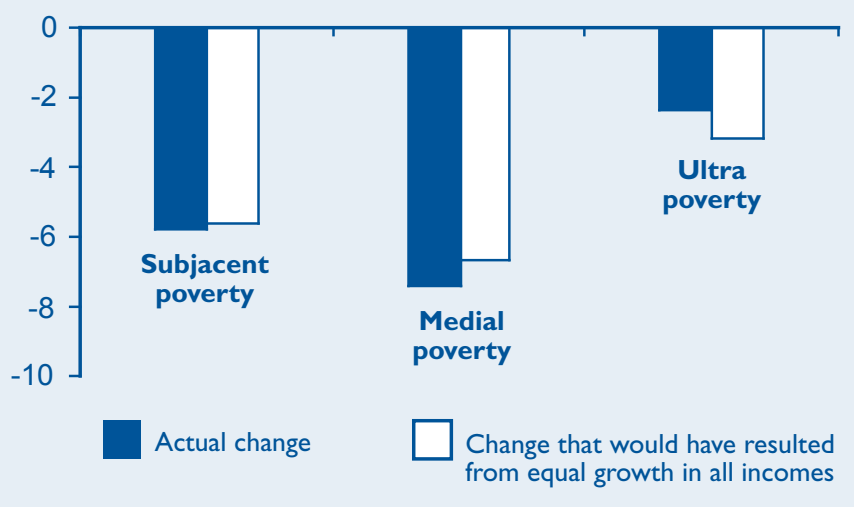

Sources: Devised by authors using data from the World Bank's PovcalNet <http://iresearch.worldbank.org/PovcalNet/jsp/index.jsp>. Regional Gini coefficients are from T. Besley and R. Burgess, "Halving Global Poverty," Journal of Economic Perspectives 17, no. 3 (2003); developing world Gini coefficients are from B. Milanovic, "True World Income Distribution, 1988 and 1993: First Calculations Based on Household Surveys Alone," Economic Journal I22, January (2002). 
- subjacent hungry: acquiring 1,800-2,200 kilocalories (kcals) per person per day;

- medial hungry: acquiring 1,600-1,800 kcals per person per day; and

- ultra hungry: acquiring less than 1,600 kcals per person per day.

Each group is defined by progressively deeper and more lifethreatening hunger associated with a deficiency of dietary energy, which is arguably the most essential nutrient for survival, physical activity, and health.

Again, South Asia is the region in Asia with the greatest hunger problems (see Figure 5). In South Asia, the overall prevalence of food-energy deficiency in the four study countries (Bangladesh, India, Pakistan, and Sri Lanka) is quite close, ranging from 51 percent in Pakistan to 61 percent in Bangladesh. Given that all of these countries had aggregate food surpluses at the time of their surveys, these high incidences are mainly due to the households' inability to access available food. However, the prevalence of ultra hunger (severe food-energy deficiency) was the highest in Timor-Leste and Sri Lanka, where conflict has probably exacerbated the hunger situation.

\section{WHO ARE THE POOREST AND THE HUNGRY? COUNTRY CASE STUDIES}

Eight Asian countries in which poverty and/or hunger are major development problems-Bangladesh, India, Laos, Pakistan, Sri Lanka, Tajikistan, Timor-Leste, and Vietnam-were examined to better understand who the poorest and hungry are. The data employed in the analysis were from nationally representative household expenditure surveys conducted in these countries. The survey years for each of the countries were: Bangladesh, 2000; India, 1999; Laos, 2002; Pakistan, 1998; Sri Lanka, 1999; Tajikistan, 2003; Timor-Leste, 2001; and Vietnam, 1998.

\section{Rural Poverty and Remoteness}

Despite a global trend toward an increase in the proportion of poor in urban areas, the incidence of rural poverty was found to be much higher than the incidence of poverty in urban areas in all of the study countries for which poverty data are available. At the dollara-day poverty line, the difference between the rural and urban incidences is 15 percentage points in Vietnam-the highest among the case study countries. In contrast, the differences are low in Tajikistan, Pakistan, and Sri Lanka.

\section{Figure 4-The Global Hunger Index, 1992, 1997, and 2003}

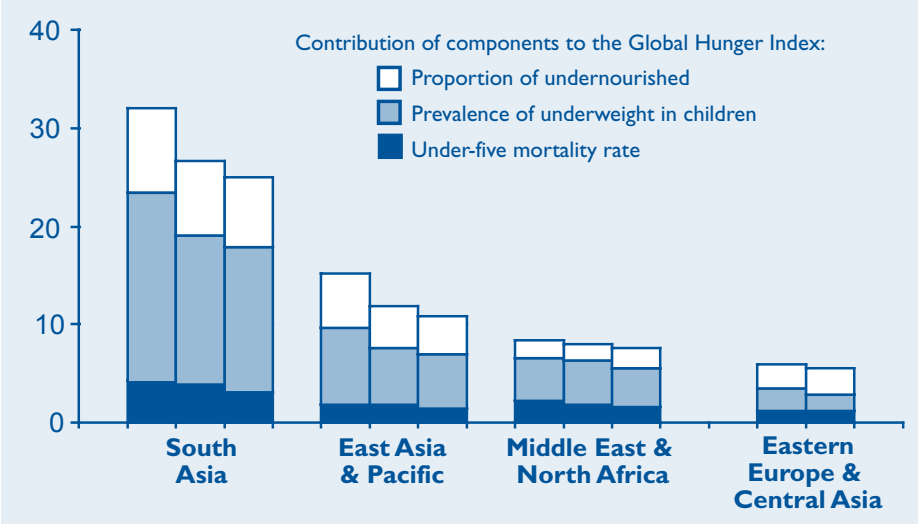

Source:Authors' presentation based on D.Wiesmann, A Global Hunger Index: Measurement Concept, Ranking of Countries, and Trends, Food Consumption and Nutrition Division Discussion Paper No. 212 (Washington, DC: International Food Policy Research Institute, 2006).
The same pattern of rural disadvantage is found when looking below the dollar-a-day line, but there is a tendency toward greater rural-urban differences as poverty deepens. The poorest and most food-insecure households are located furthest from roads, markets, schools, and health services. In Laos, for example, poverty is lower in villages with roads than in those without.

To further examine the correlation between remoteness and poverty, the proportion of households with an electricity connection was considered. In addition to being an indicator of wealth, an electricity connection also indicates, to a certain extent, the "connectedness" of households to roads, markets, and communications infrastructure, and the resulting income-earning opportunities and public services. Consistently across countries, poor households have considerably lower access to electricity than those living above \$1 a day. Those living well below $\$ 1$ a day in ultra poverty are even less likely to be connected.

\section{Spending on Food, Fuel, Housing, and Health Care}

Across income groups and case-study countries, expenditures on food represent the highest share of household budgets. In general, poorer households and those in rural areas spend a relatively higher proportion of the family budget on food than do others but the differences are not large. Expenditures on fuel represent the second highest share in Bangladesh, India, and Pakistan, while housing costs represent the second highest share in Tajikistan.

No clear pattern between health-care expenditure and poverty emerges across these countries. This is a potentially worrisome finding since poverty assessments for these countries have repeatedly found that ill health is more prevalent among poor people. For example, in Bangladesh, serious illness, accidents, or death occurred in 43-48 percent of poor households compared with 29 percent of households classified as nonpoor. In Vietnam, long-term illness was repeatedly mentioned in the participatory poverty assessment as being a defining characteristic of poor families. The finding that poorer households spend no more on health suggests that the poorest spend less on health care per need than wealthier households.

\section{Education}

In all parts of Asia, women and men without schooling are much more likely to experience poverty. In nearly all the study countries, the proportion of adult males without schooling is almost double or more among the ultra poor than the nonpoor, and in Vietnam, adult males living in ultra poverty are three times more likely to be unschooled than those living above $\$ 1$ day. In Bangladesh, nearly

Figure 5-National Incidences of Hunger (FoodEnergy Deficiency) for the Subjacent, Medial, and Ultra Hungry

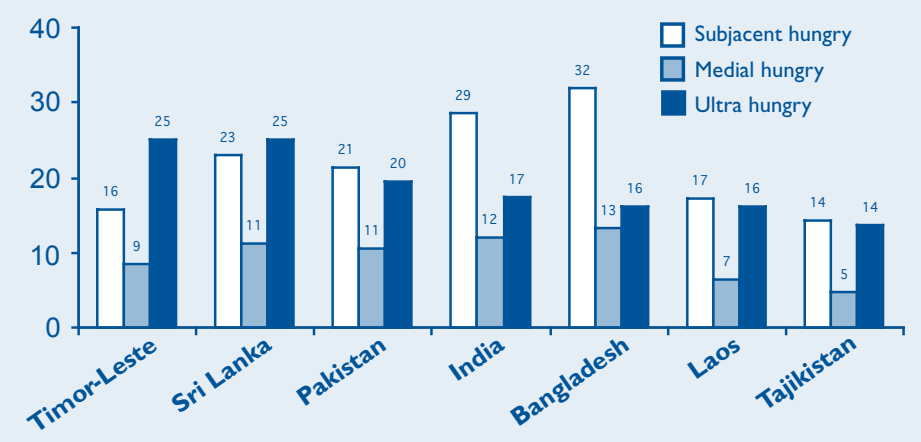

Source: Based on data presented in A. U.Ahmed, R. V. Hill, L. C. Smith, D. M. Wiesmann, and T. Frankenberger, The World's Most Deprived: Characteristics and Causes of Extreme Poverty and Hunger, 2020 Discussion Paper (Washington, DC: International Food Policy Research Institute, 2007). 
Figure 6-Proportion of Scheduled Castes and Scheduled Tribes in the Indian National Population Living in Subjacent, Medial, and Ultra Poverty

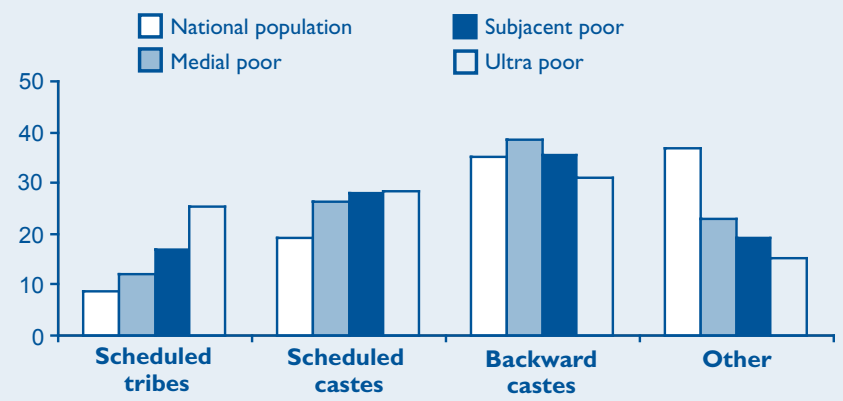

Source:Authors' calculations from the National Sample Survey 55th Round Socio-Economic Survey, National Sample Survey Organization, India.

all women in ultra poor households are uneducated (92 percent) compared with less than half in households living on more than \$1 a day (49 percent). The data overwhelmingly show that the poorest are the least educated.

Quality primary education can provide children from poor families with the tools to move out of poverty. In all study countries, however, the evidence is the same: children from poorer families are less likely to go to school. In India, 48 percent of children living in ultra poverty attend school compared with 81 percent of children living on more than $\$ 1$ a day-a 33 percentage-point gap. In Vietnam, the gap is 30 percentage points. Without education, the future of children living in ultra poverty will be a distressing echo of their current experience.

\section{Landlessness in Rural Areas}

The ownership or control of productive assets is an important indicator of livelihood because assets generate income. In all parts of Asia, the poorest are landless. Rates of landlessness are higher among those living on less than $\$ 1$ a day, and the incidence of landlessness increases for those living in ultra poverty. For example, nearly 80 percent of the ultra poor in rural Bangladesh do not own land.

\section{Excluded Groups}

Individuals in groups excluded from regional progress against poverty remain among the poorest in Asia. In Laos, for example, the prevalence of poverty is more than twice as high among the minority Mon-Khmer than the majority Lao, and in Vietnam the incidence is more than six times higher among ethnic minorities that among the Kinh and Chinese. In India, disadvantaged castes and tribes (referred to as scheduled castes and tribes) are overrepresented among the ranks of the poor, particularly among those living in ultra poverty (see Figure 6).

\section{Women}

In general, large differences were not found between male- and female-headed households. However, examining only the differences between male- and female-headed households hides the reality that, within households headed by men, the welfare of women and girls may be lower than that of their male family members. While empirical evidence on this is limited, a previous study by the International Food Policy Research Institute (IFPRI) found that at the individual level, women were poorer than men in 6 of the 10 countries considered, but significantly so in only 3 of these countries. Some studies in South Asia have shown that, within households, women take in significantly less food and sometimes less high-quality food, such as meat and eggs.

\section{CONCLUSION}

The persistence of severe deprivation suggests that business as usual will take too long to improve the welfare of the world's most deprived. This finding motivates a focus on policies and programs that are particularly effective at improving the welfare of Asia's poorest and hungry.

Understanding who the poorest and hungry are is crucial for the effective design of interventions to improve their welfare. Without context-specific and timely information, it is difficult to design programs that fit their needs. It is thus important to broaden the collection of and access to accurate data on the poorest and hungry.

The evidence presented in this brief suggests that effective interventions to reach Asia's poorest should be targeted to remote households, traditionally excluded from resources and markets, and should take into account both low levels of education and landlessness. This study suggests that interventions to insure the poor against health shocks, address the exclusion of groups, prevent child malnutrition, and enable investments-particularly in education-for those with few assets are essential to helping the poorest move out of poverty.

For Further Reading: A. Banerjee and E. Duflo, "The Economic Lives of the Poor," Journal of Economic Perspectives (forthcoming); C. Barrett, M. Carter, and P. Little, "Understanding and Reducing Persistent Poverty in Africa: Introduction to a Special Issue," Journal of Development Studies 42, no. 2 (2006); J. Hoddinott, "Shocks and Their Consequences Across and Within Households in Rural Zimbabwe," Journal of Development Studies 42, no. 2 (2006); J. Jalan and M. Ravallion, "Geographic Poverty Traps? A Micro Model of Consumption Growth in Rural China," Journal of Applied Econometrics 17, no. 4 (2002); N. Kabeer, "Social Exclusion: Concepts, Findings and Implications for the MDGs," Background paper for the Social Exclusion Policy Paper (Department for International Development, London, 2005).

Akhter Ahmed (a.ahmed@cgiar.org) is a senior research fellow in the Food Consumption and Nutrition Division of the International Food Policy Research Institute (IFPRI); Ruth Vargas Hill (r.v.hill@cgiar.org) is a postdoctoral fellow in IFPRl's Director General's Office; Doris M.Wiesmann (d.wiesmann@cgiar.org) is a postdoctoral fellow in IFPRl's Food Consumption and Nutrition Division; and Lisa Smith (Ismith@chuparosa.us) is a research consultant at Technical Assistance for Non-Governmental Organizations (TANGO) International. This brief is based on A. Ahmed, R.V. Hill, L. Smith, D. Wiesmann, and T. Frankenberger, The World's Most Deprived: Characteristics and Causes of Extreme Poverty and Hunger (Washington, DC: International Food Policy Research Institute, 2007). 


\section{Focus I5 • Brief 4 OF I5 • March 2008}

E xclusion on the basis of race, religion, and ethnicity exists in many nations under diverse social, economic, and political systems. Such exclusion is a problem in several countries in Asia. And while many Asian countries-such as China, India, Japan, Malaysia, Nepal, and Pakistan-have developed equal opportunity policies to overcome economic discrimination, the nature of both market and nonmarket discrimination is still not well-understood, and neither are its direct and indirect effects on poverty. The limited number of studies on exclusion in Asia has affected the development of appropriate policies to overcome discrimination and its impact on poverty.

This brief presents the argument that market- and nonmarketrelated forms of discrimination directly affect poverty but also exacerbate it indirectly by reducing growth. The brief highlights the need for socially inclusive policies, offers an analysis of the consequences of discrimination through the historical example of scheduled castes in India, and indicates potential policy options to redress exclusion and its effects.

\section{THE CONCEPT OF ECONOMIC EXCLUSION AND ITS RELATIONSHIP TO POVERTY}

Broadly speaking, social exclusion can be defined as "the process through which individuals or groups are wholly or partially excluded from full participation in the society within which they live." The concept rightly focuses on both the processes by which social and economic institutions exclude groups, and the multidimensional nature of the adverse consequences experienced by those who are excluded.

Social exclusion is group-based in nature. Economic exclusion or discrimination affects whole groups in a society, independent of the income, productivity, or merit of individuals within the group. Anyone can be excluded from access to markets because of lack of income, or from employment on the grounds of low productivity, or from admission to educational institutions on the basis of low merit. In the case of group-based exclusion, however, the basis for exclusion is group identity and not the economic or productive characteristics of the specific individual. While exclusion does result in the denial of economic opportunities-such as access to capital assets, development of skills, and education-the originating cause is not lack of income, productivity, or merit but rather the individual's group identity.

It is quite clear that in so far as exclusion and discrimination involve the denial of access to resources, employment, education, and public services, they certainly impoverish the lives of excluded individuals. Economic theory also implies that such discrimination can hamper economic growth by reducing efficiency. Labor market discrimination causes less than optimal allocation of labor among firms and sectors (given that those who are discriminated against receive a lower wage than their marginal product), and it reduces the effort expended by workers who perceive themselves to be discriminated against. Discrimination also results in inefficiency by reducing the magnitude of investments in human capital by discriminated groups and by reducing the return to any human capital investments made. Discrimination is thus a concern not only for equity but also for economic growth, and in this way it affects poverty both directly by adversely affecting the income distribution and indirectly by affecting economic growth. Moreover, discrimination can also lead to intergroup conflict by exacerbating existing inequality and contributing to its perpetuation from one generation to the next.

\section{THE NEED FOR SOCIALLY INCLUSIVE POLICIES}

Conclusions regarding the consequences of market discrimination on economic growth and income distribution are derived from mainstream economic theory of discrimination, which also predicts that in highly competitive markets, discrimination will prove to be a transitory, self-correcting phenomenon because market discrimination comes at a cost to employers and firms, which erodes their profits and acts as a deterrent.

The free-market solution is not, however, a final and practical remedy for a number of reasons. For example, market discrimination is a competitive equilibrium if social norms ensure that all the employers are discriminators. This is the likely reality, as the persistence of labor market discrimination in high-income countries over decades attests. In the absence of interventions, markets will continue to operate imperfectly, and discrimination will persist. Interventions are thus called for in the form of legal safeguards and policies that ensure fair and equal access and redress longstanding inequities through affirmative action and other measures. Given that excluded groups face discrimination through many market and nonmarket channels, policy interventions are required in the provision of social services and in various markets, such as for land, labor, capital, and produce.

\section{A FOCUS ON CASTES IN INDIA}

While exclusionary practices are evident throughout Asia-for example, ethnic minorities in Laos and Vietnam, and religious minorities in Central Asia-this brief focuses on one example of exclusion, the case of scheduled castes in India. This is a useful example because the Indian government has taken significant action to reduce the incidence and impact of exclusionary policies against scheduled castes, so a discussion of the policies introduced in India provides some indication of the type of interventions that can be used to combat social exclusion.

\section{Present Social and Economic Conditions of Scheduled Castes}

The caste system is based on the division of people into social groups, whereby each group's occupations and property rights are inherited. The assignment or division of occupations and property rights across castes is unequal and hierarchal, with some occupations considered socially inferior. Castes at the top of the order enjoy more rights at the expense of those located at the bottom. The caste hierarchy is maintained through a system of 
Poverty incidence

Average monthly per capita consumption expenditure of rural households (rupees)

$4|8.5|$

$577.22^{\mathrm{a}}$

Average monthly per capita consumption expenditure of urban households (rupees)

Landownership

Landless (\% of rural households)

608.79

$1,004.74$

Owning land, but less than half an acre (\% of rural households)

10.00

65.00

Employment

Self-employed in agriculture (\% of rural households)

16.40

27.30

51.40

Agricultural wage labor (\% of rural households)

26.50

5.00

$174.50^{\mathrm{b}}$

not available

not available

Unemployment rates based on the current daily status (\%)

Average weekly wage earning (rupees per week in 1993-94 prices)
41.10

35.50

19.00

7.40

3.50

$197.05^{b}$

Sources: Employment/Unemployment Survey, 1999-2000, and Consumption Expenditure Survey, 55th Round (National Sample Survey Organisation, Central Statistical Office, New Delhi).

Notes: "Other" refers to nonscheduled castes and tribes. Scheduled tribes, though not considered here, are found in certain regions of India and often face greater poverty than scheduled castes.

a Excludes those castes classified as "backward."

b Estimates are based on 1999-2000 National Sample Survey employment data, calculated by A. Dubey, Note and statistical tables on social groups prepared for the U.K. Department for International Development (New Delhi, 2003).

social and economic penalties that are philosophically justified and supported by elements of the Hindu religion.

It is important to recognize the uniqueness of caste discrimination. The caste system involves exclusion and discrimination in multiple market and nonmarket transactions and societal interactions. Exclusion for scheduled castes (those at the very bottom of the caste hierarchy) may involve

1. limited access to markets such as land, inputs, consumer goods, and social services;

2. differences between prices charged or received and market prices;

3. exclusion from participating in certain categories of jobs and the sale of certain consumer goods such as vegetables or milk because the occupational and physical touch of individuals from scheduled castes is considered "polluting";

4. discrimination in the use of public services such as roads, temples, and water bodies; and

5. physical or residential exclusion that prevents contact with community members and full participation in community life.

Some statistics illustrate the multifaceted nature of this discrimination and its impact (Tables 1 and 2). Those in scheduled castes (SCS) have a lower average level of expenditure than those in other castes, resulting in a rural poverty rate of 35 percent among SCs compared with 21 percent among other castes, and an urban poverty rate of 39 percent among SCs compared with 15 percent among other castes (Table 1). Individuals from scheduled castes are less likely to own land or any productive assets to enable selfemployment; they are more likely to depend on casual wage labor for income, resulting in higher levels of underemployment; and, when they are employed, they receive lower average wages that their non-SC counterparts.

Historically, in addition to being excluded from property rights, SCs have also been denied rights to education. High dropout rates, poor-quality education, and discrimination in education are some of the problems children from scheduled castes have faced. As a result, there are large gaps in literacy rates and education levels between children of SCs and those of other castes. In 1991 (the last census year for which data are available), the literacy rate among children of SCs was 37 percent, whereas among children of other castes it was 58 percent.

Data from the 1998-99 National Family Health Survey also reveal a wide gap between SCs and other castes in health status and access to public services (Table 2). Infant and child mortality is much higher in SC households than in others, and women's health and childbearing are much worse (perhaps a contributing factor). The extent of malnutrition and undernutrition among children of SCs is also much higher than among children of other castes.

\section{Policies and Strategies for Combating Exclusion}

Despite the continued exclusion of individuals from scheduled castes, the level of discrimination they face has in fact declined over time. Self-employment rates among SCs suggest that about onethird of SC households in rural and urban areas have acquired access to capital assets from which they were traditionally prohibited. The literacy rate improved threefold from 1961 to 1991, rising from 10 to 37 percent. Assessed against the background of the traditional restrictions facing SCs in the ownership of capital assets and education, these are gains indeed. The cumulative impact of this 
Table 2-Health Indicators for Women and Children

\begin{tabular}{|c|c|c|}
\hline Indicator & Scheduled Castes & Other \\
\hline Infant mortality (per I,000) & 83.0 & 62.0 \\
\hline Under-five mortality (per I,000) & 119.0 & 82.0 \\
\hline $\begin{array}{l}\text { Proportion below } 3 \text { standard deviatio } \\
\text { of the average weight for age (\%) }\end{array}$ & ons & 13.8 \\
\hline $\begin{array}{l}\text { Proportion below } 2 \text { standard deviatio } \\
\text { of the average weight for age (\%) }\end{array}$ & ns & 41.1 \\
\hline Women with anemia (\%) & 56.0 & 48.0 \\
\hline Women with antenatal checkup (\%) & 61.8 & 72.1 \\
\hline Home-delivered births (\%) & 72.1 & 59.0 \\
\hline
\end{tabular}

Source: National Family Health Survey, 1998-99 (Central Statistical Office, New Delhi).

Note: "Other" refers to nonscheduled/nonbackward castes and nonscheduled tribes.

and other improvements is reflected in the decline in rural poverty among SCs, from 59 percent in 1983/84 to 35 percent in 1999/2000.

The Government of India has been proactive in addressing exclusion and undertaking policies to foster social and economic empowerment among SCs. These efforts have had some success, but, as previously suggested, they have not fully addressed exclusion. Although the caste economy has undergone changes, some of its traditions persist. In order to reduce the disparities between SCs and other castes, improvements in asset and income levels need to be faster among SCs. This, however, is not the case: calculations by both Dubey and de Haan indicate that although poverty fell among SCs between 1983 and 2000, the rate of reduction was lower for SCs than for other castes (-2.50 percent per year compared with -3.02 percent per year).

With this in mind, it is instructive to consider the policies implemented in India. The government's approach draws mainly from provisions of equality for SCs laid out in the constitution and is influenced by two considerations: to overcome the multiple deprivations that SCs inherited from their past exclusion, and to provide protection against ongoing exclusion and discrimination.

The result is a twofold strategy as follows:

1. Anti-discriminatory or protective measures. The Protection of Civil Rights Act (1955) and Prevention of Atrocities Act (1989) outlawed "untouchability" and other forms of discrimination in public places or in the provision of public services and provided legal protection to SCS in the event of acts perpetrated against them by higher castes. The practice of reservations in government services, state-supported educational institutions, and various democratic bodies also falls under this category. Reservations are used by the government to ensure proportional participation of SCs in public spheres.

2. Developmental and empowerment measures. In the absence of legal affirmative action policy in the private sector, the State has used general programs to promote economic, educational, and social empowerment for SCs. These programs have been primarily undertaken as a part of anti-poverty programs that target or fix specific quotas for SCs where possible, as follows:
- Measures for economic empowerment include improving the ownership of capital assets; enhancing the business capabilities and skills of SC members; distributing surplus land to landless households; subsidizing credit and input provision to SC households; providing employment generation schemes to address the lack of employment opportunities in the lean season; and providing programs to support the release and rehabilitation of bonded laborers, given that SCs constitute about 61 percent of bonded laborers in India.

- Educational development programs comprise about half of the central government's spending on SCs. These programs include improvements in educational infrastructure in areas predominantly populated by SCs; admission to educational institutions through quotas and other measures; financial support for education at various levels; remedial coaching; and special hostels for boys and girls from SCs. Under all of these schemes, girls are given particular attention.

- Additional schemes focus on improving SC access to civic amenities like drinking water, housing, sanitation, electricity, roads, and public food distribution, since SCs often live in segregated residential areas with unequal access to these civic amenities.

While SCs are represented in parliament through reserved seats, it is perceived that they have not been able to effectively participate, contribute to decisionmaking processes, or monitor program implementation. The paucity of the studies on the role of government representatives from SCs makes it difficult to understand the reasons behind this. Isolated research indicates that problems stem in part from the presence of numerous, fragmented political groups; limited understanding of the complexity of the issue and its required policy response; and the absence of institutional support to enhance the capacity of representatives to effectively participate in political decisionmaking.

Similar constraints to effective participation are also observed in civil society. While many civil society initiatives targeting SCs exist, many of them having rich grassroots knowledge (and some 
even receiving selective support from the government), their effectiveness in bringing about change is limited by their lack of access to resources, knowledge of appropriate working methods, and connections to those with influence.

\section{A CALL FOR RESEARCHTO DEVELOP INCLUSIVE POLICIES}

Given the importance of exclusion in aggravating persistent poverty, the need for action in this area, and the lack of clear insight on how to do this (particularly in the Asian context), research on these issues needs to be undertaken. Systematic studies would support the development of appropriate policies. In particular, research should be undertaken on the following:

1. The structural context of exclusion. Further theoretical research is needed on the institutionalization of exclusion associated with caste, ethnicity, religion, color, and other forms of group identity; the effects of such forms of discrimination on economic growth, poverty, and governance; and the remedies against discrimination and deprivation.

2. The nature and dynamics of exclusion. A gap exists in empirical research on the economic, social, and political conditions of excluded groups and the forms and dynamics of market discrimination (in land, capital, employment, product, input, and consumer markets) and nonmarket discrimination (in the provision of social services and in public institutions and political bodies).

3. The consequences of discrimination. Further empirical research is needed on the poverty consequences of discrimination and the resulting effects on excluded groups in terms of their access to livelihood opportunities, markets, services, and political institutions.
4. Policy interventions. Further research is needed to analyze the impact of public policies intended to combat exclusion and alleviate its impact on poverty. Such research must incorporate scientific analyses of interventions undertaken in Asia to empower marginalized groups in economic, educational, political, and sociocultural spheres, as well as analyses of civil society initiatives, issues relating to implementation and governance, and policy experiences in other countries.

5. Collective action. Research is needed on effective forms of collective action by deprived groups and other sections of society-such as political parties, social organizations, and nongovernmental organizations-in striving to secure human rights.

\section{CONCLUSION}

While the purpose of this brief has been to highlight the direct and indirect effects of economic discrimination on poverty and the need for socially inclusive policies, above all, the brief draws attention to the current paucity of knowledge on the full impact of discrimination and how this knowledge gap can be effectively addressed. Studies on these issues, as outlined above, are a necessary foundation for the development of appropriate policies to combat discrimination and reduce poverty.

For Further Reading: A. de Haan, “Extreme Deprivation in Remote Areas in India: Social Exclusion as Explanatory Concept," presented at the conference on Chronic Poverty (Manchester, April 2003); A. Sen, "Social Exclusion: Concept, Application, and Scrutiny," Social Development Papers No. I (Office of Environment and Social Development, Asian Development Bank, 2000); S. Thorat, A. Negi, and P. Negi, Reservation and Private Sector: Quest for Equal Opportunity and Growth (Jaipur, India: Rawat, 2004).

Sukhadeo Thorat (skthorat@hotmail.com) is professor of economics at Jawaharlal Nehru University, New Delhi, and currently chairman of the University Grant Commission, New Delhi, India. This brief was originally prepared for a policy consultation process coordinated by the International Food Policy Research Institute (IFPRI) on the World's Poor and Hungry People and published by IFPRI as a 2020 Focus Brief in 2007. 
I is difficult to characterize "women's status" in Asia because women's conditions in Asia are diverse, reflecting the continent's variety of societies and cultures, and because conditions are always changing. In an attempt to capture the nature of the gender gap across countries and regions, the Gender Gap Index 2006 examines the gap between men and women in 115 countries, representing more than 5 billion people, in four fundamental categories: economic participation and opportunity, educational attainment, health and survival, and political empowerment. Although one Asian country (the Philippines) is among the top 10 countries in terms of closing the gender gap, the region as a whole fares poorly with respect to gender equality. Out of eight regions, Asia ranks third from the bottom overall, with the lowest performance in the health and survival subindex, second to the lowest in the economic opportunity and participation subindex, and third from the lowest in the educational attainment subindex. The low rankings in Asia are driven by large, highly populated nations. China ranks 114th out of the 115 countries in the health and survival subindex, largely because of a disproportionate sex ratio at birth, which contributes to China's well-documented "missing women" phenomenon. Bangladesh, India, and Pakistan exhibit large disparities between men and women in all four areas of the index. Women may be holding up "half the sky," as the Chinese say, but get less than their equal share of the household'sand society's-resources.

Why does closing the gender gap in Asia matter for hunger and malnutrition? Countries that have most successfully promoted equal education for men and women-in East Asia, Southeast Asia, and Latin America-have also experienced the most economic and social progress in the past decades and the greatest increases in food security. In contrast, countries that have invested less in women's schooling-in South and West Asia, the Middle East and North Africa, and Sub-Saharan Africa-have lagged behind in growth.

Although cross-national comparisons may be flawed because of problems of data comparability and reverse causality, evidence from micro-level studies worldwide has shown that equalizing resources controlled by women and men-giving women more control over resources and improving women's status, especially in Asia-is important in reducing hunger and malnutrition and increasing investments in the next generation.

\section{THE ASIAN ENIGMA}

A 2003 study by Lisa Smith and coauthors investigated the links between women's status and child nutrition in developing countries using data on 117,242 children under three years old from 36 developing countries, collected under the auspices of the Demographic and Health Surveys. The study sought to answer three main questions: First, is women's status an important determinant of child nutritional status in South Asia, Sub-Saharan
Africa, and Latin America and the Caribbean? Second, if so, what are the pathways through which improved status operates? Third, why is South Asia's child malnutrition rate so much higher than Sub-Saharan Africa's, when it does so much better with respect to many of the long-accepted determinants of child nutritional status, such as national income, democracy, food supplies, health services, and education? In a 1996 commentary, Ramalingaswami and others attempt to explain this "Asian enigma" by suggesting that the extremely low status of women in South Asia compared with Sub-Saharan Africa is at the root of the regions' nutritional status gap.

Smith and her coauthors define women's status as women's power relative to men. Previous research has shown that, compared with higher-status women, women with low status tend to have weaker control over resources in their households, tighter constraints on their time, more restricted access to information and health services, and poorer mental health, selfconfidence, and self-esteem. Yet these factors are thought to be closely tied to women's own nutritional status and the quality of care they seek for themselves and, in turn, children's birth weights and the quality of care provided to children. Two measures of women's status were employed in this study. The first, measured at the household level, is women's decisionmaking power relative to their male partners, usually their husbands. This measure is based on four underlying indicators: whether a woman works for cash, her age at first marriage, the age difference between her and her husband, and the education difference between her and her husband. The second, measured at the community level, is societal gender equality. It is based on girl-boy differences in nutritional status and preventive health care, as well as gender differences in adult education. This additional measure was included to capture the effects of gender discrimination that women may face outside the home. Both women's status measures were constructed by combining the underlying indicators into an index ranging from 0 (lowest status) to 100 (highest) using factor analysis. Country fixed-effects multivariate regression, with controls for child, woman, and household characteristics, was the main empirical technique. Separate analyses were carried out for each region.

Figure 1 shows the percentage of underweight, stunted, and wasted children by region. By all measures malnutrition is worst in South Asia, followed by Sub-Saharan Africa and Latin America and the Caribbean.

Figure 2 compares women's status across the three regions. Both measures show that South Asian women have the worst status relative to men, followed by Sub-Saharan Africa and Latin America and the Caribbean. Women's status is very low in both South Asia and Sub-Saharan Africa compared with women's status in Norway, the country where women are considered to be most equal to men. 


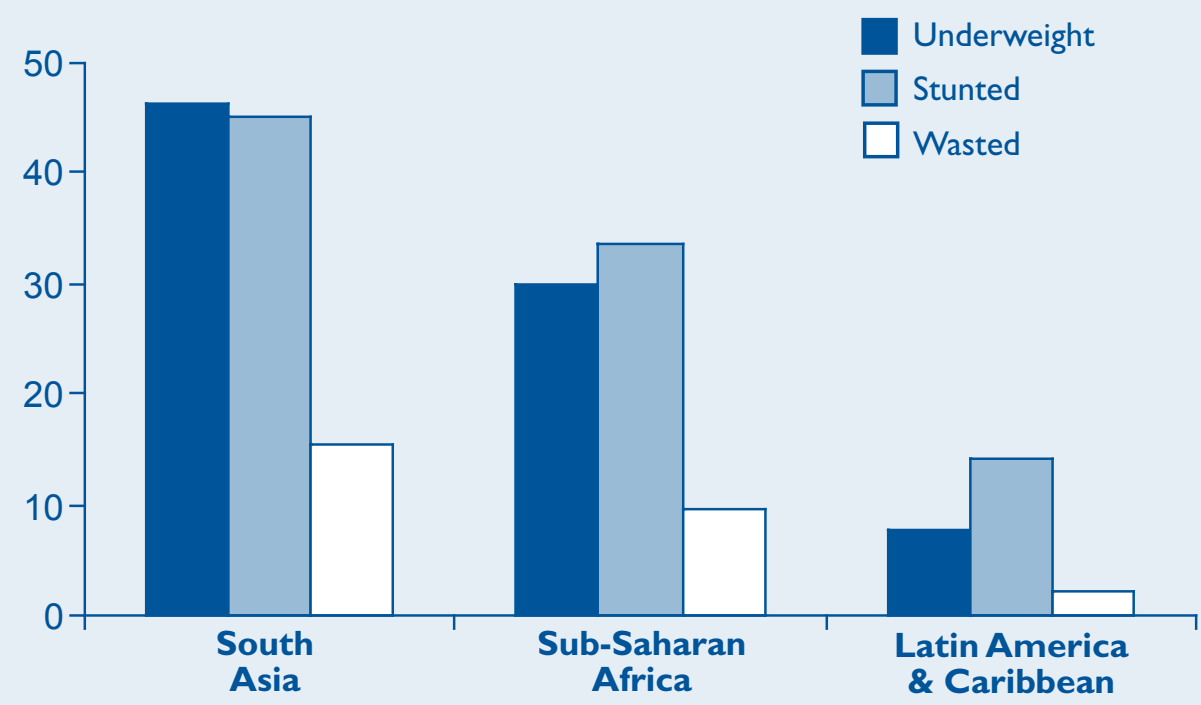

Source: L. C. Smith, U. Ramakrishnan, L. Haddad, R. Martorell, and A. Ndiaye, The Importance of Women's Status for Child Nutrition in Developing Countries, Research Report No. I3I (Washington, DC: International Food Policy Research Institute, 2003).

\section{Figure 2-Women's Status Indexes, by Region}

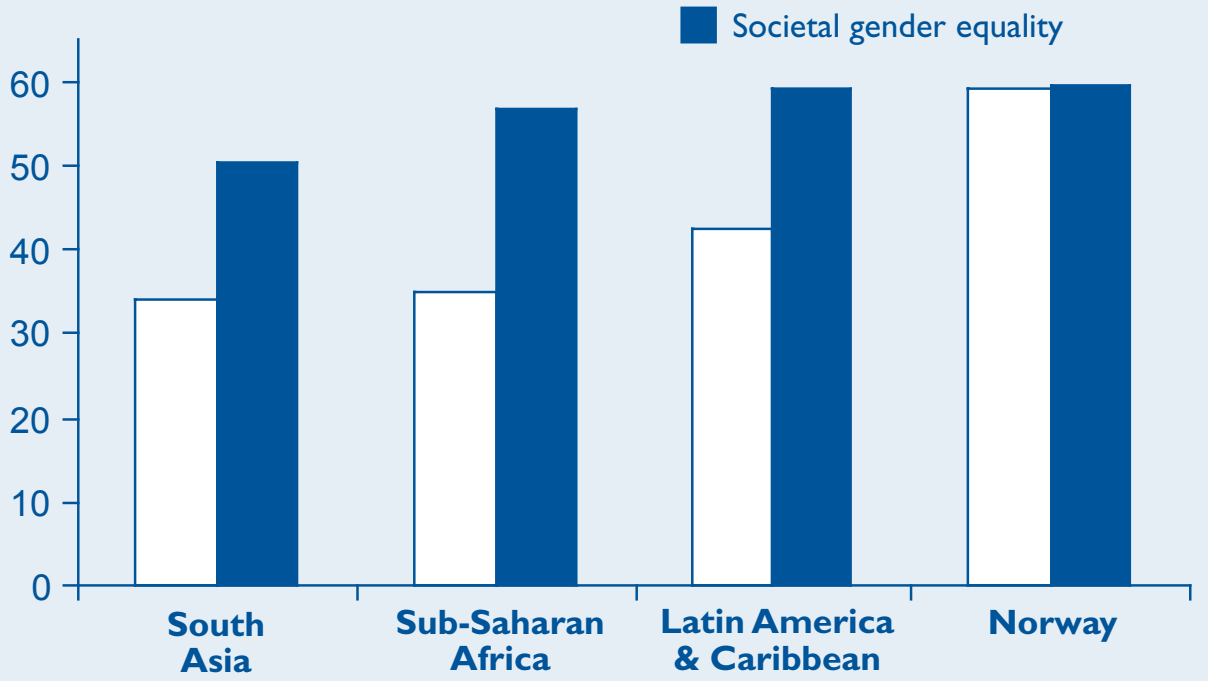

Source: L. C. Smith, U. Ramakrishnan, L. Haddad, R. Martorell, and A. Ndiaye, The Importance of Women's Status for Child Nutrition in DevelopingCountries, Research Report No. I3I (Washington, DC: International Food Policy Research Institute, 2003).

Results from the regression analysis show that women's status has a significant, positive effect on children's nutritional status in all three regions. The results provide proof that women's status improves child nutrition because women with greater status have better nutritional status, are better cared for themselves, and provide higher-quality care to their children. The strength of the influence of women's status, however, differs widely across the regions. Women's status has the most influence where it is lowest. The strongest effect is found in South Asia, followed by Sub-Saharan Africa, and it is weakest in Latin America and the Caribbean. Women's status may also vary significantly within each country and may be influenced by factors such as caste, class, and religion.

\section{WOMEN'S STATUS AS A KEY ELEMENT IN IMPROVING WELFARE, INCOMES, AND PRODUCTIVITY}

The evidence described shows that improving women's status can improve children's and women's health and nutrition in South Asia. What are the pathways by which this takes place? In South 
Asia increases in women's status have a strong influence on both long-term and short-term nutritional status of children, leading to reductions in both stunting and wasting. The study estimates that if the status of men and women were equalized, the underweight rate among children under three years old would drop by approximately 13 percentage points-a reduction of 13.4 million malnourished children. As women's status improves in the region, improvements would also take place in women's nutritional status (as measured by body mass index [BMI]), prenatal and birthing care for women, complementary feeding practices for children, treatment of illness and immunization of children, and the quality of substitute child caretakers.

Aside from its impact on both children's and women's well-being, women's empowerment may operate through other pathways, such as through improvements in agricultural productivity and improving household incomes. Much of the evidence on the effects of increasing resources controlled by women-or equalizing women's control of resources with men's control of resources-comes from Sub-Saharan Africa, where men and women farm separate plots. Similar evidence from Asia is scarce, owing to the lack of gender-disaggregated data on women's agricultural output in Asia. This lack of data stems from the assumptions that men and women farm jointly in Asia and that most labor input into Asian agriculture is male. In actuality, women farm small plots-usually homestead plotsindependently, are engaged in livestock raising, and may take over agricultural decisionmaking as men migrate to urban areas or abroad in search of work.

The little direct evidence that is available on agriculture is encouraging. A recent IFPRI assessment of the impact of vegetable and fishpond technologies on poverty in rural Bangladesh found that untargeted technology dissemination was more likely to benefit men and better-off households. Efforts designed to reach women within poor households-such as through provision by nongovernmental organizations (NGOs) of training and credit for vegetable improvement-achieved greater impacts on poverty. Successfully reaching women with these technologies gave them greater mobility, more control over resources, and political awareness and resulted in fewer incidents of domestic violence. The NGO vegetable program was successful because vegetables could be grown on homestead land, allowing even women from very poor households with no agricultural land to participate. Because the women had less need to seek employment outside the homestead, they felt less vulnerable to harassment. Also, NGOs have been successful in reaching poor women in Bangladesh, where status issues make it difficult for these women to gain access to government extension services.

An example from China, where the distribution of resources between men and women tends to be more egalitarian than in South Asia, provides additional support for the argument that giving women equal access to resources benefits agricultural productivity. In contrast with other parts of the world, femalemanaged households in China have equal access to many of the key inputs required for farming-including family labor, adequate quantity and quality of land, irrigation, and credit. Using a variety of measures of female farm management, the authors find no evidence that female farm management is negatively associated with plot-level crop revenues, holding household and plot characteristics constant-in other words, women are at least as good at farming as men. In fact, the estimates even suggest that women may be better farm managers than men in China. Despite women's significant nonformal employment responsibilities and contributions to farm labor, plot-level earnings for femalemanaged farms are at least equivalent to earnings on plots that men manage. De Brauw and coauthors argue that policies that ensure equal access to land, regulations that dictate open access to credit, and economic development strategies that encourage competitive and efficient markets have all contributed to an environment in which women farmers can and do succeed. China has also begun to promote the use of female agricultural extension agents. Although less than 30 percent of extension agents in China are women overall, nearly 40 percent of young ones are. When women have access to inputs and information and new technologies, there is no reason that they cannot produce as efficiently as men.

Returns to empowering women may even be greater outside agriculture. The decision to earn additional income-whether at home or outside the home-and to enter the labor force is one of the components of the women's status index described. In Indonesia, the Philippines, South Korea, Sri Lanka, and Thailand, the most important determinants of women's labor force participation are schooling attainment and gender roles. Women in the Philippines have the highest labor market participation among the five countries. Indeed, in the rural Philippines, where girls have higher educational attainment than their brothers, they are more likely to enter nonagricultural occupations and earn higher incomes from nonagriculture than from farming. Females account for the bulk of rural-urban migrants in the Philippines and are more likely to be employed in better-paying occupations than men, owing to their higher educational attainment. In South Korea and Sri Lanka, where rigid gender roles prevail, an increase in women's schooling attainment is less likely to increase women's labor market participation rates, owing perhaps to women's traditionally low bargaining position at home. And in countries where women's mobility is limited, women may not be able to realize economic returns to their human capital. In rural Pakistan, for example, women's education and nutrition have insignificant effects on economic productivity.

Enabling women to realize returns to investments in human capital and in asset ownership is part of a virtuous cycle that promotes both empowerment and productivity. In Indonesia, women are acquiring secondary and tertiary education in larger numbers than men, in response to the greater relative returns to female higher education. Because parents realize returns to investing in daughters, they have an incentive to send girls to school. Improvements in women's economic productivity may also improve their status at home and in the marriage market. A recent paper on India finds that increases in female labor productivity are associated with decreases in the marriage rate of prime-age females and lower dowries paid by the bride's family, indicating a rise in the bargaining power of the bride's family during dowry negotiations.

\section{TRENDS IN RURAL LIVELIHOODS AND APPROPRIATE POLICIES TO IMPROVE WOMEN'S STATUS}

The most effective ways of empowering rural women and enabling them and their families to move out of poverty will depend on local economic, cultural, and political conditions and the relative importance of the agricultural and nonagricultural 
sectors in rural livelihoods. The process of rural transformation is dynamic, and one should expect that relationships between men and women will change as well. This process will not take place in exactly the same way throughout Asia, but three major trends in rural livelihoods are likely to affect gender relations: (1) increasing male migration from rural to urban areas; (2) the declining importance of agriculture and the growth of the nonfarm sector; and (3) increasing female migration to urban areas (and overseas). The relative importance of each of these changes will determine which policy to improve women's status will be most appropriate and effective.

In areas where feminization of agriculture may be taking place because of male migration to urban areas or abroad, policies to improve women's status would include (1) giving women equal access to land and credit; (2) guaranteeing the delivery of extension and other services to women, possibly through a cadre of female agricultural extension workers; and (3) adopting economic development policies that encourage competitive and efficient markets. These policies will be important both for agricultural productivity and for the family's well-being.

In areas where agriculture may be declining in importance owing to a growing nonfarm sector, appropriate policies would involve (1) reducing barriers to female participation in nonfarm enterprises and nonfarm employment; (2) investing in women's human capital through schooling and continuing education programs; and (3) providing equal access to credit, markets, and information. In other areas, such as the Philippines and Thailand, the rural-urban migration stream is composed mainly of women. In these areas, appropriate policies include (1) investing in women's education; (2) encouraging competitive and efficient labor markets; and (3) investing in infrastructure to enable families to maintain social and economic support networks (roads, communications, and banking).

Empowering both men and women to take advantage of new opportunities goes hand-in-hand with more general policies to improve income-earning abilities and opportunities for women. These general policies include (1) extending and strengthening schooling systems in rural areas; (2) promoting competition in nonfarm labor markets to eliminate discrimination against women; (3) reforming property rights systems in general to be more equitable toward women; and (4) developing agricultural technologies that increase the returns to female labor, whether through increased demand or increased labor productivity. Many studies have shown that gender equity is not incompatible with productive efficiency. Increasing women's educational attainment, strengthening women's rights to property, removing barriers to women's participation in the labor market, and developing technologies that increase the returns to women's labor all work together to raise women's economic and social status either by improving women's opportunities outside the home or by increasing their bargaining power within the family.

For Further Reading: J. R. Behrman and A. Deolalikar, “Are There Differential Returns to Schooling by Gender? The Case of Indonesian Labor Markets," Oxford Bulletin of Economics and Statistics 57, no. I (1995): 97-II7; L. Cameron, J. M. Dowling, and C. Worswick, "Education and Labor Market Participation of Women in Asia: Evidence from Five Countries," Economic Development and Cultural Change 49, no. 3 (200I): 459-477; A. de Brauw, Q. Li, C. Liu, S. Rozelle, and L. Zhang, "Feminization of Agriculture in China? Debunking Myths Surrounding Women's Participation in Farming," China Quarterly (forthcoming); M. Fafchamps, and A. R. Quisumbing, “Human Capital, Productivity, and Labor Allocation in Rural Pakistan," Journal of Human Resources 34, no. 2 (1999): 369-406; K. Hallman, D. Lewis, and S. Begum, "Assessing the Impact of Vegetable and Fishpond Technologies on Poverty in Rural Bangladesh," in M. Adato and R. Meinzen-Dick, eds., Agricultural Research, Livelihoods, and Poverty: Studies of Economic and Social Impacts in Six Countries (Baltimore: Johns Hopkins University Press, 2007); R. Hausmann, L. D. Tyson, and S. Zahidi, The Global Gender Gap Report 2006 (Geneva: World Economic Forum, 2007); I. Mbiti, “Moving Women: Household Composition, Labor Demand, and Crop Choice" (Department of Economics, Brown University, unpublished manuscript, 2006); A. R. Quisumbing, ed., Household Decisions, Gender, and Development: A Synthesis of Recent Research (Washington, DC: International Food Policy Research Institute, 2003); A. R. Quisumbing, J. P. Estudillo, and K. Otsuka, Land and Schooling: Transferring Wealth across Generations (Baltimore, MD: Johns Hopkins University Press for the International Food Policy Research Institute, 2004); V. Ramalingaswami, U. Jonsson, and J. Rohde, "Commentary: The Asian Enigma," in The Progress of Nations 1996 (New York: United Nations Children's Fund [UNICEF], 1996); T. P. Schultz, "Why Governments Should Invest More to Educate Girls," World Development 30, no. 2 (2002): 207-225; L. C. Smith, U. Ramakrishnan, L. Haddad, R. Martorell, and A. Ndiaye, The Importance of Women's Status for Child Nutrition in Developing Countries, Research Report I3I (Washington, DC: International Food Policy Research Institute, 2003).

Agnes Quisumbing (a.quisumbing@cgiar.org) is a senior research fellow in the Food Consumption and Nutrition Division of the International Food Policy Research Institute (IFPRI). 
A sia has made significant progress in increasing its agricultural productivity and reducing poverty since the 1960s. Yet real world food prices for most cereals and meats are now projected to rise, reversing a long-established downward trend and adversely affecting poor consumers. Growing resource scarcity, particularly of water, will increasingly constrain food production growth, and climatic stresses will likely shrink Asian farmers' abilities to produce more food. Meanwhile, growing demand for high-value foods, such as livestock, fish, vegetables, and fruits, will put further pressure on the natural resource base, as bioenergy demands introduce new competition for land and water resources. These pressures will adversely affect food security and human well-being outcomes. However, if aggressive investments in agricultural research and knowledge are combined with complementary sectoral advances, such as access to water and secondary education, positive impacts could actually be strengthened. This brief examines the challenges and opportunities inherent in these changes and looks at the policy implications of investment choices for Asian development.

\section{CHALLENGES FOR ASIAN AGRICULTURE}

Today, Asia both produces and consumes a great proportion of the world's food in order to feed its own large and growing populations, as well as to supply its expanding export sectors. Asia accounts for 91 percent of global rice production and 42 percent of global cereal production. Asia is also the largest exporter of fish and fish products, and its meat production accounts for 39 percent of the global total. Hence, Asia's food production systems are directly connected to human welfare outcomes. Yet, despite its rapid economic growth since the 1960s, Asia remains home to the world's largest number of poor and hungry people. Figure 1 maps the top 10 Asian farming systems by numbers of stunted children, indicating the strong correlation between cropping systems and malnutrition outcomes. The rice/wheat system houses the largest number of stunted children in Asia, followed by mixed-rainfed, upland mixed-intensive, and lowland rice systems. Note also that the marginal upland areas house the smallest number, but the highest concentration, of stunted children.

\section{Figure I-Top 10 Asian Farming Systems by Numbers of Stunted Children}

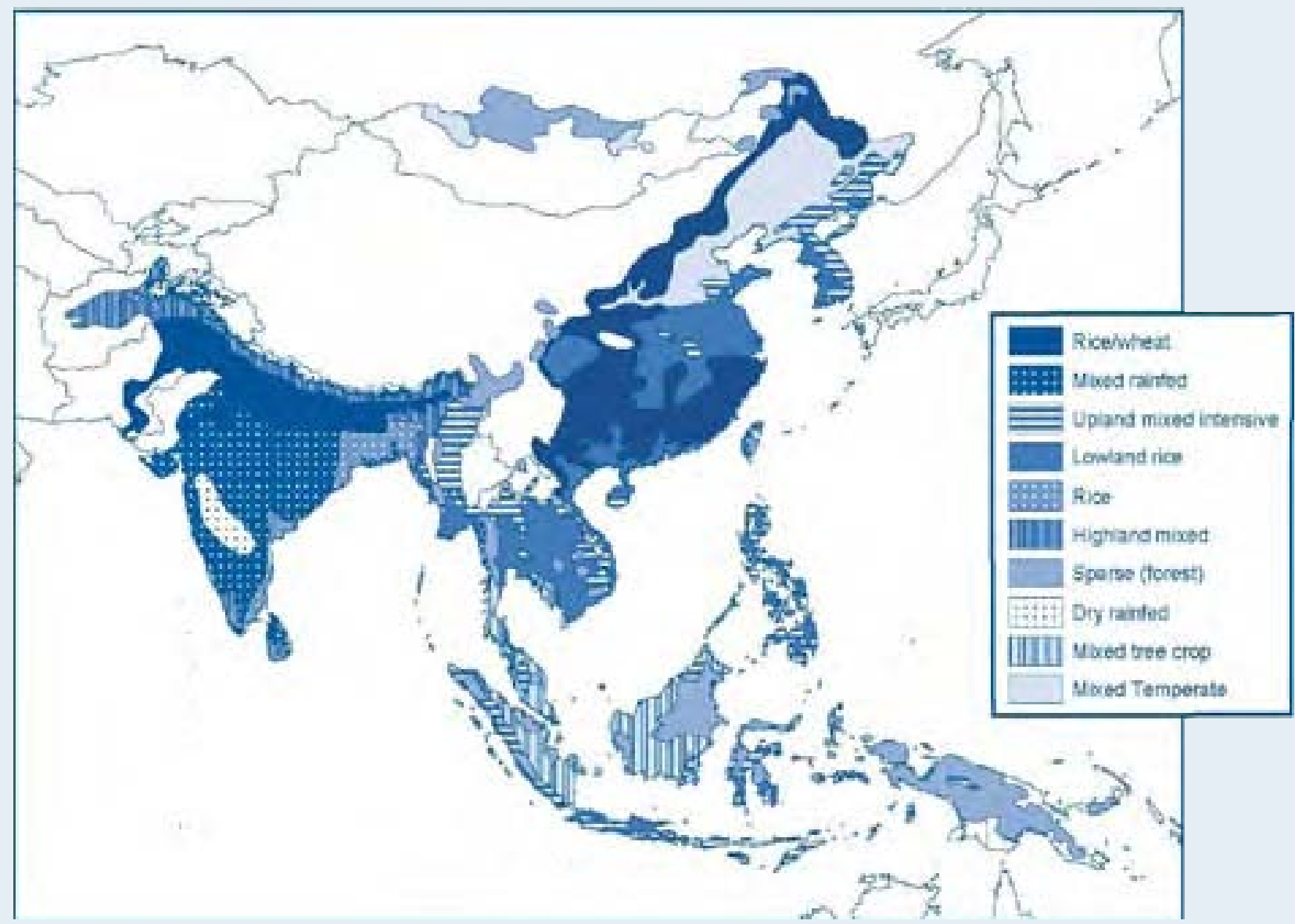

Source: Adapted from G. Hyman, P. Jones, S. Fujisaki, S. Wood, and J. Dixon, "Strategic Approaches to Targeting Technology Generation: Assessing the Coincidence of Poverty and Drought-prone Crop Production" (Cali, Colombia, 2007). 
Against this backdrop, consider that real world prices of cereals and meats are projected to rise by 20-40 percent by 2050, driven by demand and supply factors; increased population growth and regional economic growth will fuel the demand for food and change the composition of that demand; and biofuel demand will introduce new, and growing, competition for land and water resources, while natural resources-particularly water-are increasingly being degraded and becoming scarce. Further, crop breeding has failed to achieve significant impacts in risk-prone or resource-poor areas, which are only likely to expand under the growing resource pressures. Water scarcity, drought stresses, and declining irrigation availability will lower expected yields and increase production risk, which in turn will act as a disincentive for poor farmers to adopt much-needed innovative technologies. Climate change will only exacerbate these stresses, adversely affecting wheat productivity in the Indo-Gangetic Plains, reducing rice yields due to increased nighttime temperatures, and increasing evapotranspiration and thus the demand for water, as various studies have shown.

Available water for agriculture has already declined sharply over the past several decades, particularly in Asia. The situation is particularly challenging for China and India, where water is increasingly transferred out of agriculture to meet growing demands

\section{Figure 2-Projected Change in Irrigation Water Consumption as a Share of Total}

Water Consumption for Selected Asian Countries and Regions, 2000 and 2050

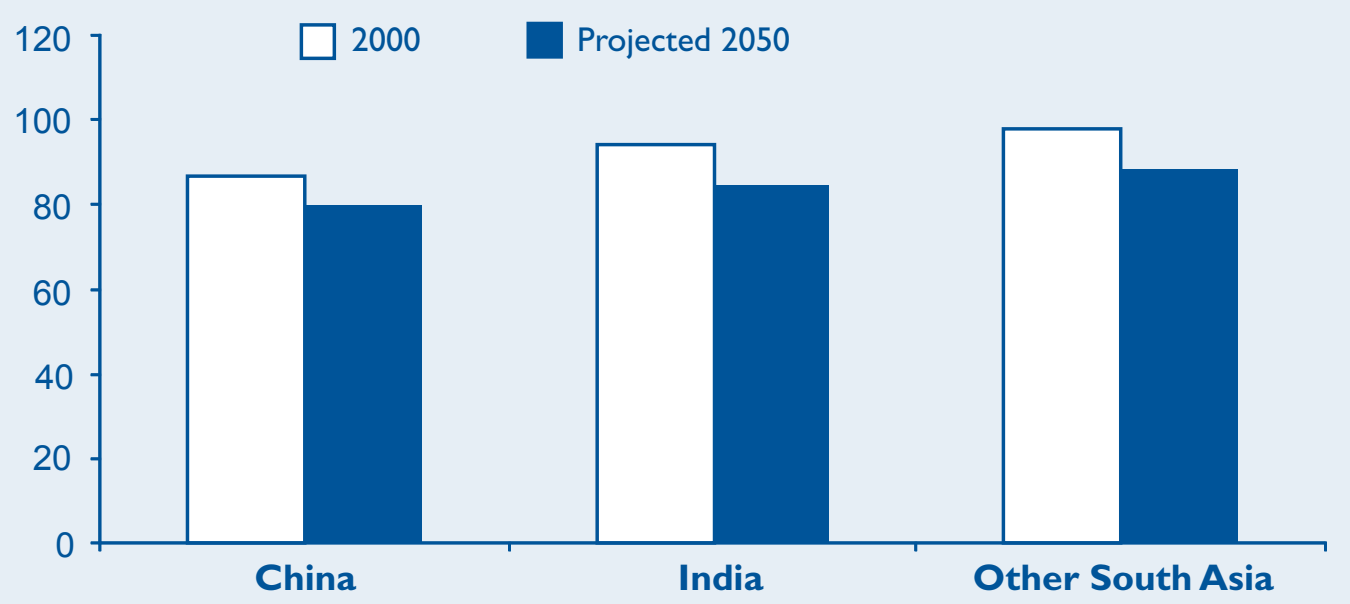

Source: Data prepared for the draft version of M. Rosegrant et al.,"Looking into the Future for Agriculture and Agricultural Knowledge, Science and Technology," Chapter 5 of 2007 Global Outline Report (International Assessment of Agricultural Science and Technology for Development, San Jose, 2007).

\section{Figure 3-Projected Child Malnutrition Trends in Developing Asian Countries under} Five Prospective Scenarios, 2000 and 2050

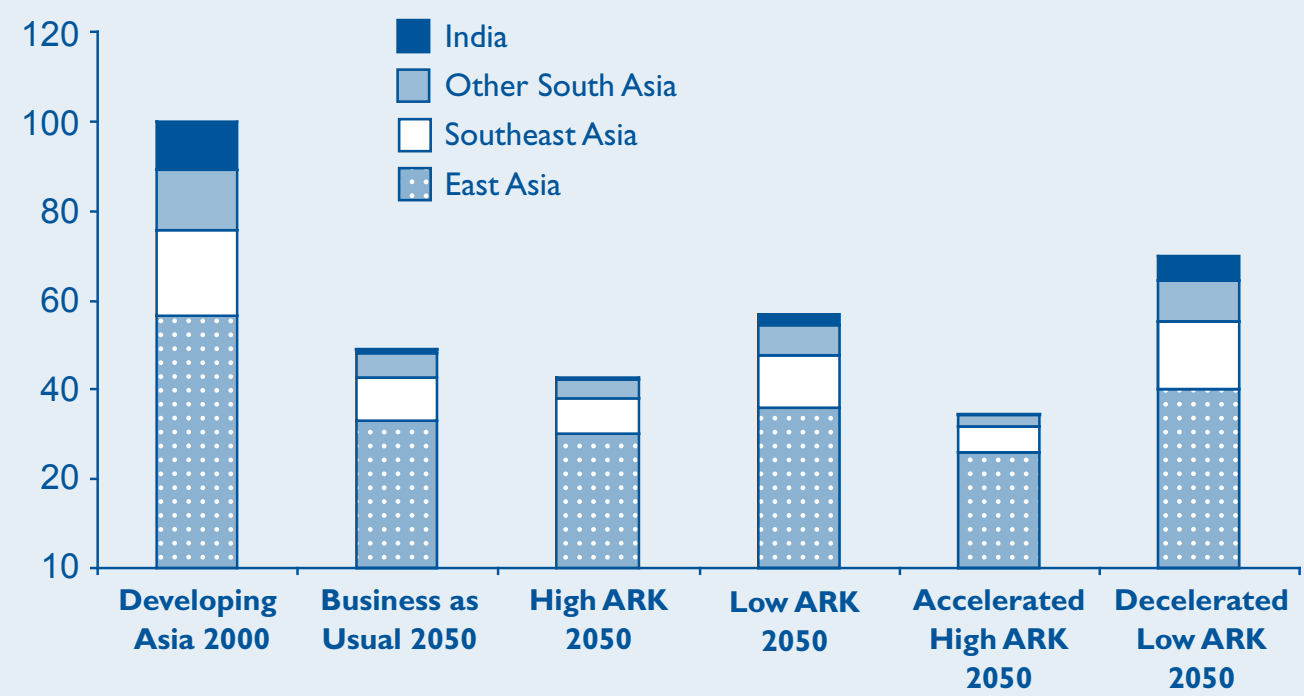

Source: Data prepared for the draft version of M. Rosegrant et al.,"Looking into the Future for Agriculture and Agricultural Knowledge, Science and Technology," Chapter 5 of 2007 Global Outline Report (International Assessment of Agricultural Science and Technology for Development, San Jose, 2007).

Note: "ARK" signifies investment in agricultural research and knowledge. 
from domestic and industrial sectors. Figure 2 shows the estimated share of irrigation water consumption in total water consumption in selected Asian countries and regions.

\section{SELECTED MODELING RESULTS BASED ON EXISTING, IMPROVED,AND DETERIORATING CIRCUMSTANCES}

The International Model for Policy Analysis of Agricultural Commodities and Trade (IMPACT), developed by the International Food Policy Research Institute (IFPRI) in the early 1990s, enables a variety of possible future agricultural and economic development scenarios to be analyzed and compared. The five scenarios relevant to this discussion follow:

1. A continuation of the status quo, under which increasing population, land pressure, water scarcity, and environmental degradation lead to rising food prices with potentially dramatic negative consequences for poor rural populations and children's nutritional status ("Business as Usual")

2. High investment in agricultural research and knowledge ("High ARK"), whereby more aggressive investments in and better management of agricultural research and knowledge drive significant improvements in food security objectives

3. Low investment in agricultural research and knowledge ("Low ARK"), which results in lower crop yields and lower growth in livestock numbers, negatively affecting food security and agricultural growth outcomes

4. The High ARK scenario combined with accelerated complementary investments in irrigation, water access, water use efficien$c y$, rural roads, and female secondary education, which results in increased crop yield growth and livestock numbers, expanded irrigated area, improved water access, and advances in female secondary education ("Accelerated High ARK")
5. The Low ARK scenario combined with decelerated complementary investments in irrigation, water access, water use efficiency, rural roads, and female secondary education, which overall results in the worst food security and agricultural development outcomes. ("Decelerated Low ARK")

Based on these scenarios, projected child malnutrition trends in Asia's developing countries to 2050 (Figure 3) and projected changes in international food prices (Figure 4) are just two examples of the critical importance of targeted investments in agricultural research and knowledge, on the one hand, and complementary rural infrastructure, on the other.

\section{POTENTIAL OPPORTUNITIES}

Strong potential remains to increase crop productivity through effective management of water resources, such as through water harvesting, minimum tillage practices, and soil fertility management; targeted rural investments to improve access to markets, credit, and inputs; and innovative agricultural research and development (REDD) emphasizing crop breeding on both irrigated and rainfed lands and utilizing genetic modifications to build stress tolerance against water scarcity, salinization, and groundwater contamination.

Innovative R\&D in agricultural technology will be crucial to addressing the growing pressures on food systems. Agricultural biotechnology is making significant progress in the areas of drought tolerance, salt tolerance, and nitrogen use to alleviate the pressure on water demand. Large benefits, both in terms of increased crop yields and reduced irrigation demand, could be seen in rainfed and marginal environments. Despite implementation issues, advances have been made with Bt cotton; drought-tolerant maize could be in the fields in the United States within the next five to six years and be adapted for developing countries thereafter; and the development of salt-tolerant rice is progressing well. Nonetheless, the issues of public acceptance, biosafety, and technology transfer must be resolved to pave the way for these advances. Public-private

\section{Figure 4-Projected International Food Prices under Five Prospective Scenarios, 2000}

and 2050

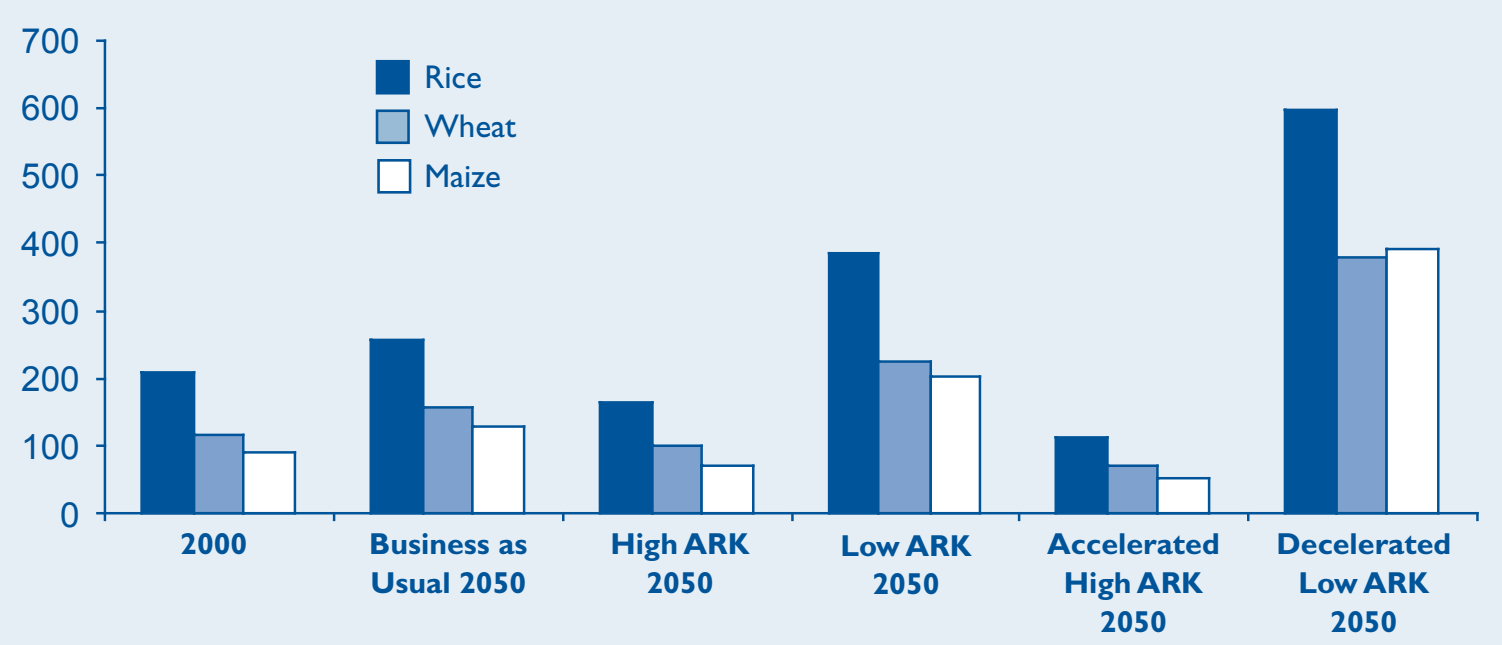

Source: Data prepared for the draft version of M. Rosegrant et al.,"Looking into the Future for Agriculture and Agricultural Knowledge, Science and Technology," Chapter 5 of 2007 Global Outline Report (International Assessment of Agricultural Science and Technology for Development, San Jose, 2007).

Note:"ARK” signifies investment in agricultural research and knowledge. 
partnerships will be extremely important in the development and commercialization of genetically modified varieties.

Production processes for biofuels have the potential to bring about benefits for the poor, but for these opportunities to be realized, production systems should be designed to integrate rural households into the value chain and to incorporate onfarm value addition rather than the simple extraction of raw biomass. Funding for mitigation and adaptation strategies will also be important to support bioenergy transitions in developing countries.

Creating and expanding markets for natural resources is another key factor in accelerating agricultural growth. Examples include establishing economic incentives around water use by creating strong water rights for users and paying irrigators to use less water; developing more aggressive markets for agricultural and forest carbon, thereby generating new value streams in rural areas; and expanding markets for environmental services, such as watershed management and biodiversity.

\section{STRATEGIC DIRECTIONS FOR POLICY AND INVESTMENTS}

Since poverty is largely a rural phenomenon and many of the poor directly or indirectly depend on the farm sector for their incomes, growth that raises agricultural productivity and the incomes of small-scale farmers and landless laborers is particularly important in reducing poverty; growth alone is insufficient. Policies must also reach out directly to the poor by supporting investments in human capital. Investments in health, nutrition, and education address not only the worst consequences of poverty, but also some of its most important causes. Moreover, even with rapid economic growth, some of the poor will be reached slowly, if at all, and many of them will remain vulnerable to economic reversals. These groups will need to be reached through income transfers or other safety nets that help them through short-term stresses or disasters.

In the agricultural sector, the poor benefit most when land is distributed relatively equitably; agricultural research focuses on the problems of small farmers as well as large; new technologies are scale-neutral and can be profitably adopted by farms of all sizes; efficient input, credit, and product markets ensure that farms of all sizes have access to needed modern farm inputs and receive similar prices for their products; the labor force can migrate or diversify into the rural nonfarm economy; and policies such as subsidies do not discriminate against agriculture in general or small farms in particular.

Policies intended to promote growth and environmental sustainability need to be fully integrated. Such policies must deal with the issues of scarce land and water resources, and tradeoffs with the environment can only be met if externalities are brought into the growth equation. Policies also need to encourage the creation of markets and new value streams for agricultural ecosystem services.

Staple food crops will remain essential for poverty-reducing growth. Since value chains start at the farm level, achieving propoor growth will require that new production technology be embedded in improved managements systems. Biotechnology, including genetically modified organisms, is likely to be central to the development of technology adapted to less-favored areas.

The biggest challenge facing the agricultural sector is to increase investments in relevant agricultural research and knowledge to support food security improvements and contribute to raising incomes-and to do so without adding to existing environmental stresses.

For Further Reading: R. Barker and M. W. Rosegrant, “Establishing Efficient Use of Water Resources in Asia," in Reasserting the Rural Development Agenda: Lessons Learned and Emerging Challenges in Asia, A. Balisacan and F. Nobuhiko, eds. (Singapore and Los Banos, the Philippines: Institute of Southeast Asian Studies and the Southeast Asia Regional Center for Graduate Study and Research in Agriculture, 2007); X. Cai and M. W. Rosegrant, "Future Prospects for Water and Food in China and India: A Comparative Assessment," in The Dragon and The Elephant: Agricultural and Rural Reforms in China and India, A. Gulati and S. Fan, eds. (Baltimore: Johns Hopkins University Press, 2007); X. Cai and M. W. Rosegrant, "Water Management and Food Production in China and India: A Comparative Assessment," Water Policy 7 (2005): 643-663; P. Pingali, "Westernization of Asian Diets and the Transformation of Food Systems: Implications for Research and Policy," Food Policy 32 (2006): 28I-298; M. W. Rosegrant and P. Hazell, Transforming the Rural Asian Economy: The Unfinished Revolution (New York: Oxford University Press for the Asian Development Bank, 200I).

Mark W. Rosegrant (m.rosegrant@cgiar.org) is director of the Environment and Production Technology Division (EPTD) of the International Food Policy Research Institute (IFPRI).Also within EPTD, Claudia Ringler (c.ringler@cgiar.org) and Stanley Wood (s.wood@cgiar.org) are senior research fellows; Siwa Msangi (m.msangi@cgiar.org) is a research fellow; Tingju Zhu (t.zhu@cgiar.org) is a postdoctoral fellow; and Timothy B. Sulser (t.sulser@cgiar.org) and Rowena Valmonte-Santos (r.valmonte-santos@cgiar.org) are research analysts. 
A sian food markets are undergoing a profound and extremely rapid transformation, with implications for employment in value-added and primary production for small-scale processors, intermediaries, farmers, and landless laborers. As markets become broader and deeper, allowing for quality differentiation and more value added, they are creating new opportunities for poverty alleviation and income growth. But market transformation also raises challenges for small-scale actors by stimulating greater competition; increasing demands for quality, safety, consistency, and volume; pushing for reduced costs; and requiring modern postharvest handling and commercial practices. Meeting these challenges calls for "threshold investments" by those actors-in equipment, skills, land improvements, and knowledge-that can prove daunting to the asset-poor. Policies and public investments have an important role to play in helping small producers over those hurdles so that they can benefit from rapid market transformation.

Market transformation can be analyzed in terms of changes in the characteristics of the exchange itself-such as its location and volume-and changes in the demand and supply sides of the exchange. The demand side can be analyzed in terms of food consumption levels and composition, with the latter broken down into food obtained from home production versus the market and into types of food bought in the market-processed versus raw, staples versus nonstaples. The supply side can be analyzed in terms of the supply chain from the farmer to the last point (usually retail) before the final demand point. That supply chain is composed of retailers, processors, wholesalers, farmers, and input supply firms. Analysis of market transformation is thus a complex and vast terrain, especially in Asia, where all these elements are changing simultaneously and quickly.

This brief concentrates on two key trends that have triggered change in Asian food markets and therefore have associated implications for smallholders, policies, and investments. The first trend is the fast diversification of diets toward high-value agricultural products such as fruits and vegetables, milk, meat, and fish. The second trend is the rapid rise of organized retail in foodthe "supermarket revolution." These two trends share some causes and are mutually reinforcing.

\section{MORE DIVERSE DIETS}

Following Bennett's Law, the share of nonstaples has risen quickly in diets across developing Asia. During 1991-2005, data from eight major countries of South and Southeast Asia (Bangladesh, China, India, Indonesia, Pakistan, the Philippines, Thailand, and Vietnam) showed that average annual consumption of meat rose by 3.9 percent, vegetables by 3.7 percent, eggs by 3.1 percent, milk by 2.7 percent, fish by 2.4 percent, and fruits by 1.9 percent, whereas consumption of grains fell by -0.4 percent (Figure 1). The biggest changes took place in China, which experienced the fastest overall rate of growth in per capita gross domestic product (GDP) in the region during this period.

\section{Figure I-Average Annual Growth in Per Capita Consumption in Eight Countries in South and Southeast} Asia, 1991-2005

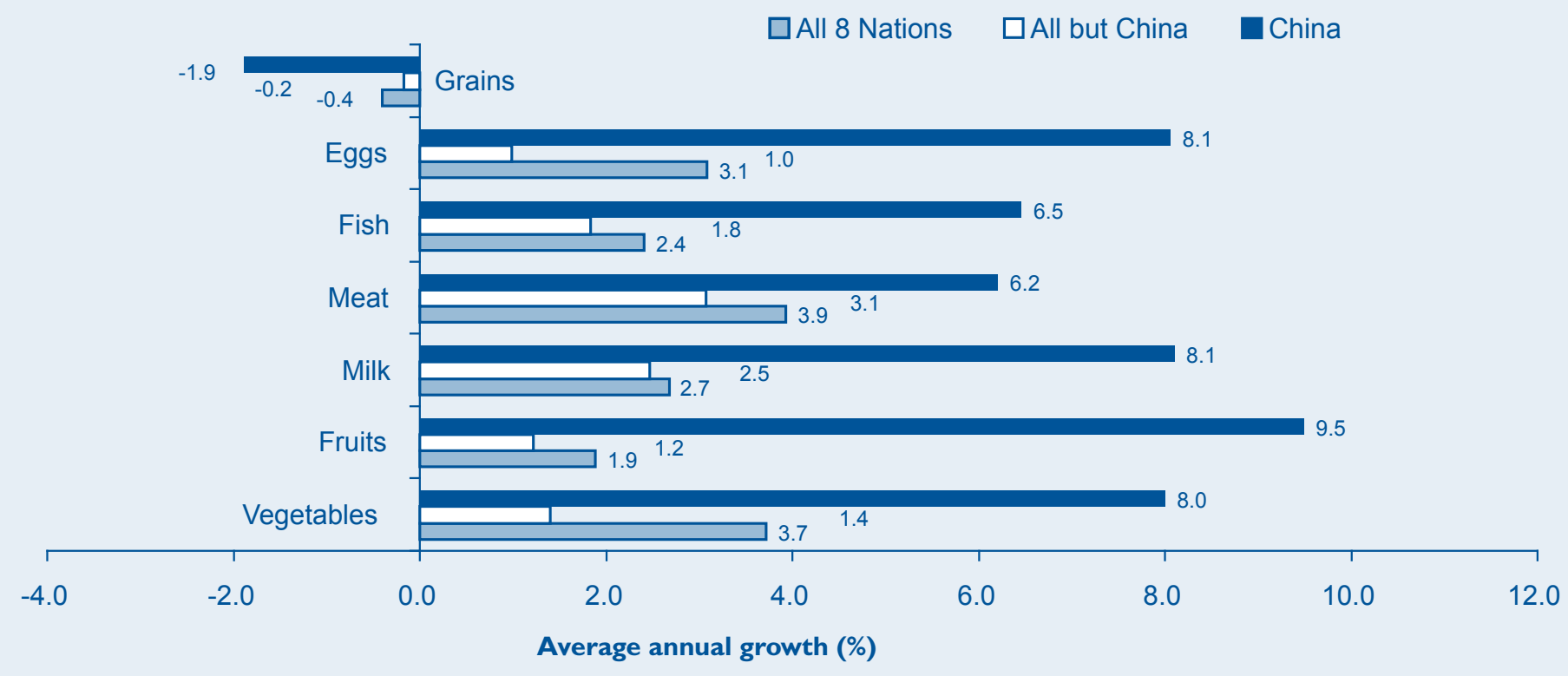

Notes: Grains include cereals and pulses. Consumption is measured as grams/capita/day. The eight countries are Bangladesh, China, India, Indonesia, Pakistan, the Philippines, Thailand, and Vietnam. 
Bennett's Law is having the effect not of reinforcing and expanding the traditional Asian diet, but of "westernizing" the Asian middle-class diet into nontraditional products-wheat, temperate fruits and vegetables, and high-protein foods like dairy and meat. A stunning example of this change is the spectacular increase in the production of milk in China (a nontraditional food in Asia) from 1.14 million tons in 1980 to 27.5 million tons in 2005, a 24-fold increase over 25 years. Urban milk consumption in China leapt from 8 kilograms per capita in 1996 to 25 in 2005, nearing the 35 kilograms per capita of India, a traditional consumer of dairy products.

Although quantity and food price still reign supreme for the average Asian consumer, there is also a trend toward quality and food-safety differentiation in the food market that is likely to grow significantly in the coming decades. Income growth in the middleclass consumer segment has created demand and reward for quality differentiation, and greater vertical coordination in supply chains has created the capacity to achieve it, especially through supermarkets, hotels, restaurants, and catering. Various crises of food adulteration (such as fish in Indonesia), avian flu, severe acute respiratory syndrome (SARS) and other food-borne illnesses, and pesticide poisonings have also pushed urban consumers to be food-safety conscious.

\section{THE SUPERMARKET REVOLUTION}

Although the growth of wholesale markets and the growth and consolidation of the food-processing industry were important trends in Asian food markets in the 1980s and 1990s, the most striking recent change in market structure has been the supermarket revolution that occurred in Southeast Asia in the early to mid-1990s and in China in the mid- to late 1990s. It is currently spreading to South Asia, notably India.
The spread of supermarkets has been taking place in three established waves, and a fourth emerging wave. The first-wave countries experienced supermarket-sector takeoff in the early to mid-1990s. These countries include much of East Asia outside China and Japan. In these countries, the average share of supermarkets in food retail went from roughly 10-20 percent around 1990 to 50-60 percent by the early 2000s. These countries are moving toward convergence with the United States and Western Europe, where supermarkets had a roughly 75-80 percent share of food retail in 2005. These first-wave countries experienced supermarket diffusion in a single decade that took some five decades in the United Kingdom and United States. The second-wave countries include much of Southeast Asia. In these areas, the share went from about 5-10 percent in 1990 to 30-50 percent by the early 2000s, with the takeoff occurring in the mid- to late 1990s. The third-wave countries include those where the supermarket revolution takeoff started only in the late 1990s or early 2000s, reaching about 1-15 percent of national food retail today. These areas include "transition East Asia" (China and Vietnam) and India. During 2000-2006 the top 10 grocery retailers in six selected countries of South and Southeast Asia registered average annual growth rates ranging from 65.5 percent in Vietnam to 28 percent in Indonesia (Figure 2). The fourth wave is just barely emerging in the poorest areas, such as Bangladesh, Cambodia, and West Africa, and in postconflict countries that are now opening to investment. It may take decades before supermarket diffusion in these areas is appreciable.

Supermarkets also spread in waves over space within an Asian country, over consumer segments, and over product categories. Supermarkets tend to start in large cities, then spread to intermediate cities and towns, and then enter small towns in rural areas. The business strategy is the same as that used by chains as

Figure 2-Average Annual Growth Rate of Grocery Sales of Top 10 Retailers in Six Selected Countries in South and Southeast Asia, 2000-06

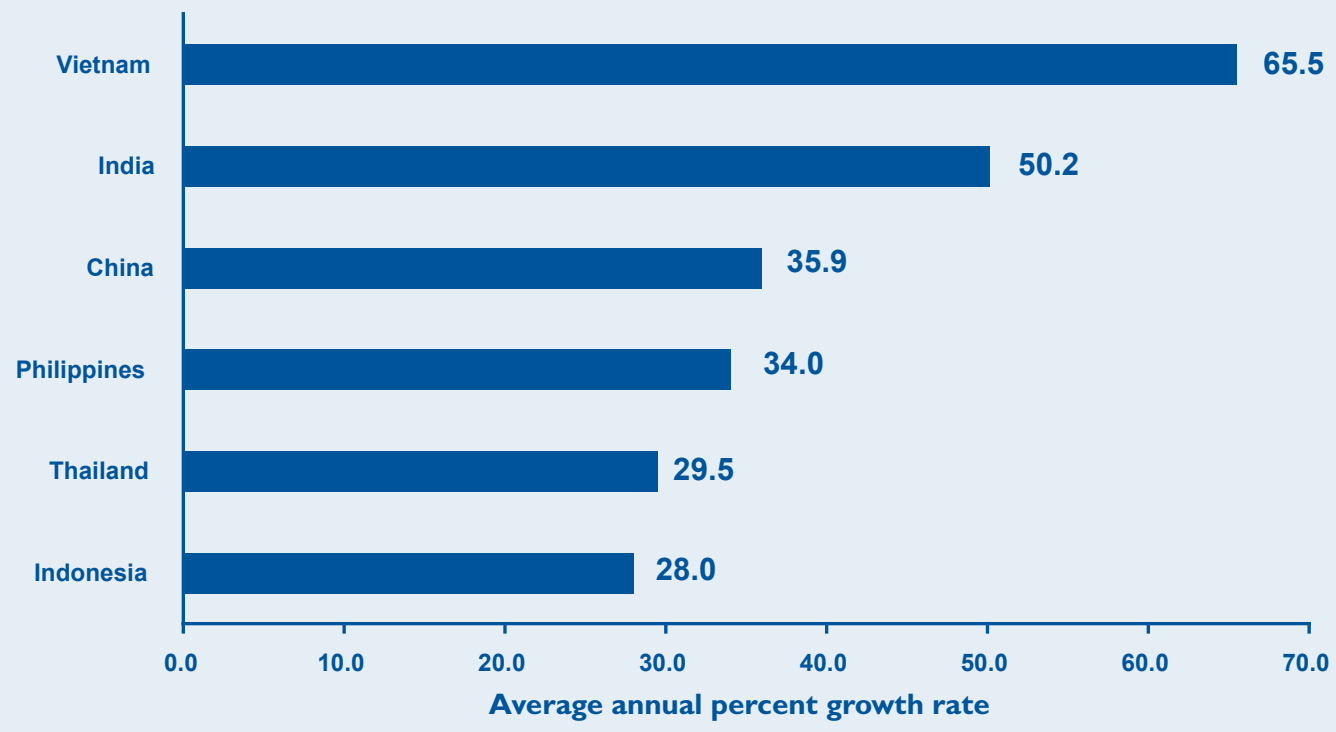

Source: Planet Retail website (www.planetretail.net), accessed July 3I, 2007.

Notes: Grocery sales include food, beverages, tobacco products, drugstore items, and small everyday nonfood household goods. The ranking of the top 10 retailers (in the grocery segment) is based on the grocery banner retail sales in 2006. 
they spread: the richest and largest market is entered first owing to the highest profit per unit of capital invested. As competition grows and saturation takes place in the initial market, chains invest in subsequent markets.

Controlling for the pattern of spatial diffusion, there are similar waves of diffusion over socioeconomic groups and consumer segments. Obeying the same business logic as in spatial diffusion, supermarkets focus first on upper-income consumer segments (national and expatriate), then move into the middle class, and finally spread into the markets of the urban poor.

As modern retailers spread, they tend to diversify formats to facilitate spatial and consumer segment differentiation. For example, to penetrate the markets of inner cities and small towns where space is limited and product assortment can be narrower, chains use discount stores, convenience and neighborhood stores, and small supermarkets.

Product penetration spreads from processed foods (canned, dry, and packaged items such as rice, noodles, and edible oils) to semiprocessed foods (with extensive or minimal processing such as dairy products or with minimal processing and packing such as chicken, pork, beef, and fruit) to fresh fruits and vegetables.

The experiences of China and Hong Kong illustrate this pattern of penetration of supermarkets and products. A new study of a random sample of 1,200 consumers in the six largest cities in China shows that modern retailers already have a retail market share of 94 percent in nonfood, 79 percent in packaged and processed goods, 55 percent in baked goods, 46 percent in meat, 37 percent in fresh fruit, 35 percent in poultry, and 33 percent in fish, but only 22 percent in fresh vegetables. In the more advanced case of Hong Kong, which may represent the average Asian consumer sometime in the medium-term future, supermarkets have a 59 percent share in fruit retail but only a 55 percent share in vegetables (similar to supermarket penetration for produce in Brazil), 52 percent in meat, 39 percent in poultry, and 33 percent in fish.

Several drivers are behind the supermarket revolution. First, incomes and urbanization are increasing. Second, foreign direct investment (FDI) in retail was liberalized in the 1990s and 2000s and accompanied by competitive domestic retail investments. Third, some countries have adopted pro-supermarket policies, such as state-supported supermarket chains (such as in China), municipal tax breaks for supermarkets, and regulation of wet markets (in most countries) or even conversion of wet markets to supermarkets (in some Chinese cities). These policies have to some extent been balanced by policies constraining supermarket diffusion, such as rules on locations and hours in Thailand and continued FDI limitations in India. Fourth, recent food safety crises have spurred consumers to shift to modern retail and large processors for their food, as in Vietnam after the bird flu outbreaks. Fifth, the modernization of procurement systems, especially for processed and semi-processed products, including dry goods, oils, meat, fish, and dairy (which together make up 85 percent of what supermarkets sell), has driven down costs and thus prices, helping supermarket diffusion.

\section{IMPLICATIONS FOR PRODUCERS AND POLICY}

The trends of diet diversification and the supermarket revolution share some common drivers (income growth and urbanization), reinforce each other (as supermarkets build and extend markets for processed and semi-processed products like dairy, processed horticulture products, and meat), and transform each other (as consumers press for high-quality and safe produce, supermarket chains transform their supply chains for more coordination and traceability).

Supermarkets and large processors tend to source from a combination of wholesale markets, specialized and dedicated wholesalers, and farmers and processors. The impacts on farmers occur mainly through the effects of supermarket sourcing on processors and in turn processors' imposition of cost and quality demands on farmers.

Recent empirical studies point to several patterns concerning the kinds of suppliers from which supermarkets source:

- Supermarket chains tend to source from large and mediumsize suppliers where they are available. This tendency typically means sourcing from larger companies that produce meat, dairy products, and other processed foods, as shown in India and Indonesia.

- Supermarket chains also tend to source, where possible, fresh products from large and medium-size farmers. This is rarely possible in most developing countries, however, except for a few products (which vary by country) and for countries that have developed export sectors supplied by large and mediumsize produce farms.

- Supermarket chains usually source from small farmers only indirectly, through wholesalers and processors. These small farmers tend to be in the upper stratum in terms of capital assets (organization, equipment, and training), infrastructure access, and size.

- Where small farmers lack the needed assets but the channel must still rely on them, sometimes a nearby intermediary or even retailer assists them with training, credit, and other requirements (as Carrefour and Metro are presently doing in China).

- Because most fresh produce growers in Asia operate on a small scale, small farmers are not excluded on the basis of the size of their landholding or land tenure, except when these factors affect their capacity to implement technologies that have an impact on quality, productivity, costs, or delivery schedule. Rather, other assets besides land appear to play a much bigger role. In particular, participating farmers have more education, more access to transport and roads, and greater prior holdings of physical assets such as wells, cold chains, greenhouses, and good-quality irrigation water (free of contaminants). In the rare instances when small farmers sell directly to supermarkets, they have a very good rural producers' organization (RPO).

Farmers in the supermarket channel tend to earn from 10 to 100 percent more in net terms than other farmers, so the payoff to making the threshold investments is substantial. Those who sell to supermarkets, however, tend to be the asset-elite among small farmers. One implication for policy is that it is the asset-poor (not necessarily the smallholders) who may be left out of these supermarket chains. Concern about the exclusion of asset-poor small farmers in the early stages of supermarket penetration should be understood in the context that in developing countries where supermarket share is around 20-30 percent of food retail, typically only 10-30 percent of all farmers are selling through modern channels. That number will continue to grow (from nearly zero only a decade ago), creating an increasing market challenge for farmers 
as they seek to meet supermarkets' quality norms, as well as an opportunity for the asset-poor. Smallholders' efforts to build assets thus need to be supported through, for instance, market information, education, credit disbursement, and extension services.

To understand better how organized retail can help small, asset-poor producers, one must imagine the process from plate to plough, or retail to tail (farming). Organized retailers are the first interface with consumers who buy in organized channels, and retailers can effectively communicate consumers' preferences about quantity, quality, food safety, and other traits of commodities back to producers. This market information is critical for small producers to mitigate their market risk and encourage investments.

The process can be strengthened and expedited if retailers or their specialized procurement agencies (especially processors) not only link up with farmer organizations for their output, but also provide critical inputs such as technical expertise and extension, which are in general scarce or even missing in the public support systems used by the broad mass of farmers. Given the scale at which organized retailers and processors operate, they can bring in specialized services like banking and even insurance. This step would not only remove the credit constraints that most farmers, especially small ones, face, but also reduce their production risks as they move from low-value to high-value agriculture. This surge of access to inputs would empower farmers to modernize and become more competitive in both the national and the international market. Supplying supermarkets (or their dedicated processors) can thus serve as a springboard or training ground for exports even by small and medium-size farmers.

Given the size of demand by organized retailers and their processors, it is difficult for individual farmers, especially small ones, to enter into contracts with these retailers. The challenge lies in clustering farmers into groups large enough to meet the type and size of demand by organized retailers. This grouping can be done through farmer cooperatives supported by governments, as India did for dairy farmers through Operation Flood. Today in India the retail network of Mother Dairy procures milk from these farmer cooperatives. It could also be done through farmer-floated companies or through civil society organizations.

Because organized retailers sell largely (85 percent or so) processed and semi-processed food, major linkages with farmers are likely to emerge through large processors. Nestlé in India, for example, is procuring milk from more than 85,000 farmers, most of whom are medium to small in size. Similarly, the corporate house
ITC in India is linked to 3.5 million mostly medium-sized and small farmers for its procurement of soya, wheat, and other products through its e-choupal network. In sum, the backward integration of organized retailers and processors can take several forms-through farmers' organizations, through "lead" farmers who act as villagelevel collectors, through specialized and supported procurement agents, or through processors. But this integration happens when the front end of organized retail is big enough to necessitate large-scale procurement and thus pay price premiums to reward consistency and quality differentiation. Once supermarkets reach a critical level of, say, 20-30 percent of total retail, their impact on modernizing wholesale markets and logistics and their role in providing necessary inputs to farmers starts becoming visible. Governments, business associations, and civil society organizations may have to work together to ensure that this opportunity is not lost but used in a manner that benefits the majority of stakeholders in the chain from retail to tail.

For Further Reading: R. Natawidjaja, T. Reardon., and S. Shetty, with T. I. Noor, T. Perdana, E. Rasmikayati, S. Bachri, and R. Hernandez, Horticultural Producers and Supermarket Development in Indonesia, report by Universitas Padjadjaran (UNPAD) and Michigan State University (Jakarta: World Bank/Indonesia, 2007); P. Pingali, “Westernization of Asian Diets and Transformation of Food Systems: Implications for Research and Policy," Food Policy 32, no. 3 (2007): 28I-298; T. Reardon and C. P. Timmer, "Transformation of Markets for Agricultural Output in Developing Countries since 1950: How Has Thinking Changed?" in R. E. Evenson and P. Pingali, eds., Handbook of Agricultural Economics, 3: Agricultural Development: Farmers, Farm Production, and Farm Markets (Amsterdam: Elsevier, 2007); T. Reardon and C. P. Timmer, “The Supermarket Revolution with Asian Characteristics," in A. M. Balisacan and N. Fuwa, eds., Reasserting the Rural Development Agenda: Lessons Learned and Emerging Challenges in Asia (Singapore: Institute of Southeast Asian Studies and Southeast Asian Regional Center for Graduate Study and Research in Agriculture, 2007); T. Reardon and J. A. Berdegué, "The Retail-led Transformation of Agrifood Systems and Its Implications for Development Policies," background paper prepared for the World Bank's World Development Report 2008: Agriculture for Development (Latin American Center for Rural Development [RIMISP], Santiago, Chile, and Michigan State University, East Lansing, MI, 2007).

Ashok Gulati (a.gulati@cgiar.org) is director in Asia of the International Food Policy Research Institute (IFPRI). Thomas Reardon (reardon@msu.edu) is a professor of agricultural economics at Michigan State University. Gulati and Reardon are codirectors of the IFPRI/MSU Joint Program "Markets in Asia." 


\section{Focus I5 • BRIEF 8 OF I5 • MarCH 2008}

I the 1970s and 1980s, it was believed that high population pressure on Asia's closed land frontier was one of the major causes of the region's rural poverty. High population pressure leads to a decline in farmland area and an increase in the incidence of landlessness, even though farmland is a major asset for rural households. This also means that agricultural wages remain low and the demand for agricultural labor is both limited and uncertain. In addition, the accelerated use of labor-saving technologies, such as mechanization and direct-seeding, further contributes to reduced agricultural labor demand. Indeed, one study found that the Green Revolution in Asia has had only modest impacts on the demand for agricultural labor, in contrast to its dramatic impacts on grain yields. Nevertheless, amidst the unfavorable scenario of increasing scarcity of farmland and declining employment opportunities in agriculture, Asian households have succeeded in escaping from poverty. According to the Asian Development Bank, between 1990 and 2003, the proportion of the population living on less than US\$1 per day declined from 20 to 14 percent in the Philippines, from 10 to 1 percent in Thailand, from 34 to 30 percent in Bangladesh, and from 42 to 31 percent in India. During this period, the importance of nonfarm income visibly increased, and the quality of human capital improved appreciably in terms of schooling. The intention of this brief is to trace the changing structure of household income and to identify the processes through which rural poverty has declined in selected Asian villages.

\section{CHANGES IN THE SOURCE OF HOUSEHOLD INCOME AND THE INCIDENCE OF POVERTY}

Data analysis indicates that there has in fact been a large reduc-

tion in the area of landholdings operated by farm households, along with an increase in the share of landless households (Table 1). In the Philippines, the average farm size was 1.0 hectares (ha) in 1985, but by 2004 average area had fallen to $0.76 \mathrm{ha}$, and the proportion of landless households had risen from 22 to 24 percent. These changes

Table I-Changes in Farm Size and Percentage of Landless Households in Selected Rural Areas in Asia

\begin{tabular}{lcccc} 
& \multicolumn{2}{c}{$\begin{array}{c}\text { Average Farm } \\
\text { Size (Hectares) }\end{array}$} & \multicolumn{2}{c}{$\begin{array}{c}\text { Landless } \\
\text { Households (\%) }\end{array}$} \\
\cline { 2 - 5 } Country & 1980s & $\mathbf{2 0 0 3 / 0 4}$ & 1980s & 2003/04 \\
\hline Philippines & 1.00 & 0.76 & 22 & 44 \\
Thailand & 4.24 & 2.42 & 0 & 30 \\
Bangladesh & 0.87 & 0.59 & 34 & 39 \\
Tamil Nadu (India) & 1.01 & 0.95 & na & na \\
\hline
\end{tabular}

Sources: Data for the Philippines, Thailand, and Bangladesh are from the four studies underlying this brief (see Further Reading); data for India are from the agricultural censuses of I985/86 and 1995/96, Government of Tamil Nadu, and Economic Appraisal, Chennai, Government of Tamil Nadu.

Note: na indicates data were not available. are more drastic in Thailand, whereas Bangladesh exhibits similar, but more modest changes. In Tamil Nadu (India), the census data indicate only a small reduction in average farm size from 1.0 to 0.95 ha.

Despite these unfavorable changes in rural Asia, the incidence of poverty has declined sharply. To investigate this dynamic, differences in income levels and the incidence of poverty were examined, comparing marginal areas, commonly characterized by unfavorable rainfed conditions and susceptibility to drought, with high-potential, mostly irrigated areas. While per capita income increased in both marginal and high potential areas, income growth was more remarkable in the marginal areas, with the exception of Bangladesh (Table 2). Unsurprisingly, increased income was brought

Table 2-Composition of Household Income (\%) and Poverty Incidence (Headcount Ratio) in Selected Rural Areas in Asia

\begin{tabular}{|c|c|c|c|c|}
\hline \multirow[b]{2}{*}{ Country } & \multicolumn{2}{|c|}{$\begin{array}{l}\text { High-Potential } \\
\text { Agricultural Areas }\end{array}$} & \multicolumn{2}{|c|}{$\begin{array}{l}\text { Marginal } \\
\text { Agricultural Areas }\end{array}$} \\
\hline & 1980s & $2003 / 04$ & $1980 s$ & $2003 / 04$ \\
\hline \multicolumn{5}{|l|}{ Philippines } \\
\hline Per capita income (PPP\$) & 1,065 & 2,364 & 386 & 1,119 \\
\hline Agricultural wage (\%) & 13 & II & 30 & 7 \\
\hline Rice (\%) & 37 & 12 & 20 & 9 \\
\hline Nonrice farm income (\%) & 5 & 7 & 13 & 24 \\
\hline Nonfarm income (\%) & 45 & 70 & 36 & 60 \\
\hline Incidence of poverty (\%) & 40 & 23 & 66 & 42 \\
\hline \multicolumn{5}{|l|}{ Thailand } \\
\hline Per capita income (PPP\$) & 2,014 & 4,617 & 959 & 2,543 \\
\hline Agricultural wage (\%) & 4 & 6 & 12 & 5 \\
\hline Rice (\%) & 66 & 26 & 54 & 7 \\
\hline Nonrice farm income (\%) & 21 & 22 & 13 & 14 \\
\hline Nonfarm income (\%) & 10 & 47 & 21 & 74 \\
\hline Incidence of poverty (\%) & 51 & 12 & 70 & 21 \\
\hline \multicolumn{5}{|l|}{ Bangladesh } \\
\hline Per capita income (PPP\$) & 634 & $|, 00|$ & 841 & $\mathrm{I}, 094$ \\
\hline Agricultural wage (\%) & 14 & 8 & 11 & 4 \\
\hline Rice (\%) & 35 & 20 & 24 & 13 \\
\hline Nonrice farm income (\%) & 18 & 21 & 20 & 26 \\
\hline Nonfarm income (\%) & 33 & 51 & 55 & 57 \\
\hline Incidence of poverty (\%) & 64 & 41 & 58 & 43 \\
\hline \multicolumn{5}{|l|}{ Tamil Nadu (India) } \\
\hline Per capita income (PPP\$) & 520 & 697 & 228 & 623 \\
\hline Agricultural wage (\%) & 11 & 28 & 17 & 3 \\
\hline Rice (\%) & 62 & 50 & 39 & 22 \\
\hline Nonrice farm income (\%) & 19 & 18 & 40 & 49 \\
\hline Nonfarm income (\%) & 9 & 4 & 7 & 27 \\
\hline Incidence of poverty (\%) & 72 & 13 & 84 & 47 \\
\hline
\end{tabular}

Source:The four studies underlying this brief (see Further Reading). 
about by a rise in nonfarm income. The two exceptions are (a) the marginal areas in Bangladesh, where income increases were driven by a rise in income from the production of nonrice crops, livestock, and poultry, and (b) the high-potential areas of Tamil Nadu, where increased income was driven by a rise in agricultural wage income. Nonfarm income in high-potential areas is largely derived from salaried employment, manufacturing, and remittances, whereas nonfarm income in marginal areas is largely generated through informal services and trade.

Except for the high-potential areas of Tamil Nadu, the proportion of income generated by agricultural wages declined in all areas. This can be explained in large part by stagnant productivity, decreased real prices, and reduced labor use for rice production given the adoption of labor-saving technologies. In the high-potential areas in the Philippines, for example, the use of labor in rice production declined from 81 person-days per ha in the 1985 wet season, to 51 person-days per ha in the 2004 wet season. Direct-seeding practices, tractors, and threshers have been in use in the Philippines since 1985 and in Thailand since about 1987. In Bangladesh, in contrast, complete adoption of tractors and widespread use of threshers was not achieved until 2004. Substitution of machinery for labor is relatively easy because the labor substituted is largely unskilled. Inasmuch as this labor (other than that supplied by the household itself) is primarily provided by the landless and near-landless ultra-poor in Asian villages, it is clear that relying on agricultural labor markets alone will not significantly contribute to income growth or poverty reduction.

The relative contribution of rice income has declined in all the four countries due to falling rice prices and modest increases in rice yields since the mid-1980s. In contrast, the contribution of nonrice farm income has risen, indicating a shift in Asian farming

\section{Box I-Data Description}

$\mathrm{n}$ order to investigate long-term changes in rural incomes and the incidence of poverty, household-level panel data sets were used for four countries for the period 1985-2004. In the Philippines, data was drawn from 447 randomly selected households from four villages (two in Central Luzon and two in Panay Island). These households were interviewed in 1985, 1992, 1997, 2001, and 2004. In Thailand, 295 households from six villages (three in the Central Plain and three from the North Eastern Provinces) were interviewed in 1987 and 2004. Landless households were not included in the survey due to their scarcity in 1987. The Bangladesh panel data cover most parts of the country and include information from I,239 randomly selected households in 1988, I,872 households in 2000, and I,927 households in 2004. The data sets from Bangladesh, the Philippines, and Thailand are primarily panel data, with some adjustments for deceased household heads. Pooled cross-section data were used for Tamil Nadu, India, for the period 1972-80; thereafter, three-year rotating panel data were used (198I-2003). The Indian data used a stratified random sampling based on farm size, and they include only farmers who own land, rather than landless households. systems away from the traditional dominance of grain production to diversified production of high-value crops as well as livestock. Still, given its relatively small share of total household income, this increase in nonrice farm income is not the major driver of overall income increases.

Nonfarm income shares in the Philippines and Thailand have increased dramatically alongside significant increases in per capita incomes. For example, in the high-potential study village in the Philippines, per capita income more than doubled, while the nonfarm income share grew from 45 to 70 percent. Thus, nonfarm income is clearly the major contributor to income increases overall.

Similar or even more rapid changes were found in the marginal areas of the Philippines. Because agricultural production is not as promising in the marginal areas as in the high-potential areas, households in marginal areas have more actively expanded their nonfarm activities with the result that the regional income gap has significantly declined. It should be noted, however, that remittances-which are primarily sent by overseas migrants-account for nearly half of all nonfarm income in the Philippines, attesting to the importance of overseas migrants to rural household income in this economy.

Landless households in the Philippines have shifted from farm to nonfarm activities in efforts to supplement their income in the presence of declining employment opportunities in rice farming. As a result, data indicate a remarkable movement out of poverty for the landless poor and a decline in the income gap between landless and farming households.

A more dramatic example of the structural changes in the composition of rural household income is found in the marginal area of northeast Thailand. The nonfarm income share increased from 21 percent in 1987 to 74 percent in 2004. Since the households in question are located in unfavorable areas for agricultural production, it is understandable that they looked to the nonfarm sector to increase their income share once migrating to the western regions to take up low-wage employment cutting sugarcane ceased to be an option for them. Yet the change was only made possible by the increased availability of nonfarm employment in Bangkok and in the local city of Khon Kaen. Thus, high-wage nonfarm employment has taken the place of low-wage farm employment in unfavorable areas. The increase in the share of nonfarm income in high-potential areas is also significant-growing from 10 percent in 1987 to 47 percent 2004-but far less so than the increase in marginal areas.

Somewhat unexpectedly, data indicate that per capita income in high potential areas was lower than in the marginal areas of Bangladesh, particularly in 1988, even though income from rice production was higher in high potential areas due to irrigation. It is remarkable to observe that nonfarm income accounts for a much larger share of total income in marginal areas in 1988, reinforcing the importance of access to nonfarm labor markets in determining overall rural household income. Another important observation is a rapidly declining share of rice income over time, particularly in the marginal areas. Total income in the high-potential areas has caught up with levels in the marginal areas, again through increased nonfarm income. As in Southeast Asia, the share of agricultural wage income in Bangladesh has been very low and declining.

In Tamil Nadu, per capita income in marginal areas in the mid-1980s was less than half the level in the high-potential areas, but-somewhat similar to the experience in the marginal areas of the Philippines and Thailand-households in the marginal areas increased their nonfarm income share from 7 percent in 1987 to 27 percent in 
2004. In addition, the share of nonrice farm income, which includes income from the production of high-value crops like sugarcane and milk, increased in marginal areas. As a result, per capita income in marginal areas increased from US\$228 to $\$ 623$, thus reducing the income gap between marginal and high-potential areas. Therefore, as far as Asian countries are concerned, the development of nonfarm labor markets appears to increase rural household income, especially in less-favorable areas.

Given the limited number of villages included in the study data set, it is difficult to identify the impact of the villages' proximity to cities and infrastructure on household income increases. In the Thai villages, the nonfarm income share is actually higher in the northeast, which is far away from Bangkok, than in the Central Plain, and the nonfarm income share within each region is highest in the most remote and most unfavorable village. It would therefore appear that the issue of remoteness has been overcome by the country's good road systems and the desire of its poor farmers to find nonfarm jobs in unfavorable agricultural areas, though this conclusion can obviously not be drawn with any certainty. It is also interesting to report that the Bangladesh study found positive and significant impacts of electrification on nonfarm income, but not on farm income. If, as expected, electrification is a reasonable proxy for general infrastructure development, these findings strongly suggest the importance of infrastructure in improving rural household access to nonfarm employment.

In all four countries, data indicate a decline in the regional income gap. In the Philippines, Thailand, and Tamil Nadu, the incomes of households in marginal areas were able to close the gap with those of the high-potential areas, whereas in Bangladesh households in high-potential areas were able to catch up with those in the marginal areas. In nearly all cases, there was a consistent decline in poverty. Interestingly, this decline and the rise in nonfarm income were more significant in the marginal areas in the Philippines, Thailand, and Tamil Nadu, indicating that the initial income constraints brought about by an unfavorable production environment were overcome by access to the nonfarm labor markets. In Bangladesh the decline in poverty was greater in the high-potential areas, once again because of the rise in nonfarm income.

\section{AGRICULTURAL DEVELOPMENT AND INVESTMENTS IN CHILD SCHOOLING}

It is generally hypothesized that the Green Revolution significantly increased household farm income through higher rice yields, higher cropping intensities, and higher rice prices due to improved grain quality. Household investments in child schooling, in turn, tend to rise with increased household income. So, the development of the nonfarm sector expands nonfarm employment opportunities, and the resulting increased income induces households to invest in their children's schooling. In turn, increased schooling can generate increased nonfarm income and remittances in the long run, which can secure additional investments in schooling for the next generation (Figure 1). In this way, the initial opportunity to increase household income, brought about by the Green Revolution, can promote a cycle of higher schooling investments, remittances, nonfarm wage incomes, and, in some cases, overseas migration. Schooling investments may be a prerequisite for migration, suggesting a sequential human capital investment process.

Data indicate that rural households in the Philippines and Thailand invest a major portion of their additional income in their children's schooling and that the children later engage in rural nonfarm employment or migrate to cities to seek more lucrative

Figure I-The Interrelationship among Agricultural Development, the Nonfarm Sector, and Human Capital

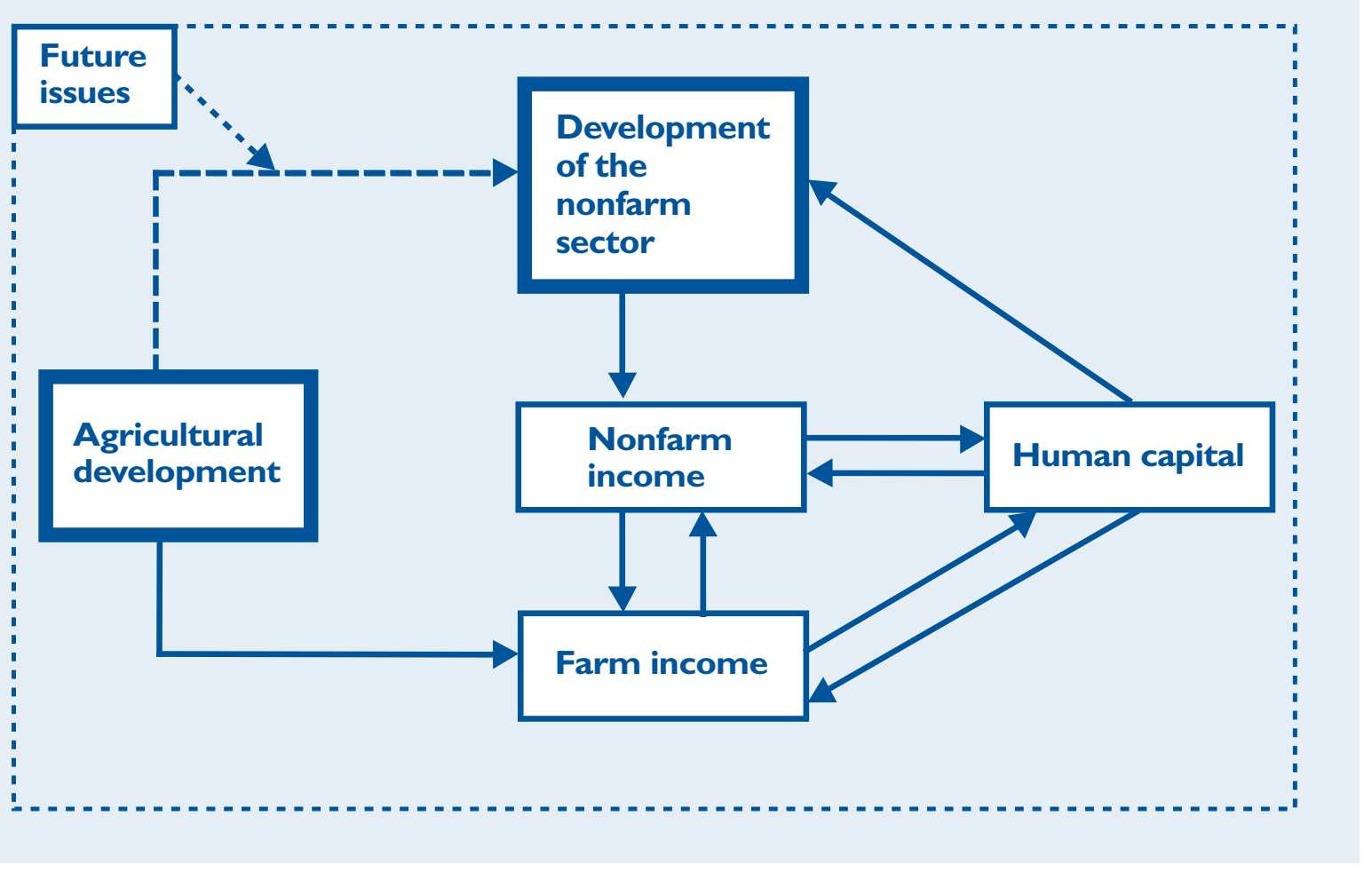


employment opportunities. Initially, a primary source of additional household income was found to be improved farm technology, such as the adoption of high-yielding, modern rice varieties. It is therefore reasonable to hypothesize that productivity growth in agriculture contributes to overall economic development by stimulating investments in child schooling in rural areas and, subsequently, supplying an educated labor force to the rural nonfarm sector.

The Asian experience shows that the Green Revolution has succeeded in breaking the intergenerational circle of poverty, the lack of child schooling, and the dominance of farming as the major rural occupation. Indeed, without the initial increase in crop income, rural Asian households could not have afforded to send their children to school or allocate more time to nonfarm incomegenerating activities.

\section{CONCLUSION AND POLICY IMPLICATIONS}

Rural Asian households have been able to move out of poverty amidst the increasing scarcity of farmland by diversifying their income sources away from rice production to nonrice crops, livestock, and nonfarm activities. Increased participation in nonfarm activities is more pronounced among households with more educated children, whose education is facilitated by increased farm incomes brought about by the Green Revolution. Thus, it is clear that agricultural development triggered the subsequent transformation of rural Asian economies by stimulating investments in schooling the younger generation. The major policy implication, therefore, is that, in order to stimulate the development of the entire economy, it is imperative to develop agriculture when the sector dominates the economy, with a view to stimulating investments in child schooling and the development of the nonfarm sector, so as to provide ample employment opportunities for the rural labor force. An important future issue is whether and to what extent agricultural development has contributed to the development of the nonfarm sector.

For Further Reading: Asian Development Bank (ADB), Key Indicators, (Manila: ADB, 2006); S. Cherdchuchai and K. Otsuka, "Rural Income Dynamics and Poverty Reduction in Thai Villages from 1987 to 2004," Agricultural Economics 35, Issue 3 Supplement (2006): 409-423; J. P. Estudillo, Y. Sawada, and K. Otsuka, "The Green Revolution, Development of Labor Markets, and Poverty Reduction in the Rural Philippines, 1985-2004," Agricultural Economics 35, Issue 3 Supplement (2006): 399-407; K. Kajisa and K. P. Palanichamy, "Changing Mechanisms of Income Dynamics over the Last Three Decades in Tamil Nadu, India," Agricultural Economics 35, Issue 3 Supplement (2006): 437-448; N. Nargis and M. Hossain, "Income Dynamics and Pathways out of Poverty in Bangladesh: 1988-2004," Agricultural Economics 35, Issue 3 Supplement (2006): 425-435; and A. R. Quisumbing, J. P. Estudillo, and K. Otsuka, Land and Schooling: Transferring Wealth across Generations (Baltimore: Johns Hopkins University Press, 2004).

Keijiro Otsuka (otsuka@grips.ac.jp) and Jonna P. Estudillo (jonna@grips.ac.jp) are professorial fellow and faculty fellow, respectively, with the Foundation for Advanced Studies on International Development, Tokyo.This brief draws on four country studies by Estudillo, Sawada, and Otsuka; Cherdchuchai and Otsuka; Nargis and Hossain; and Kajisa and Palanichamy, which appeared in a special issue of Agricultural Economics in November 2006. The authors thank their colleagues at the Foundation for Advanced Studies on International Development, as well as the 2 I st Century Center of Excellence of the National Graduate Institute for Policy Studies, Tokyo, which funded some of the data collection for the original four studies. 
Reducing Poverty and Hunger in Asia

How and When Road Investments Encourage Inclusive Growth:

Learning from the Asian Development Bank's Experience

Hemamala Hettige

\author{
Focus I5 • BRIEF 9 OF I5 • MarCH 2008
}

$\mathbf{T}$

his brief focuses on one type of infrastructure investmentrural roads. Participatory poverty assessments have long identified remoteness and isolation as critical components that prevent inclusive growth. Although it is widely assumed that investments in rural roads encourage inclusive growth, there is little evidence about how these impacts occur or what their determinants are. This brief addresses the issue based on a study of empirical evidence from a cluster of case studies drawn from past Asian Development Bank operations. The objective of the study is to help improve the design of rural road projects to achieve sustainable benefits for the poor. Because pragmatic recommendations need to capture the real-life impediments that often plague project design assumptions, the study focuses narrowly and deeply on selected case study villages within a project area. This approach enables an understanding of the factors that influence rural road impacts on inclusive growth.

\section{THE STUDY AND SELECTED FINDINGS}

The study was carefully designed to maximize the use of both qualitative and quantitative information. It did not assume an automatic link between rural roads and poverty reduction, but considered the multifaceted impacts that determine how people respond to improved rural roads and how this shapes their livelihood constraints and opportunities. Three countries-Indonesia, the Philippines, and Sri Lanka-with two projects in each, were selected. For each project, a project site with a road and a control site without a road were identified. Cumulatively, the cluster of field sites selected covered a broad range of both physical and nonphysical factors likely to condition the context for rural road interventions. From each project, a road segment was selected as a case study area. Road segments in districts where the incidence of poverty was high were purposely selected during this process, because the focus of the study was the impact of roads on poverty and inclusive growth.

Figure I-Means of Transport Used for Buying Provisions

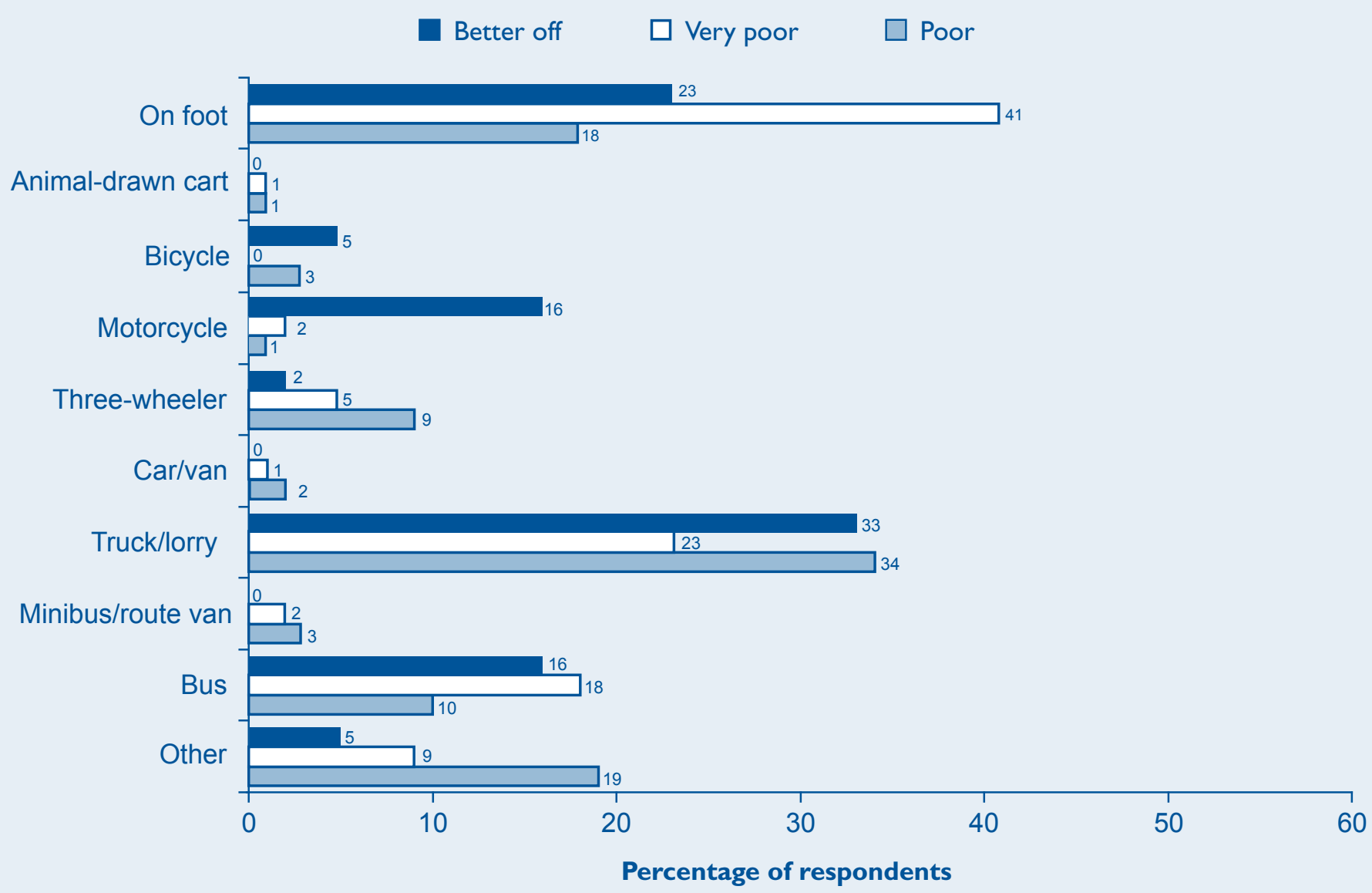

Source: Household survey data from the 2002 Asian Development Bank project "Impact of Rural Roads on Poverty Reduction:A Case Study-Based Analysis." 


\section{The Very Poor Live in a Walking World}

The study reveals that the poor and very poor inhabit a localized, walking world and make little use of medium- or long-distance transportation links. Of more importance to them are the paths, tracks, culverts, and access routes in and around their village on which they rely to reach water, firewood, fields, and local employment opportunities. Saving time in their within-community travel is important to them. Intermediate modes of transport that help them increase their carrying capacity are also useful to save time for more productive work. Incremental benefits to them are more likely to come from better access to nonmotorized transport and greater ability to cross waterways to help in their daily routine tasks. Therefore, increasing their within-village mobility is as important for poverty reduction as providing access to markets outside the village. The time savings will allow the poor and very poor to be more productive and generate small savings to explore opportunities outside the village.

\section{Travel Patterns Differ by Gender}

Inside the community, the survey shows that women are much more likely to travel for health purposes ( 55 percent compared with 5 percent for men), either for themselves or, more frequently, to accompany children. Women are also much more likely to travel for provisions within the community, with 46 percent of responses, compared with 17 percent for men and 18 percent shared by both. Men are more likely to travel for crop processing (53 percent, compared with women's 14 percent and 17 percent shared), and social travel within the village is largely shared. In travel outside the community, these patterns are broadly replicated. For various tasks, men are more likely to have access to private means of transport like a bicycle, three-wheeler, or motorcycle. Women are more likely to travel on foot to fulfill tasks, or use public transport like a bus or truck. The opportunities for men to travel outside the village and to take up outside work are reinforced and perpetuated by traditional gender roles in the study sites, with women responsible for household tasks and men for productive or economic tasks.

\section{Transport Needs Differ by Socioeconomic Group}

Figure 1 shows the modes of transport for buying provisions, a common task, for each group in the project sites. The very poor rely much more on walking than do the better off. The latter are more likely to have access to private motorized means (motorcycle or three-wheeler) or to a car or van. Interestingly, the poor are more likely to use a bicycle, whereas bicycle use among the very poor is negligible. The very poor's heavy reliance on walking is reflected in other tasks too, such as obtaining health services, going to school, and selling products.

Most of the journeys made by the rural poor are for subsistence and household tasks, rather than for activities that are directly economically productive. For the rural poor, access to local facilities and the primary transport network is critical during times of need. The very poor lack both time and energy, and factors that either reduce or exacerbate these deficiencies have a critical bearing on poverty.

Survey responses among different socioeconomic groups in the project locations show clearly how the use of transport services differs (Figure 2). Among the very poor, 47 percent say that they use transport only occasionally because they have little need to travel outside the community, compared with 21 percent of the better-off and 30 percent of the poor. The very poor do not have sufficient funds to travel to the outside market for slightly cheaper food items and therefore rely on the village store for day-to-day needs.

The case studies show little evidence that the very poor increase their travel outside the community in search of job opportunities or for any other reason following road rehabilitation. A traditional assumption is that poor people's lack of agricultural assets, particularly land, makes them more likely to seek employment outside the community and that road access helps this effort substantially. Labor markets in remote rural areas are imperfect, however, and finding job opportunities is difficult, particularly where there is a lack of information. This lack of information and inability to command rights over work opportunities are themselves a function of poverty. Better-off households are much more likely to have access to information on well-paid, or stable, outside employment, whereas the poor and very poor have access only to temporary, seasonal, and unskilled work opportunities, which are usually poorly paid. But where the economic conditions are right, better basic road access can affect the local wage-laboring and trading prospects of the poor and thus enable them to benefit from wider processes of increased agricultural commercialization and trade. In the study areas, a few households graduated from poor to nonpoor status because of the opportunities that the road provided. These households usually had some skills (carpentry, sweet making) to sell or had a temporary injection of funds to start a small business. 


\section{Village Conditions Improve}

In general, the benefits of better roads (to all socioeconomic groups as a whole) are highly evident when project villages are compared with control villages. Average travel time is often half or less for project households than for control households for all types of activities. Owing to difficulties of access, control site households must often wait and combine a number of important tasks into one trip to avoid spending long periods of travel for one purpose only. In response to questions about their primary purposes for travel and how often they travel outside their village, respondents in project sites and control sites had different priorities. Control households travel more frequently for crop processing and for selling their produce than do project households, suggesting that (1) primary agricultural activities are more important in the control areas, which may lack alternative livelihood opportunities; and (2) because of better access, many of the services that come directly to the project site are not available in the control site.

Survey data also show that project communities appear to have better access to safe sources of drinking water and better sanitary and toilet conditions. This advantage may be a function of the general increased level of development of project over control sites (itself a function of better access to roads, communications, and opportunities). It also reflects the better accessibility of state services and nongovernmental organizations (NGOs) to communities; roadside communities are more likely to have services provided under these schemes. How equitably the benefits of these roads are distributed within communities, however, is a separate issue.

\section{Small Business Development Increases}

The development of small businesses in the project communities shows that road investments have had significant indirect impacts on the general level of economic development in each of the study locations. Improved roads and better ability to transport goods provide opportunities for those who can afford the investment to start a small store in the village or sell goods in a nearby market center. They also save people time in their previous occupations, allowing those who have the necessary skills and savings to invest in other small businesses. Among project case respondents, 64 percent observed that the number of small businesses in the community had increased since the road was built or rehabilitated. Of those who had a business before road rehabilitation, 55 percent believed that the project had a positive effect on these enterprises. Of the 17 percent of project respondents who had started a business since road rehabilitation, 69 percent said that the road was a factor in their deciding to start the business.

\section{The Better-Off Get Better}

Improvements in income were a key area of inquiry for the household survey. Across all study communities, the better-off have both diversified and increased their income more than the poor and very poor. Those reporting no change were higher among control group (58 percent) than project (47 percent) respondents. Among all project site respondents, 23 percent reported receiving less income from agriculture and more from other sources, compared with 14 percent of control site respondents. About 22 percent of better-off households reported increasing both agriculture and other sources of income, whereas more than 50 percent of both poor and very poor groups reported no change at all in sources of income.

In practice, those who are most secure and have savings may be able to make the best use of the opportunities brought by better roads. The better-off have surplus funds to invest in trading, have an agricultural surplus to sell, or have a network of connections and relationships outside the community enabling them to take advantage of trading or working opportunities. In fact, case study evidence suggests that better rural roads allow those with some savings to diversify into activities with substantially better returns. People engaged as salaried workers in nearby town centers rely on a regular and rapid link and so benefit substantially from the efficiency and cost savings in commuting.

\section{Roads Provide an Economic and Social Safety Net}

The rural roads studied provided an important economic safety net by allowing for alternative livelihood opportunities. An alternative income stream, even if temporary or seasonal, is still important for household food security. A good road surface and the guarantee of all-year accessibility are important prerequisites for the development of any kind of regular enterprise.

Undoubtedly, in all case study projects, the poor and very poor benefited substantially from social impacts of rural roads through access to state services in areas such as health, education, agricultural extension, and provision of information. Roads allow regular contact with the outside world and bring remote areas within the purview of the state and other networks (Figure 3). Such improvements reduce the perception of isolation and remoteness among the poor and very poor.

\section{Some External and Structural Conditions Affect the Impact of Road Development}

The study shows that the context within which economic impacts take place is often determined by conditions such as climate, 
agricultural potential, spatial position, proximity to networks, and world market commodity prices, as well as social structure and concentration of assets. For example, a slump in commodity prices can cause the poor and very poor, being risk averse, to concentrate on subsistence food production rather than cash crops. Although road development cannot affect these conditions, carefully considering them during project identification and design would enable project designers to better assess the potential for such projects to reduce poverty and to consider possible complementary measures to increase positive impacts.

The prevailing social structure and concentration of productive assets also have an enormous bearing on determining how impacts occur in each of the study locations. The concentration and distribution of land is particularly important and largely outside the area of influence of a road project. Understanding asset ownership and the distribution of benefits from roads, however, can help project designers design complementary measures.

\section{Road Development Can Lead to Inclusive Growth under Certain Conditions}

Road development can lead to more inclusive growth, but ensuring that it does so entails deviating from traditional road investment projects in several ways:

- Use labor-based construction to provide the seed capital for poor people to start a business or to break the debt cycle and sell to traders outside the village.

- Base decisions about road access on the need for inclusive growth and not on how politically influential the community is

- Ensure that minor maintenance is not neglected either because of lack of funds or because it is not highly visible.

- Clarify who is responsible for maintaining project roads and where funds will come from.

\section{CONCLUSIONS AND LESSONS}

Roads are clearly a critical enabling condition for improvement of living conditions in rural areas. But there is no guarantee that economic benefits will be distributed in an inclusive manner between the poor and nonpoor in communities. The poor and very poor primarily benefit from road improvements indirectly, through better access to state services and other services and through opportunities for alternative livelihoods, where conditions are right. The poor can also benefit broadly from improvements to the rural economy through increased opportunities for agricultural wage labor, where preconditions are favorable. The study confirms that better rural roads are a necessary but not a sufficient condition for graduating from poverty. There is little evidence that roads directly reduce poverty among the very poor. The ability of the poor and very poor to make significant economic use of the road depends on their asset base, their entitlements to resources, and the opportunities they can command, as well as the passage of time. In a few instances, the poor who have invested savings in a small business or used their skills have graduated from poverty, using the benefits from the road.

The ability of the rural road projects studied to affect the distribution of assets and the skills capacity of the poor was limited and largely outside their scope because of external and structural conditions. Nevertheless, recognizing how assets are distributed is important both for understanding how benefits will accrue and for planning complementary measures to enable those who lack assets to benefit from the investment. Given the right complementary activities, projects can broaden livelihood opportunities. The poor need support to make use of the opportunities that rural roads may bring. Multifaceted projects are thus needed to address inclusive growth effectively.

Simply improving a road is not enough; the poor also require support in being able to make use of it. This support can come in many forms:

- For the poor to travel for productive purposes, the provision of transport services must be linked to some livelihood and income diversification activity, which builds on or supplements their existing subsistence activities.

- Integrated projects need proper preparation to be effective and sustainable. Mechanisms should be institutionalized to ensure that the poor themselves are involved in many aspects of the investment design (but not engineering design), implementation, and operation and maintenance.

- Interventions should also concentrate on removing the access and mobility constraints of the poor in their existing livelihoods, and thus making investments in tracks, paths, culverts, and crossings, as well as improving intermediate (nonmotorized) means of transport that benefit the poor.

- The poor are generally risk averse and will not engage in a new activity if they know that the road on which it depends will not be maintained periodically. Devolving responsibility for road maintenance to local communities, particularly for basic rural roads, can ensure both that the poor receive benefits through direct employment and that local communities are stakeholders in the road serving their area.

- Another important way to achieve direct benefits from rural road investments is through direct employment of the poor in labor-based road construction. Experience from Africa and Asia shows that, given a sufficiently long period of employment on the road, the poor can accumulate capital to invest in alternative livelihood opportunities and move out of poverty.

Hemamala Hettige (hhettige@adb.org) is a principal evaluation specialist at the Asian Development Bank.This brief is based on H. Hettige, When Do Rural Roads Benefit the Poor and How? An In-Depth Analysis Based on Case Studies (Manila:Asian Development Bank, 2006) <http://www.adb.org/ Documents/Books/ruralroad_benefits/rural-roads.pdf>. The views expressed in this brief are those of the author and do not necessarily reflect the views and policies of the Asian Development Bank or its Board of Governors or the Governments they represent. 


\section{Focus I5 • Brief I0 of I5 • March 2008}

M ore than 3 billion people-about half of the world's population-depend on rice for their staple food. Rice provides about 20 percent of direct human calorie intake worldwide, making it the most important food crop. Rice consumption can be very high, exceeding 100 kilograms (kg) per capita annually in many Asian countries (10 kg is the U.S. average).

Rice is the principal food for most of the world's poorest people. Rice farming is also the main economic activity for hundreds of millions of rural poor, many of whom do not own their own land. In Asia and Sub-Saharan Africa almost all rice is grown on small farms of 0.5 to 3 hectares (ha). Yields range from less than 1 metric ton $(\mathrm{t})$ per hectare under very poor rainfed conditions to more than $10 \mathrm{t} / \mathrm{ha}$ in intensive temperate irrigated systems. Small, and in many areas shrinking, farm size accounts for the low incomes of rice farm families.

Fully two-thirds of the world's poor live in Asia, and almost all of them eat rice. Rice is also becoming a staple food in SubSaharan Africa, where urban dwellers who rarely ate rice only a few decades ago now consume it daily. Per capita consumption has doubled since 1970 to $27 \mathrm{~kg}$. In the mega-cities of Asia, the poorest of the poor may spend up to 50 percent of their total income on rice-not on food in general, but on rice! So anything that lowers the price of rice will directly benefit hundreds of millions of poor consumers, and anything that increases ricefarming productivity will benefit millions of rice farmers and their families. The Green Revolution in Asia did just that and led directly to the Asian economic miracle of the past 40 years. But clearly much remains to be done.

About 50 percent of the rice area is grown under intensive irrigated systems. These are systems in which the water supply is assured from either surface sources (rivers and dams) or wells. Equally important, these systems have controlled drainage allowing farmers to control the amount of water that reaches the crop and to apply it and remove it for land preparation and harvest. Modern high-yielding varieties do very well under these conditions, and farmers typically apply fertilizer to obtain high and reliable yields. These systems were the basis for the Green Revolution in rice and lifted millions of people out of poverty. Today, about 75 percent of the rice produced in the world is produced in intensive irrigated systems. Thus, global food security depends upon their continued ability to sustain high yields.

The other half of global rice area is rainfed, meaning that it depends exclusively on rainfall, and in some cases on unpredictable floods, for water. Rainfed rice can grow on steeply sloping lands, such as in the mountainous areas of Southeast Asia, or on the flat lands that predominate over much of the delta and coastal areas of South and Southeast Asia. But only about 25 percent of the world's rice comes from rainfed systems. Because rainfall can be so variable, rice in rainfed areas typically is subject to drought and catastrophic flooding sometimes in the same year.
By far the largest rainfed areas are the rainfed lowlands. These are level fields in which farmers construct bunds or levees to capture rainwater and maintain standing water in the field for as long as possible. Rainfed lowland rice predominates in the areas of greatest poverty: South Asia, parts of Southeast Asia, and essentially all of Africa. Because the environments are so difficult and yields so unreliable, farmers rarely apply fertilizer and tend to not grow improved varieties. Thus, yields are very low (1-2 t/ha), and farm families remain trapped in poverty. Even though these farmers are very poor, it is important to keep in mind that for most, without rice, they would have no livelihood at all.

A number of worrisome signs suggest that new challenges lie ahead. Growth in rice production has slowed as the yield gains from the adoption of modern varieties in irrigated areas have been almost fully exploited and as rice area declines. Over the past five years, the international rice price has doubled, and the price for urea, the most widely used nitrogen fertilizer, has tripled owing to the rise in oil prices. Rice stocks are at their lowest level since the 1970s. Other concerns include the rising demand for biofuels, the pressures that urbanization and industrialization place on land and water resources for uses other than agriculture, and the long-term effects of global warming. Taken together, these concerns will accelerate the demand for new technologies that can be rapidly disseminated to achieve further productivity gains and permit a continuation of low and stable rice prices.

\section{A PRO-POOR STRATEGY FORTECHNOLOGY DEVELOPMENT}

In much of Asia, given the pervasiveness of the rice crop and the place of rice as a staple in the diet, the first step has been to increase rice productivity. Increasing rice productivity provides the entry point for science and technology. Adoption of new technologies can provide the stepping stone to enable farm families to diversify their incomes through both farm and nonfarm activities, including the outmigration of labor from agriculture. For many farm households these are becoming the pathways out of poverty.

To address the problems of poverty and related issues, the International Rice Research Institute (IRRI) has developed five strategic goals:

1. Reduce poverty through improved and diversified rice-based systems.

2. Improve nutrition and health of poor rice consumers and rice farmers.

3. Ensure that rice production is sustainable and stable, has minimal negative environmental impacts, and can cope with climate change.

4. Provide equitable access to information and knowledge on rice, and help develop the next generation of rice scientists. 
5. Provide rice scientists and producers with the genetic information and material they need to develop and improve technologies and enhance rice production.

These strategic goals are very much in keeping with the Millennium Development Goals-reducing extreme poverty and hunger, promoting gender equality and empowering women, ensuring environmental sustainability-in short, addressing issues of poverty in the present and sustaining rice production in the future.

\section{Addressing Issues of Poverty}

Technology development to reduce poverty calls for a twopronged approach:

- Ensure adequate and affordable food supplies for poor rice consumers through further increases in productivity and profitability on irrigated land.

- Enhance household food security and income in rainfed areas of Asia through improved varieties and management that can double yields and reduce yield variability under stress conditions such as drought or flood.

Irrigated Rice. The first approach, developing new technologies for irrigated systems, must take into account that rice-based systems, and the technologies farmers are demanding, are changing rapidly. In addition, rising incomes and urbanization are changing demand patterns for agricultural products. As consumers diversify their diets, the farm economy must also diversify to meet the new consumer demands.

Researchers are working to improve both the rice varieties available and farmers' crop management practices. Research on varietal improvement focuses on increasing the biological yield potential of rice, whereas development of improved management practices is designed to lower the unit cost of production, reduce the gap between the yield potential of improved varieties and the farm-level yield, or both.

Three technologies designed to raise the yield ceiling in the tropics are currently in the formative stage of development. These technologies include adaptation of hybrid rice to the tropics, development of a new plant type that will raise the grain-tostraw ratio, and conversion of rice from a $\mathrm{C} 3$ to a C4 plant type to increase the photosynthetic rate. These projects illustrate the often long time duration required for development, even using modern biotechnology techniques.

Meanwhile researchers are promoting improved crop management practices through the simultaneous reduction of multiple farm constraints. The farmer demand for crop management technologies is changing with changes in the farm economy. For example, there is a growing demand for laborsaving technologies that address the problem of water scarcity, reflecting women's increased participation in the labor force. At the same time, management practices such as improving seed quality and health, reducing pesticide use, and site-specific nutrient management provide the opportunity to increase yields and lower the unit cost of production.

Rainfed Rice. The second approach is to significantly increase the productivity of rainfed lowland rice. Research has thus far been less successful in this area, but scientists have made important advances in genomics and the understanding of the molecular biology of rice, enabled by the sequencing of the rice genome (the first crop species genome to be sequenced) and improved analytical approaches. These advances have allowed rice scientists, breeders, geneticists, and physiologists to make dramatic progress in developing rice lines that tolerate complete submergence, drought, and salinity. There is now an unprecedented opportunity to make massive contributions to the well-being of farmers and the landless in rainfed systems. The incorporation of major tolerance of complete submergence into varieties already grown on millions of hectares is concrete proof that this opportunity can be translated into reality.

Increasing Nutrition and Health. A major research undertaking to improve the health of rice consumers involves the biofortification of rice or the development of nutritionally improved rice, including high-pro-vitamin A, high-iron, and high-zinc rice. These nutritional traits can be incorporated into varieties that farmers wish to grow. For example, combining these traits with stress tolerance is one important way to increase the likelihood that farmers and the rural poor will adopt and consume nutritious rice. High pro-vitamin A is already being combined with submergence tolerance in widely grown varieties from South Asia.

\section{Sustaining Rice Production in the Future}

Technology development and dissemination is a never-ending process. Sustaining rice production requires initiating activities now that lay a foundation for development and dissemination of technologies to address the challenges of the future.

Research to Address Issues of Sustainability. A number of research projects now underway can be referred to as "frontier projects." The gestation period is long and future success unpredictable. These projects include the earlier-mentioned conversion of rice from a C3 to a C4 plant type and the development of varieties with tolerance to global warming and to drought. On the management side, there is the looming water crisis.

One of the most pressing environmental concerns in Asia today is growing water scarcity and the overexploitation of water resources, and management of water resources will need to undergo major changes in the future. As industrial and municipal demand for water grows, less water will be available for agriculture. Researchers are seeking ways to develop and disseminate water-saving technologies and increase water productivity, including alternate wetting and drying of paddy fields (now widely practiced in China), the development of farm ponds, the use of low-lift pumps to develop and distribute water, and the introduction of low-cost drip irrigation. Institutional factors, such as the presence or absence of farmer irrigation associations, play a major role in inhibiting or facilitating water use efficiency.

Capacity Building and Knowledge Sharing. One of the successes of the past was the long- and short-term training of thousands of national-level agricultural scientists who contributed to the success of the Green Revolution. Now the research development network has broadened to include laboratories in advanced countries on the one hand and nongovernmental organizations (NGOs) on the other. Farmer participatory research is also growing. New information and communication technologies help to tie this network together and close the communication gap. Incentives need to be in place, however, to attract and encourage the development of the next generation of rice scientists. 


\section{PROMOTING RAPID DISSEMINATION}

The traditional linear transfer-of-technology approach, which was designed to provide technology packages developed in research centers to farmers, is clearly inappropriate in the current dynamic context of farming. Rather than blanket recommendations, farmers increasingly need recommendations targeted to specific environmental conditions. Because these conditions can vary within even a small area depending on soil type, rainfall pattern, and management regime, researchers need methods and approaches that can take all of these conditions into account as they conduct adaptive research and develop conditional recommendations. Such recommendations can be complex, and the traditional extension approach is not an effective way of transmitting them. The approach to delivering technology must impart knowledge to farmers that enables them to monitor crop conditions and make appropriate adjustments in crop management. This requirement applies especially to intensive irrigated areas where farmers are more market-oriented and the economic viability of rice production depends on their ability to reduce the unit cost of production through the use of knowledge-intensive technologies.

In rainfed areas, which suffer from several constraints including poor institutional support for agriculture, the limited availability of improved seeds is an important constraint. The supply of seeds from the usual institutional sources is weak, and the private sector is too poorly developed to serve as an alternative supplier. Farmers depend mainly on their own farmkept seeds and limited exchanges of seeds among themselves. The seed replacement ratio is less than 15 percent in most cases. As a result, improved seeds spread very slowly, and the spread is often highly localized. Even where farmers have used improved seeds, productivity gains have been low and highly variable because complementary crop management practices are only partially adopted. The problem in rainfed areas is compounded by other constraints such as very small and fragmented farms, poorly developed infrastructure, poor supply of public services in general, and farmers' limited ability to gain access to and effectively use information.

Against this backdrop, IRRI's strategy for promoting rapid technology dissemination includes the following five essential elements:

\section{Farmer participatory approaches to technology} development and validation. Such approaches will ensure that technologies are consistent with farmers' needs and constraints and that farmers have early access to technologies and information through their involvement in technology development and validation processes. Farmer participatory approaches to varietal selection are now accepted in several countries and are becoming increasingly institutionalized. Early access to information and technologies during participatory validation can help get around the institutional seed supply bottleneck to some degree. IRRI, in partnership with national agencies, is increasingly working in this participatory mode to accelerate technology dissemination.

Recently, stress-tolerant genes such as Sub1 for submergence, Saltol1 for salinity, and genes for drought have been incorporated into the popular rice varieties Swarma and IR64, which are intolerant of stresses or are low yielding. Improved varieties tolerant of abiotic stresses are included in participatory varietal selection (PVS) trials conducted on-station and on farmers' fields. Farmer and community participatory approaches are being used to validate and evaluate improved crop and resource management technologies, such as reduced tillage in rice/wheat systems of the Indo-Gangetic Plain, alternate wetting and drying water management, site-specific nutrient management, ecologically based rodent management, and hermetic grain storage to reduce postharvest losses and maintain grain quality.

\section{Close partnership with NGOs and farmer and} community organizations for promoting technology dissemination. Mobilization of NGOs and farmer and community organizations is a potent strategy for initiating and sustaining developmental changes, including dissemination of agricultural technologies, in rural areas. These organizations have strong grass-roots bases and are better able to respond rapidly to local needs than the more formal line agencies. Close partnerships with these local organizations is becoming an increasing part of IRRI's mode of operation. Technologies that are found to be successful in one location are being rapidly validated and disseminated in several other locations simultaneously by mobilizing the national networks of these NGOs and farmer organizations. The role of this kind of partnership is clear from a project in Bangladesh, where such national and regional networks were mobilized to facilitate production and distribution of improved seeds to farmers. To meet local needs, these organizations also helped establish village- and communitybased seed production systems linked with institutional sources of new seeds.

3. Rice Knowledge Bank (RKB) and information and communication technologies for rapid dissemination of information. The RKB, together with information and communication technologies, serves as an important platform for providing and integrating knowledge and information about improved technologies and markets. IRRI is increasingly developing and using these information platforms to provide rapid access to recent technical and other information about rice to various stakeholders. To promote easy access, country chapters of the RKB have included locally adapted information written in local languages.

4. Mass communication. The use of mass media such as print, radio, television, and other means of mass communication can be an effective way of transmitting technology information packaged as simple messages. For example, Vietnam successfully used the mass media to promote the "three reductions and three gains" campaigns, which involved reductions in seed rates, fertilizers, and pesticides in rice production. An important challenge in this approach is to translate complex scientific information into simple and easily understood messages (such as "no early sprays") that can be effectively transmitted through mass media.

5. Training. Development of training materials and provision of training on rice technologies to partners in national agricultural research systems has remained a major strength of IRRI in its efforts to develop local capacity for 
research and technology delivery. $I R R I$ is bringing in modern approaches to training to further augment this capacity while adhering to its areas of comparative advantage by forging closer linkages with other providers of training.

IRRI is deploying all of these components as a part of an overall strategy for promoting rapid delivery and dissemination of improved technologies.

\section{CONCLUSIONS}

As productivity growth in the irrigated area slows and growth potential in the rainfed areas remains unrealized, IRRI scientists are adopting new approaches to speed the process of technology development and dissemination with the goal of reducing poverty and sustaining rice production in the long run.

A two-pronged approach to poverty reduction involves developing (1) technologies to raise productivity and maintain low and stable rice prices in the irrigated areas and (2) technologies to maintain higher and more stable yields in the rainfed environments.

Setting priorities, developing and validating technologies, and disseminating proven technologies require close interaction between scientists and stakeholders. Farmer participation with scientists at each stage is becoming widely accepted.

The biggest challenge is to scale up technologies, particularly in the rainfed areas, where, for example, new and improved seeds are often not available. The widespread adoption of improved technologies is best achieved through a close partnership with strong grass-roots organizations such as NGOs and farmer and community organizations. Information technologies are providing better awareness of technologies and markets. IRRI scientists are involved in a range of approaches for technology dissemination as part of an overall strategy for pro-poor technology delivery.

Robert Zeigler (r.zeigler@cgiar.org) is director general of the International Rice Research Institute (IRRI). 
C imate change results from an increased concentration of greenhouse gases like carbon dioxide, nitrous oxide, and methane associated with economic activities, including energy, industry, transport, and land use patterns. Rich countries emit the majority of these gases, while poor countries are more vulnerable to their negative effects. Further, developing countries, such as those of Asia, are more vulnerable and less able to adapt to these changing climatic conditions because of their locations; greater dependence on agriculture and natural resources; larger variations in weather and temperature conditions; and lower availability of critical resources like water, land, production inputs, capital, and public services.

It is far from clear how these changes will affect global agriculture and natural resources and, especially, how they will affect the poor in developing countries. Appropriate climate change policies, if adopted now, can stimulate pro-poor investment. More specifically, they can increase the profitability of environmentally sustainable practices even as they generate income for small producers and investment flows for rural communities.

\section{THE ASIAN CONTEXT}

The anthropogenic signal of climate change has been detected in Asia with strong statistical significance, making mitigation strategies a sensible option, especially in South Asia and China, where the highest concentrations of rural poor relying on agriculture reside. The effects of climate change will exacerbate stresses on agricultural production, particularly in low- and mid-latitude countries; will adversely affect wheat productivity in the Indo-Gangetic Plains; will reduce rice yields due to increased night-time temperatures; and will increase demand for water. Table 1 estimates sectoral vulner- abilities for the subcontinental regions of Asia. It is widely accepted, however, that mitigation alone is not sufficient to solve the climate problem; a combination of the two approaches is most effective. In China, for example, a study by Erda et al. shows that areas of northwest China-such as Inner Mongolia, Ningxia, Gansu, Shanxi, and Shaanxi-are highly vulnerable to major meteorological disasters because of their low levels of development and lack of investment in adaptive measures. In addressing this vulnerability, the study stresses the importance of agricultural insurance, such as risk management, and income transfers to support and protect the agricultural sector, as well as the exploration of the gradual establishment of agricultural insurance policy as an adjunct to assistance provided by the Chinese government in the event of disasters affecting food security. In many instances, reform of existing policies is needed to promote adaptation to climate change. For example, diesel fuel for irrigation pumps in India is highly subsidized, leading to overpumping of water that exacerbates the increase in water scarcity due to climate change.

\section{ADAPTATION AND RISK MANAGEMENT STRATEGIES}

Emissions of greenhouse gases universally contribute to observed and anticipated climate change, but their benefits are experienced locally. Anthropogenic climate change is thus an exploitation of the global commons that requires policy intervention. Given the lack of capacity to adapt to climate change in many developing countries-and the imperative to do so-the key issue is how national governments and the international community can work together to assist poor constituencies in adapting to observed and anticipated climate-related stresses, even as they also work to reduce emissions.

Table I-Sectoral Vulnerability for Key Sectors for the Subcontinental Regions of Asia

\begin{tabular}{|c|c|c|c|c|c|c|c|}
\hline Subregions & $\begin{array}{c}\text { Food and } \\
\text { fiber }\end{array}$ & $\begin{array}{c}\text { Bio- } \\
\text { diversity }\end{array}$ & $\begin{array}{l}\text { Water } \\
\text { resource }\end{array}$ & $\begin{array}{c}\text { Coastal } \\
\text { ecosystem }\end{array}$ & $\begin{array}{c}\text { Human } \\
\text { health }\end{array}$ & Settlements & $\begin{array}{c}\text { Land } \\
\text { degradation }\end{array}$ \\
\hline North Asia & $+\mathrm{I} / \mathrm{H}$ & $-2 / M$ & $+I / M$ & $-I / M$ & $-I / M$ & $-I / M$ & $-I / M$ \\
\hline \multicolumn{8}{|l|}{ Central Asia and } \\
\hline West Asia & $-2 / H$ & $-I / M$ & $-2 / \mathrm{VH}$ & $-I / L$ & $-2 / M$ & $-I / M$ & $-2 / \mathrm{H}$ \\
\hline Tibetan Plateau & $+I / L$ & $-2 / M$ & $-I / M$ & $\begin{array}{c}\text { Not } \\
\text { applicable }\end{array}$ & $\begin{array}{l}\text { Information } \\
\text { not available }\end{array}$ & $\begin{array}{l}\text { Information } \\
\text { not available }\end{array}$ & $-I / L$ \\
\hline East Asia & $-2 / \mathrm{VH}$ & $-2 / H$ & $-2 / H$ & $-2 / H$ & $-\mathrm{I} / \mathrm{H}$ & $-\mathrm{I} / \mathrm{H}$ & $-2 / \mathrm{H}$ \\
\hline South Asia & $-2 / \mathrm{H}$ & $-2 / \mathrm{H}$ & $-2 / \mathrm{H}$ & $-2 / \mathrm{H}$ & $-2 / M$ & $-I / M$ & $-2 / \mathrm{H}$ \\
\hline Southeast Asia & $-2 / \mathrm{H}$ & $-2 / \mathrm{H}$ & $-\mathrm{I} / \mathrm{H}$ & $-2 / \mathrm{H}$ & $-2 / \mathrm{H}$ & $-I / M$ & $-2 / \mathrm{H}$ \\
\hline
\end{tabular}

Source: Intergovernmental Panel on Climate Change, "Climate Change 2007: Impacts, Adaptation and Vulnerability," Contribution of Working Group II to the Fourth Assessment Report, M. L. Parry, O. F. Canziani, J. P. Palutikof, P. J. van der Linden, and C. E. Hanson, eds. (Cambridge University Press, Cambridge, UK, 2007). Notes: Key to vulnerability: -2 indicates highly vulnerable; $-\mathrm{I}$, moderately vulnerable; and $+\mathrm{I}$, moderately resilient. Key to level of confidence: $\mathrm{VH}$ indicates very high; H, High; M, medium; and L, low. 
Table 2-Sectoral Vulnerability for Key Sectors for the Subcontinental Regions of Asia

Sector

Farm management

Livestock production

Fisheries

Agricultural

biotechnologies

Agricultural

infrastructure

\section{Adaptation Measures}

Choice of crop and cultivar areas under water stress

- Use salt-tolerant varieties varieties in cold regions

- Alter application of nutrients/fertilizer

- Alter application of insecticide/pesticide

- Change planting date to effectively use the prolonged growing season and irrigation periods improved grasslands and pastures of pastures animals

- Plant native grassland species

- Increase plant coverage per hectare feed and veterinary services with impacts of climate change pest-, and salt-tolerant crop varieties technologies in livestock production

- Improve pasture water supply
- Use more heat/drought-tolerant crop varieties in

- Use more disease- and pest-tolerant crop varieties

- Introduce higher yielding, earlier maturing crop

- Develop adaptive management strategy at farm level

- Breed livestock for greater tolerance and productivity

- Increase stocks of forages for unfavorable time

- Improve pasture and grazing management, including

- Improve management of stocking rates and rotation

- Increase the quantity of forages used to graze

- Provide location-specific support in supplementary

- Breed fish tolerant to high water temperatures

- Develop fisheries management capabilities to cope

- Develop and distribute more drought-, disease-,

- Develop improved processing and conservation

- Improve crossbreeds of high-productivity animals

- Improve irrigation systems and their efficiency

- Increase (and improve) use and storage of rain and snow water

- Improve information exchange on new technologies (at national, regional, and international levels)

- Improve sea defense and flood management

- Improve access of herders, fishers, and farmers to timely weather forecasts

Source: Intergovernmental Panel on Climate Change, "Climate Change 2007: Impacts, Adaptation and Vulnerability," Contribution of Working Group II to the Fourth Assessment Report, M. L. Parry, O. F. Canziani, J. P. Palutikof, P. J. van der Linden, and C. E. Hanson, eds. (Cambridge University Press, Cambridge, UK, 2007).
This includes the type of assistance required and how it can be targeted effectively to the poor.

\section{Adaptation Measures, Policies, and Strategies}

Most of the literature about adaptation focuses on a variety of adaptation "measures." In any given context, however, the choice of measures may be constrained by factors such as their expense, lack of knowledge on how to implement them, and countervailing beliefs and cultural practices. Notwithstanding these impediments, farmers and others at risk from climate change can be provided with external help. Possibilities include the provision of technical information, advice, or guidance; the provision of weather and seasonal climate forecasts and warnings; drought or flood relief; and insurance or other forms of financial assistance and risk spreading.

Decisions about adaptation measures are shaped by public policy, which can be supportive or provide barriers or disincentives. Issues include how much the government and international community is doing to create and deploy improved technology and management techniques; the effect of public policy on crop and livelihood diversification; the agricultural policies in place; and how climate variability and change is factored into policy choices. Many of the policies that can be adopted or strengthened represent existing needs. Effective adaptation requires the judicious selection of measures within a policy context and within a strategic development framework. Table 2 provides a list of relevant adaptation measures for Asia.

\section{Modes of External Assistance}

Public intervention in implementing adaptation measures and policies, encouraged and facilitated by the international community, falls into five categories:

1. Providing information and advice. Government agencies can provide information and advice about climate risk and available adaptation or coping strategies.

2. Providing guidance and training. Beyond information and advice, governments can proactively demonstrate how specific adaptation measures can be designed and implemented.

3. Promoting adaptation measures. A further step is for governments to promote desirable adaptation outcomes through policy measures, including eliminating inappropriate measures, such as electricity subsidies in India that promote overuse of electricity and overmining of groundwater.

4. Mandating adaptation. In certain cases, it is appropriate for governments to require adaptation to safeguard public health and safety. For example, vulnerability to climate change would rise if irrigation agriculture were to expand beyond available water resources.

5. Institutionalizing adaptation capacity and policy. It is not unusual for climate change policy to be managed and kept within the confines of one ministry or department, but some form of interdepartmental cooperation is necessary.

\section{Mainstreaming Adaptation into Development Planning}

Economic growth is necessary for poverty reduction and promoting adaptation to climate change, but long-term 
growth cannot be sustained without ensuring that emerging patterns of agriculture, industry, and trade do not unduly impinge on ecological health and resilience. The tendency has been to treat adaptation to climate change as a stand-alone activity, but it should be integrated into development activities. Development policy issues must inform the work of the climate change community such that they combine their perspectives in the formulation and implementation of integrated approaches and processes that recognize how persistent poverty and environmental needs exacerbate the adverse consequences of climate change.

A significant adaptation gap exists in many developing countries, particularly those populated by the rural poor who subsist on agriculture. While mitigation within the United Nations Framework Convention on Climate Change (UNFCCC) includes clearly defined objectives, measures, costs, and instruments, this is not the case for adaptation. Much less attention has been paid to making development more resilient to climate change impacts and to identifying barriers to mainstreaming climate change adaptation within development activities. A recent study by Wang et al. demonstrated that the ability of Chinese farmers to change and adapt to new conditions enabled them to outperform other agricultural economies globally, and that this advantage will continue to be an important factor under climate change. This alone is not sufficient, however, for the farmers to endure future climatic changes. Policies to provide them with access to the most available factors of production and natural resources are critical, particularly in terms of water, and especially in China's water-scarce regions. Climate change puts pressure on policymakers to develop institutions and infrastructure in these regions as part of their agricultural development strategy. Furthermore, the study concluded that China must consider developing management practices and new crop and livestock varieties for warmer regions as part of its adaptation and mitigation strategies for the rural farmers.

\section{Moving Forward}

Much can be done with international support at the national level to foster local adaptation initiatives. Three such actions are described below:

1. National adaptation action plans. All countries should have national adaptation plans that take a broad strategic view of future development paths and expected climate change impacts, and examine and adjust policies, including those related to agriculture, forests, fisheries, water, and other natural resources, as well as health, infrastructure, and ecosystems. Climate change adaptation policy should go beyond general development policy to explicitly target the impacts of climate change, particularly on the poor. Much additional work is needed to assess the costs and benefits of specific adaptations in specific locations.

2. Financing for national adaptation plans. A common concern of developing countries is that their participation in multilateral environmental agreements imposes high costs. It seems realistic to suggest that developed countries, acting collectively through the Global Environment Facility (GEF), support the preparation of adaptation plans. This would help not only to ensure that climate is adequately considered in national development plans and sectoral policies, but also to reassure donors and investors that climate change adaptation measures are well conceived and represent sound expenditures. Plans also need to be implemented, requiring further support.

3. Climate insurance. A further suggestion concerns the provision of insurance against climate risk. Countries, communities, and individuals in most developing countries have little or no insurance coverage against extreme weather events. The private insurance industry is poorly developed in many cases, and fear of losses in uninsured catastrophic events is a significant deterrent. The need and opportunity exists to develop public-private partnerships to expand insurance against climate-related events in developing countries.

\section{PRO-POOR MITIGATION STRATEGIES}

Since adaptation becomes costlier and less effective as the magnitude of climate changes increases, mitigation of climate change remains essential. The greater the level of mitigation that can be achieved at affordable cost, the smaller the burdens placed on adaptation. Effective reform of carbon trading and carbon offsets to better include farmers and foresters in developing countries could have significant benefits in mitigation in addition to encouraging environmentally sustainable practices and improving rural incomes to enhance adaptive capacity. Global carbon trading will increase dramatically under present trends, but two key constraints need to be overcome before significant benefits can be channeled to rural areas in developing countries: first, the rules of access-which still do not credit developing countries for reducing emissions by avoiding deforestation or improving soil carbon sequestration-must change; and second, the operational rules, with their high transaction costs for developing countries and small farmers and foresters in particular, must be streamlined.

\section{Greenhouse Gases, Land Use, and Agriculture}

Land use change (18.2 percent) and agriculture (13.5 percent) together create nearly one-third of greenhouse gas emissions. The share of these kinds of emissions is far larger in developing countries and still larger in least developed countries. Achieving significant carbon mitigation in developing countries will require tapping carbon offsets from agriculture and land use change. While not as large as the potential for savings from reducing the consumption of fossil fuels, the total potential savings from various agricultural and land use change activities is still substantial and is achievable at a competitive cost. With as much as 13 gigatons of carbon dioxide per year at prices of US\$10-20 per ton, this represents potential financial flows of US\$130-260 billion annually, comparable to annual official development assistance of US $\$ 100$ billion, and foreign direct investment in developing countries of US\$150 billion.

\section{Adopting Innovative Pro-Poor Approaches for Developing Countries}

In addition to the crucial steps of including offsets for soil carbon and avoided deforestation in the Convention's Clean Development Mechanism (CDM), a number of other changes are needed. To ensure that these emerging carbon markets benefit developing countries, CDM rules should encourage the participation of small farmers and community forest and agroforestry producers, and protect them against major livelihood risks while still meeting investor needs and rigorously ensured carbon offset goals. This can be supported through the following mechanisms:

1. Broadening the definition of afforestation and reforestation. Agroforestry, assisted natural regeneration, forest rehabilitation, forest gardens, and improved forest fallow projects should all be eligible under CDM, because they offer a low-cost approach to carbon sequestration while offering fewer social risks and significant community and biodiversity benefits. Short-duration tree-growing activities should be permitted, with suitable discounting. Limiting project types would introduce forest product market distortions unfairly favoring large plantations. 
2. Promoting measures to reduce transaction costs. Rigorous but simplified procedures as typified by the Chicago Climate Exchange should be adapted to developing-country carbon offset projects. According to the Marrakesh Accords, smallscale projects can benefit from simplified ways of determining baselines and monitoring carbon emissions. Small-scale agroforestry and soil carbon sequestration projects should be eligible for simplified modalities to reduce the costs of these projects. The permanence requirement for carbon sequestration should be revised to allow shorter term contracts, or contracts that pay based on the amount of carbon saved per year, which would avoid the need for "locking up" land in forest land uses for prolonged periods.

3. Establishing international capacity building and advisory services. The successful promotion of livelihood enhancing CDM forestry projects will require investment in capacity-building and advisory services for potential investors, project designers and managers, national policymakers, and leaders of local organizations and federations. Regional centers could be established to assist countries and communities involved in forest carbon trading. Institutional innovations can provide economies of scale and specialization. Companies or agencies can provide specialized business services for low-income producers to help them negotiate deals or design monitoring systems. Locally accountable intermediary organizations can manage projects and mediate between investors and local people.

Finally, further investment in advanced measurement and monitoring can dramatically reduce transaction costs. Measurement and monitoring techniques have been improving rapidly thanks to a growing body of field measurements and the use of statistics and computer modeling, remote sensing, global positioning systems, and geographic information systems, so that changes in stocks of carbon can now be estimated more accurately at lower cost.

\section{CONCLUSIONS}

Policies focused on mitigating the effects of climate change, if carefully designed, can create a new development strategy that encourages the creation of new value in pro-poor investments by increasing the profitability of environmentally sustainable practices. To achieve this goal, it will be necessary to streamline the measurement and enforcement of offsets, financial flows, and carbon credits for investors. It is important to enhance global financial facilities and governance to simplify rules and increase funding flows for mitigation in developing countries.

Challenges and opportunities are not quite as clear when it comes to adaptation, however. There is no single definition of what it means to adapt to a stress, and there are no firm quantitative measures for adaptive capacity. It is, however, widely accepted that the underlying determinants of a high capacity to adapt (and to mitigate, for that matter) include routine access to resources, strong social and human capital, and routine access to risk-spreading mechanisms. The rural poor are lacking in most of these factors; thus, they are highly vulnerable under climate change. Moreover, climate impacts vary over space and time. As global adaptation funds accrue (as more members of the UNFCCC sign on to Kyoto and a successor agreement to Kyoto is developed), care must be taken to allow countries to follow their own approaches; but success across nations must be measured against consistent and as yet undefined standards.

Some will read these recommendations with trepidation because very little climate change has occurred to date in many-but not all-places, so fears arise that large-scale adaptation programs may be premature or run the risk of being misdirected. It is also widely understood that the sources of low adaptive capacity are extraordinarily diverse. Will poor farmers in a particular location, for example, fail to adapt because of lack of knowledge, lack of resources, or poor government policies, and what would be the appropriate role of the international community in each case? The counterargument presented here is that these concerns do not constitute reasons not to act but rather are reasons to proceed cautiously in recognition that no single approach will work everywhere. The only way to learn what works, where, and why is to try, and-in the most difficult circumstances where action can actually begin to help the most vulnerable-now is the time to start trying in earnest.

For Further Reading: N. Adjer, J. Paavola, S. Huq, and M. J. Mace, eds., Fairness in Adaptation to Climate Change (Cambridge, MA: Massachusetts Institute of Technology Press, 2006); K. A. Baumert, T. Herzog, and J. Pershing, Navigating the Numbers: Greenhouse Gas Data and International Climate Policy (Washington, DC: World Resources Institute, 2005); L. Erda, Z. Ji, Z. X. Yinlong, J. Hui, M. Shiming, W. Shaohong, F. Xiangzhao, W. Xuechen, M. Shan, and C. Yizhou, "Climate Change Impacts and its Economics in China," Report prepared for the Stern Review (2006) <http://www. sternreview.org.uk>; Intergovernmental Panel on Climate Change (IPCC), Climate Change 2007: The Science, Contribution of Working Group I to the Fourth Assessment Report, S. Solomon, D. Qin, M. Manning, M. Marquis, K. Averyt, M. M. B. Tignor, and H. Miller, eds. (Cambridge University Press, 2007); IPCC, Climate Change 2007: Impacts, Adaptation and Vulnerability, Contribution of Working Group II to the Fourth Assessment Report, M. L. Parry, O. F. Canziani, J. P. Palutikof, P. J. van der Linden, and C. E. Hanson, eds. (Cambridge University Press, 2007); IPCC, Climate Change 2007: Mitigation of Climate Change, Contribution of Working Group III to the Fourth Assessment Report, B. Metz and O. Davidson, eds. (Cambridge University Press, 2007); J. Wang, R. Mendelsohn, A. Dinar, J. Huang, S. Rozelle, and L. Zhang, Can China Continue Feeding Itself? The Impact of Climate Change on Agriculture, Policy Research Working Paper 4470 (Washington DC: World Bank, 2007).

Gary Yohe (gyohe@wesleyan.edu) is Woodhouse/Sysco Professor of Economics at Wesleyan University, Middletown, Connecticut, U.S.A.; Ian Burton (ianburtonian@aol.com) is scientist emeritus at Environment Canada,Toronto; Saleemul Huq (saleemul.huq@iied.org) is group head of the Climate Change Program at the International Institute for Environment and Development, London, U.K.; and Mark W. Rosegrant (m.rosegrant@cgiar.org) is director of the Environment and Production Technology Division at the International Food Policy Research Institute, Washington, DC, USA. This brief is based on a 2020 Focus Brief published by IFPRI in 2007 and originally prepared for a policy consultation process coordinated by IFPRI on the World's Poor and Hungry People. 
$\mathbf{A}$ high percentage of the Indian population is engaged in agricultural and rural activities, mostly in the unorganized sector. According to the last census, in 2001 India's population reached 1.025 billion, of whom 740 million (72 percent) live in rural areas. Seventy-seven percent of the country's workforce is based in rural areas. More than 28 percent of these people in rural areas live below the poverty line.

These poor rural households are vulnerable to a number of risks. Some of these, like minor illnesses, are frequent and have relatively little impact, whereas others, like cyclones, can be infrequent but have great impact. The risks facing these households can also be distinguished based on whether they are idiosyncratic or covariant. Covariant shocks, such as drought, can affect all households in a locality, whereas idiosyncratic shocks, such as theft, may be restricted to only one household.

The poor adopt a variety of strategies depending on the severity and covariability of the shocks they face. Households first use savings, then borrowing, and finally pledging/liquidating (see Figure 1). Households also use several self-insurance strategies, such as reduc-

Figure I-Household Strategies for Dealing with Shocks Based on Their Severity and Covariance

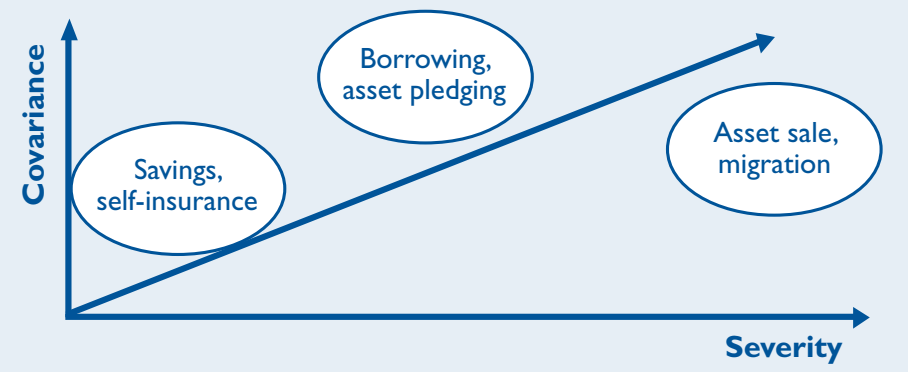

ing consumption of foodgrains, removing children from school, migrating temporarily, and diversifying income sources. Some of these strategies, however, reduce the ability to withstand future shocks. If there are successive droughts or bouts of illness, for example, then the family becomes increasingly vulnerable to risk.

Although minor shocks are best handled by dipping into one's savings, or occasionally borrowing from another source, severe shocks require outside support, in the form of insurance payouts or disaster relief. What is needed is a sustainable market mechanismnamely, insurance-to mitigate these risks.

\section{INSURANCE NEEDS OF THE RURAL POOR}

A 1997 study by Price Waterhouse identified the need for microinsurance based on major adverse events that rural households experienced during the previous 10 years. Forty-four percent of households reported losses due to floods and heavy rains, 39 percent due to drought, and 27 percent due to pest attack. Furthermore, the survey revealed that only 15 percent of the respondents already possessed an insurance policy, and 64 percent of the respondents desired some form of insurance.

Rural households face different risks-and require different insurance solutions-depending on the activities in which they are engaged. The following provides a brief profile of each type of household, the economic risks they face, and possible insurance interventions and current insurance products available.

\section{Cultivators (Farmers)}

Self-employed cultivators, who make up 32 percent of the total workforce, face a variety of risks ranging from damage to incomegenerating assets and loss of livestock to price fluctuations and occupational hazards. Table 1 shows the risks faced by cultivators and the insurance products available to help them mitigate these risks.

Table I-Self-Employed Cultivators: Risks Faced and Insurance Products Available

\begin{tabular}{|c|c|c|c|c|}
\hline Risk & $\begin{array}{l}\text { Remarks on } \\
\text { the Risk }\end{array}$ & $\begin{array}{l}\text { Possible Insurance } \\
\text { Products }\end{array}$ & $\begin{array}{l}\text { Offered by } \\
\text { Public Insurers }\end{array}$ & $\begin{array}{l}\text { Offered by } \\
\text { Private Insurers }\end{array}$ \\
\hline $\begin{array}{l}\text { Loss of or damage to } \\
\text { income-generating assets }\end{array}$ & Agricultural implements & $\begin{array}{l}\text { Motor insurance; } \\
\text { produce stock insurance }\end{array}$ & $\begin{array}{l}\text { Offered, but reach is } \\
\text { limited }\end{array}$ & $\begin{array}{l}\text { Offered by very few } \\
\text { companies }\end{array}$ \\
\hline Loss of livestock & $\begin{array}{l}\text { Critical for cultivation, } \\
\text { milk production }\end{array}$ & $\begin{array}{l}\text { Livestock insurance } \\
\text { covers death of animals }\end{array}$ & $\begin{array}{l}\text { Offered, but mostly } \\
\text { linked to government } \\
\text { schemes and credit }\end{array}$ & $\begin{array}{l}\text { Offered by few } \\
\text { companies }\end{array}$ \\
\hline $\begin{array}{l}\text { Loss of recovery of } \\
\text { expenses and profit }\end{array}$ & $\begin{array}{l}\text { Input cost and surplus } \\
\text { expected }\end{array}$ & $\begin{array}{l}\text { Crop and weather } \\
\text { insurance }\end{array}$ & $\begin{array}{l}\text { Offered, but limited } \\
\text { success }\end{array}$ & $\begin{array}{l}\text { Offered by few } \\
\text { companies, but little } \\
\text { reach }\end{array}$ \\
\hline $\begin{array}{l}\text { Credibility risk due to } \\
\text { inability to honor loan } \\
\text { repayment because of } \\
\text { mismatch in cash flows }\end{array}$ & $\begin{array}{l}\text { Delay in marketing, } \\
\text { receipt of cash }\end{array}$ & $\begin{array}{l}\text { No insurance product is } \\
\text { possible, but a short- } \\
\text { term line of credit will } \\
\text { solve the problem }\end{array}$ & Not applicable & Not applicable \\
\hline Market risks & Price risk & $\begin{array}{l}\text { There is scope for an } \\
\text { insurance product, but } \\
\text { commodity futures are } \\
\text { also a solution }\end{array}$ & Not applicable & Not applicable \\
\hline Occupational hazards & $\begin{array}{l}\text { Snake bites, pesticide } \\
\text { poisoning, electrocution }\end{array}$ & Accident insurance & $\begin{array}{l}\text { No specific product } \\
\text { for farmers is offered, } \\
\text { but Janata Accident } \\
\text { Insurance offers a policy }\end{array}$ & $\begin{array}{l}\text { No specific product } \\
\text { offered for farmers, } \\
\text { but there is general } \\
\text { accident insurance }\end{array}$ \\
\hline
\end{tabular}

\section{Potential \\ Good potential \\ Great scope, if channeled properly \\ Crop insurance has not been performing satisfactorily}

Microfinance institutions have been extending credit to meet this need to a large extent

NCDEX (National Commodity Derivative Exchange) offers futures and derivative services

Some risks, such as snake bites, are excluded 


\section{Agricultural Laborers}

Agricultural employment is a seasonal phenomenon. Locations with good rainfall and irrigation facilities offer employment to agricultural laborers, who constitute 26 percent of the total workforce, throughout the year. In drought-prone areas, however, only rainfed cultivation is possible, requiring laborers to find secondary employment in nonagricultural activities, such as well digging and construction, during the off season.

Furthermore, nonagricultural labor depends on the performance of seasonal agricultural productivity. Hence, there is scope for using weather derivatives as a mechanism to hedge against labor scarcity.

Neither public- nor private-sector insurers offer insurance coverage to laborers to protect against loss of wage employment. India's National Employment Guarantee Scheme, however, provides 100 days of assured wage employment to rural youth during periods of high rural unemployment. This employment provides work in constructing and maintaining rural infrastructure and is paid for by the government.

Table 2 shows in more detail the risks faced by laborers and the insurance products available to help them mitigate these risks.

\section{Artisans}

Artisans in India include individuals who possess specialized skills that support agriculture and serve needs. These skills are gained and nurtured through generations, and inheriting an artisan profession can mean stable employment. But market competition from heavy mechanization and availability of ready-made products has reduced demand for artisans' products, putting these artisans at risk of going out of business. This risk is beyond the scope of insurance protection. Many artisans have been required to find unskilled employment or become entrepreneurs. Insurance products can, however, provide protection against risks faced by some artisan groups such as fishers, shepherds, and toddy tappers (people who collect toddy, the liquor fermented from coconut or palm sap). These are outlined in Table 3.

\section{INDIA'S INSURANCE SECTOR}

Between 1999 and 2000, private insurers began to enter the Indian insurance sector. The Insurance Regulatory and Development Authority (IRDA) is responsible for governing their operations.

Life insurance is one of the most desired forms of insurance protection in India, and both the public and private sectors have responded to this demand. Currently 15 private-sector insurance companies and one public-sector entity provide life insurance.

Among non-life insurance providers, there are six publicsector entities and nine private-sector companies. There is only one reinsurance company, the General Insurance Corporation of India, which is a public-sector company.

\section{Table 2-Agricultural Laborers: Risks Faced and Insurance Products Available}

\begin{tabular}{|c|c|c|c|c|c|}
\hline Community & Risk Faced & $\begin{array}{l}\text { Likely Insurance } \\
\text { Product }\end{array}$ & $\begin{array}{l}\text { Offered by Public } \\
\text { Insurers }\end{array}$ & $\begin{array}{l}\text { Offered by Private } \\
\text { Insurers }\end{array}$ & Potential \\
\hline $\begin{array}{l}\text { Loss of recovery of } \\
\text { expenses and profit }\end{array}$ & $\begin{array}{l}\text { Wage loss due to } \\
\text { drought and floods }\end{array}$ & $\begin{array}{l}\text { Weather insurance could } \\
\text { address this risk }\end{array}$ & Offered by AIC & $\begin{array}{l}\text { Two companies offer } \\
\text { this product }\end{array}$ & Tremendous potential \\
\hline $\begin{array}{l}\text { Credit risk for mismatch } \\
\text { in cash flows }\end{array}$ & $\begin{array}{l}\text { Inability to pay debts } \\
\text { and consumption needs }\end{array}$ & & Not applicable & Not applicable & $\begin{array}{l}\text { Savings, credit are } \\
\text { alternative services }\end{array}$ \\
\hline Market risks & $\begin{array}{l}\text { Decreased labor } \\
\text { opportunities due to } \\
\text { economic recession }\end{array}$ & & Not applicable & Not applicable & Not applicable \\
\hline Occupational hazards & $\begin{array}{l}\text { Snake bites, } \\
\text { electrocution, pesticide } \\
\text { poisoning, road } \\
\text { accidents }\end{array}$ & Accident insurance & $\begin{array}{l}\text { Tailor-made products } \\
\text { are not available }\end{array}$ & $\begin{array}{l}\text { Tailor-made products } \\
\text { are not available }\end{array}$ & $\begin{array}{l}\text { A special product can be } \\
\text { designed to address the } \\
\text { risk profile of this group }\end{array}$ \\
\hline
\end{tabular}

Table 3-Artisans: Risks Faced and Insurance Products Available

\begin{tabular}{|c|c|c|c|c|c|}
\hline Community & Risk Faced & $\begin{array}{l}\text { Likely Insurance } \\
\text { Product }\end{array}$ & $\begin{array}{l}\text { Offered by Public } \\
\text { Insurers }\end{array}$ & $\begin{array}{l}\text { Offered by Private } \\
\text { Insurers }\end{array}$ & Potential \\
\hline Fishers & $\begin{array}{l}\text { Loss of fish from } \\
\text { drought, excess rainfall, } \\
\text { temperature variations, } \\
\text { and malicious poisoning }\end{array}$ & $\begin{array}{l}\text { An insurance product } \\
\text { to protect against the } \\
\text { loss of fish from risks } \\
\text { listed can be designed for } \\
\text { the rural communities } \\
\text { to help them increase } \\
\text { income and employment }\end{array}$ & $\begin{array}{l}\text { Offered, but reach is not } \\
\text { significant }\end{array}$ & $\begin{array}{l}\text { Offered by few } \\
\text { companies }\end{array}$ & Good potential \\
\hline \multirow[t]{2}{*}{ Shepherds } & Dwindling grazing lands & $\begin{array}{l}\text { No insurance product } \\
\text { is possible for this risk } \\
\text { component }\end{array}$ & Not applicable & Not applicable & $\begin{array}{l}\text { Government needs to } \\
\text { ensure that the use } \\
\text { of agricultural land is } \\
\text { regulated appropriately }\end{array}$ \\
\hline & $\begin{array}{l}\text { Death of sheep and } \\
\text { goats due to epidemics }\end{array}$ & Sheep and goat insurance & $\begin{array}{l}\text { Offered, but mostly } \\
\text { linked to government } \\
\text { schemes and credit }\end{array}$ & $\begin{array}{l}\text { Offered by a few } \\
\text { companies only }\end{array}$ & $\begin{array}{l}\text { Great potential, if } \\
\text { appropriate channels are } \\
\text { explored }\end{array}$ \\
\hline Toddy tappers & $\begin{array}{l}\text { Death or disability from } \\
\text { falling from trees }\end{array}$ & $\begin{array}{l}\text { Accident insurance } \\
\text { designed for this } \\
\text { community would serve } \\
\text { the purpose }\end{array}$ & $\begin{array}{l}\text { Offered by Janata } \\
\text { Accident Insurance and } \\
\text { Road Accident Policy }\end{array}$ & $\begin{array}{l}\text { Offered as part of } \\
\text { accident insurance }\end{array}$ & \\
\hline
\end{tabular}


Table 4-IRDA-Mandated Targets for Rural and Social-Sector Coverage of Private Insurance Companies

\begin{tabular}{|c|c|c|c|c|}
\hline Years in Operation & 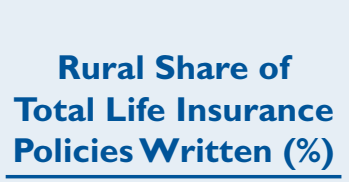 & $\begin{array}{c}\text { Number of Lives } \\
\text { in Social Sector } \\
\text { Covered by Life } \\
\text { Insurance }\end{array}$ & $\begin{array}{c}\text { Gross Premiums } \\
\text { Collected on } \\
\text { General Insurance } \\
\text { Policies (\%) } \\
\end{array}$ & $\begin{array}{c}\text { in Social Sector } \\
\text { Covered by } \\
\text { General Insurance } \\
\text { Companies }\end{array}$ \\
\hline I & 7 & 5,000 & 2 & 5,000 \\
\hline 2 & 9 & 7,000 & 3 & 7,000 \\
\hline 3 & 12 & 10,000 & 5 & 10,000 \\
\hline 4 & 14 & 15,000 & 5 & 15,000 \\
\hline 5 & 16 & 20,000 & 5 & 20,000 \\
\hline 6 & 18 & 25,000 & 5 & 25,000 \\
\hline
\end{tabular}

IRDA has mandated that private-sector insurance companies focus some of their efforts on serving the rural and social sector. The social sector is defined as lower income groups mentioned in the list issued by IRDA. The degree to which they must serve these groups depends on a number of factors, such as years in operation, as outlined in Table 4.

These targets are conservative in light of the significant need to reach low-premium clients in India. More aggressive and innovative approaches are needed to deliver the benefits of insurance to rural poor people. IRDA is expected to soon develop target numbers for private insurance companies in operation for more than seven years.

According to a 2006 study by the Deutsche Gesellschaft für Technische Zusammenarbeit (GTZ) called "Micro-Insurance Demand and Market Prospects," current insurance service penetration in India is abysmally low, reaching less than 3 percent of the insurable population, even though private insurers have been active for seven years and more than 31 insurance companies are currently operating in the country. Worldwide, India ranks 54th in terms of market penetration and 19th in premium collection. This anomaly persists because life insurance has traditionally been positioned as a savings and tax-minimization tool rather than as a risk protection tool.

\section{BASIX'S EXPERIENCE AND INNOVATION}

BASIX is a livelihood promotion institute that seeks to provide financial and technical assistance services to the poor in an integrated manner. It started microcredit operations in 1996 and provided technical assistance to some of its clients through programs to exchange expertise between borrowers, self-help groups, and agricultural experts, all at the cost of company.

A 2001 impact study of BASIX's services by the Indian Market Research Bureau revealed that approximately 52 percent of clients expressed a positive difference in their income during the time these services were provided, 23 percent reported no change, and 25 percent saw a decline in income. Further research showed that it was the presence of unmanaged risk that caused the decline in income levels. Subsequently, BASIX revised its strategy to provide livelihood financial services, agriculture and business development services, and institutional development services, which together are known as the triad strategy.

In 2000, after the opening of the insurance sector to privatesector companies, BASIX initiated dialogues with private insurers. It then established partnerships with insurance entities to work on developing and distributing products and processes: AVIVA Life Insurance Company (for life insurance products), Royal Sundram
Alliance General Insurance Company (for health, livestock, and microenterprise insurance), and ICICI Lombard General Insurance Company (for weather insurance). In 2003 BASIX partnered with the World Bank and ICICI Lombard to pilot the first weather insurance product for farmers.

Since 2002 BASIX has provided life and health insurance to nearly 500,000 people, livestock insurance to 34,000 people, and weather insurance to 19,000 people across India. BASIX has innovated in the design of insurance products, the information used to process insurance claims, and the means by which insurance is made accessible. Its efforts have allowed for the provision of insurance products that respond to the needs of rural households at prices they can afford. Box 1 provides additional information about each insurance product.

Overall, BASIX has experienced solid product performance, with outgo accounting for about 55 percent of overall premiums collected. The premium outgo on health products is expected to rise as customer awareness of the utility of these products increases. Performance is staying strong as the products and processes are improved every year.

\section{LOOKING FORWARD}

Meeting the insurance needs of the rural poor in India and other developing countries raises several challenges:

- Educating the rural poor about insurance. Life insurance is largely viewed only as a savings instrument-people expect a portion of their premiums back, even when no event occurs. This misunderstanding about the purpose and use of life insurance causes many people to prefer what they perceive as higher-return savings products. In the face of this misunderstanding, selling life insurance products is a challenging task.

- Developing appropriate insurance products and services to meet client needs. A wide range of insurance tools are currently available, but they cater primarily to urban clients. These products and services are rarely customized for the poor, and so they are unattractive to the poor in terms of features and price. Processes for participation are also extremely cumbersome for the rural poor.

- Creating context-specific insurance products. The poor face risks that are location-specific and thus may not find universal insurance products attractive for the unique challenges of rural areas. 


\section{LIFE INSURANCE: Credit Plus}

This group life insurance product insures a loan of up to 1.5 times its value in the event of the death of a borrower. The product features three innovations: (I) the premium is collected monthly, along with loan installments; (2) the non-exclusion of suicide death decreases the operating cost; and (3) BASIX provides all the front-end support to customers. These innovations have helped reduce the product premium from Rs. $8.6 \mathrm{I}$ to 3.98 . In addition, the average claim settlement period is 72 days from the date of death and II days from the date of submission of claim papers. The value of this product is seen from its popularity among staff and customers. The table below provides details on use of this product.

\begin{tabular}{|c|c|c|}
\hline \multicolumn{3}{|c|}{ Performance of Credit Plus Life Insurance } \\
\hline Indicator & FY 2006 & Cumulative since 2002 \\
\hline Person-years covered & 280,357 & 499,497 \\
\hline Claims settled & 920 & ।,487 \\
\hline Mortality rate per I,000 lives per year & 3.28 & 2.98 \\
\hline Premium outgo for claims & & $68 \%$ \\
\hline
\end{tabular}

\section{HEALTH INSURANCE: Grameen Arogya Raksha}

This limited health insurance product provides clients with Rs. I,500 in cash in the case of a hospital visit, Rs. 10,000 in the case of a critical illness, and Rs. 25,000 in the case of permanent and total disability. This project features three innovations: (I) the premium is collected monthly, along with loan installments; (2) BASIX provides all the front-end support to customers; and (3) BASIX deploys claim facilitators, separate from staff who enroll customers. As a result of these innovations, the annual premium is reduced from Rs. 137 to 67 and the average claim takes only 44 days from the time of illness and 15 days from the submission of papers. Again, this product is highly popular. The table below provides details on use of this product.

\begin{tabular}{|c|c|c|}
\hline \multicolumn{3}{|c|}{ Performance of Grameen Arogya Raksha } \\
\hline Indicator & FY 2006 & Cumulative since 2002 \\
\hline Person-years covered & 271,454 & 499,497 \\
\hline Claims settled & 3,600 & ।,487 \\
\hline Morbidity rate per I,000 lives per year & 1.33 & 1.2 \\
\hline Premium outgo for claims & & $24 \%$ \\
\hline
\end{tabular}

\section{LIVESTOCK INSURANCE}

This product pays 100 percent of the insured value of dairy animals and cattle (up to Rs. 20,000) on death. This product also features three innovations: (I) the premium is collected upfront; (2) insurability certification is done by BASIX staff, and animal death certification is done by a claim surveyor; and (3) BASIX staff does all the front-end support. As a result of these innovations, the premium charged is only between 3.5 and 4.0 percent, and average claims take 50 days from the date of death and 20 days from the time of claim submission. The insurance company that BASIX works with on this product is actively pursuing further sales of the product. The table below provides details of BASIX's experience to date on this product.

Performance of Livestock Insurance

\begin{tabular}{lcc} 
Indicator & FY 2006 & Cumulative since 2002 \\
\hline Number of livestock insured & $\mathrm{II}, 250$ & 33,808 \\
Claims settled & 230 & 1,005 \\
Mortality rate per 100 animals per year & Around 3.03 & Around 3.8 \\
Premium outgo for claims & Around 92\% & Around 92\%
\end{tabular}

\section{WEATHER INSURANCE}

This product uses local weather indexes to insure cultivators against loss of income due to shortfalls or excess levels of rainfall. This product's three innovations are as follows: (I) products are tailored to local crops, weather conditions, and customer preferences; (2) rainfall measurement stations were set up in BASIX operational locations; and (3) claims are settled within 30 days after the closure of the window period. Thanks to these innovations, the premiums range from only 7 to II.4 percent of the sum insured, and claims are settled quickly whenever data are available. The constraint BASIX faces in providing this product is the timely availability of reliable data, particularly from the Indian Metrological Department stations. The table below details BASIX's experience with this product to date.

\section{Performance of Weather Insurance}

Indicator FY 2006 Cumulative since 2002

\begin{tabular}{lcc}
\hline Number of policies sold & 11,244 & 18,565 \\
Claims settled & 2,379 & 3,716 \\
Share of farmers who received compensation & $21 \%$ & $20 \%$ \\
Premium outgo for claims & $144 \%$ & $87 \%$
\end{tabular}

- Reaching the rural poor. Providing micro-insurance to the rural poor is a huge challenge. Serving this market becomes operationally feasible only when product premiums are reduced to ensure they are affordable.

- Investing in insurance. The experiences of microcredit institutions and bankers offer lessons. In 1996 microfinance institutions (MFIs) began operations in India with limited access to grants and equity. Banks were largely unwilling to lend to MFIs, and in 1998 BASIX was the institution that lent the largest amount of money to self-help groups. Today the majority of banks are proactively lending to such groups, and it is estimated that lending levels are well above US\$500 million. Thus there is a need to invest in the insurance market before it becomes attractive to investors. The investment should ideally come from the insurance industry itself in the form of investment in market development.

Three strategic approaches can foster the future development of micro-insurance. The first is to use technology to catalyze innovations in insurance products and processes, reduce operating costs, and increase client services; the second is to invest in data collection and management to enable players to enter the market; and the third is to pursue concept development and testing of micro-insurance products to create a "demonstration effect," whereby poor people witness the ability of insurance to protect people from risk and become convinced that insurance services are good for them as well. 


\section{Focus I5 • BRIef I3 OF I5 • MARCH 2008}

$\mathbf{L}$ ife has improved for most rural Asians, yet about 600 million still live on less than US\$1 a day, held back by low levels of health, literacy, and general well-being and by a lack of understanding of their rights and how to exercise them. Another 300 million are likely to join their ranks by 2020 .

The vast majority of these rural inhabitants still depend, directly or indirectly, on agriculture, forestry, or fishing for their sustenance. They rarely control the conditions that shape their livelihoods, however, having little income and limited access to land and other productive resources. Among the poor, women are more deprived than men, having noticeably less access to knowledge, assets, services, education, and employment.

For many rural people-smallholders, landless wage laborers and sharecroppers, small entrepreneurs, nomadic pastoralists, artisanal fishermen and -women, indigenous peoples, ethnic minorities and members of scheduled castes-voicelessness and lack of a collective organization deprive them of the power to influence decisions affecting their lives, to negotiate better terms of trade, to interact on equal terms with generally stronger market intermediaries, and to make governmental and nongovernmental organizations (NGOs) accountable to them. Indeed, most of Asia's poor are excluded from interacting fully within the political processes of their countries.

Where resource rights and security of access have been addressed, there has been a break with Asia's feudal systems. There have also been greater food security, income gains, a steady rural economy, safety net effects, lower levels of conflict, higher educational participation of children, and adoption of more sustainable resource practices.

An institutional approach to poverty reduction must have two key objectives: (1) strengthening the capacity of the rural poor and their organizations and (2) increasing access to assets, financial services, and markets. To be successful, poverty reduction efforts must recognize the rural poor for what they are-a largely untapped resource that can contribute to improving a nation's productive capacities, enlarging its domestic markets, and advancing innovation.

\section{WHY ARE RURAL INSTITUTIONS IMPORTANT?}

Rural institutions are the rules and formal and informal structures that govern the interaction among economic, social, and political organizations in rural areas. The best, and perhaps the only, way to accelerate rural poverty reduction is to harness the rural poor's underutilized capacity by creating an institutional framework that offers them a greater voice in decisionmaking and, in the process, facilitates their access to assets, financial and other services, technologies, and markets.

Two key institutions that strengthen the voice of the rural poor are (1) organizations that empower the poor and
(2) accessible financial services and markets that link the rural poor to dynamic sectors of the rural economy. Small farmers' organizations are institutional platforms for collective action to deal with problems of barriers to market access, economies of scale, and transaction costs.

\section{WHY IS THERE A NEED FOR A NEW INSTITUTIONAL FRAMEWORK?}

New institutional approaches are needed for several reasons. First, development has moved from a system in which the poor take part in officially led development programs toward one in which governments and external donors support peopleinitiated development. This strong drift away from welfare transfers toward empowerment for income generation and social development has yielded greater success.

Second, for individual producers, macroeconomic reforms have highlighted a pressing need for transition strategies that can assist the poor in coping with new uncertainties. Inadequate resources and skills prevent rural folk from participating in opportunities offered by-and avoiding the risks associated with-trade liberalization, resulting in their exclusion from the global economy.

Third, new institutions are needed that recognize the heterogeneity of circumstances. Asian governments and international donors must be particularly mindful of local particularities in the rural poor's setting and environment to ensure successful delivery of public goods and services.

Last but not least, anti-poverty initiatives need to be shielded from elite manipulation and capture. Rural institutions tend to be controlled by the powerful nonpoor. Program capture by vested interests often occurs with the collusion or acquiescence of state elites. To restrain the nonpoor and rural elites from fixing matters to their own advantage, the poor must have a direct role in setting policies affecting access to natural resources and related factor markets.

\section{ARE THERE NEW OPPORTUNITIES FOR SUCCESS?}

\section{Leveraging Social Capital}

Recent research has shown that local networks of social capital cut across traditional family, clan, tribal, or local community groups (typically, Asian collective action is characterized by shared norms of fairness, reciprocity, and trust), thus helping mobilize the scarce resources of these communities and linking them to external networks and the dynamic sectors of the economy. Improving the social capital base of the rural poor will enable them to interact with power wielders on more equitable and informed bases and thus to act more effectively on issues that affect their livelihood and well-being. 


\section{Transforming Poor Women into Agents of Change}

Rural development works best when poor rural people are agents, not recipients of charity. Enhancing women's role as agents of change in rural organizations, for example, often leads to successful economic activities and improved influence on government policies. As women begin to exercise the powers to which they have gained access, including as heads of committees, many studies from South Asia show more concessions on the part of governments (for instance, adoption of community-based budgeting), less corruption in the use of public funds, and higher spending for family and child welfare and education.

\section{Incorporating Culture and the Environment}

Making the poor and their organizations the focal point is the best way to incorporate culture and heritage into empowerment strategies. Studies report that indigenous groups have played responsible roles in rural upland organizations, acting as stewards of natural resources and biodiversity in a context where their rich traditional knowledge systems are increasingly attracting the attention of commercial interests. Innovative laws can be tools of empowerment. For instance, recent Philippine legislation granting rights of ownership and management over ancestral domain to indigenous groups is a step that can be used by disadvantaged local minorities to assert rights to their share of resources.

\section{Building on Large Gains}

There is some evidence that if the gains are large, a more rapid process of empowerment usually follows. For example, community-based water projects in central Java, Indonesia, have attracted a larger network of participating groups because they produced such large gains for participants in the process achieving scale economies.

\section{WHAT ARE THE ENTRY POINTS?}

Efforts to reduce rural poverty can be effective only if good strategies are in place to draw the poor into collective action.

\section{Empowering Organizations of the Poor (and by the Poor)}

Some organizations of the poor and by the poor are engaged in rural development in Asia. These bottom-up organizations have both a solid membership base and a coherent set of objectives derived from members' core interests. The leadership of these organized groups comes mostly, though not always, from among the members. These rural organizations include traditional village and subvillage work groups, small self-help groups, savings and credit associations, water users' associations, rural workers' unions, women's and indigenous peoples' groups, and farmer cooperatives. They are part of the social and institutional context within which rural households build and adapt their livelihoods. They simultaneously supply social capital for rural people and serve as a political resource.

Access to Markets through Producer Groups. Studies show that rural producer groups are key to promoting coordination in the rural economy and leveraging market functions for smallholder farmers and poor fisherfolk. These groups can facilitate access to credit and integrate production, processing, and collective marketing of the small marketable surpluses of many widely dispersed small producers. Such collective action allows small-scale farmers and fisherfolk to spread costs, raises their ability to pull off better deals, and improves their market power. Producer associations shorten the supply and marketing chain by directly connecting small producers to input providers, as well as secondary and tertiary markets, thus eliminating middlemen. Likewise, they can set off efforts to diversify income sources through nontraditional cropping or through off-farm employment.

Access to Resources through Collective Action. Collective action is particularly critical for managing common property resources such as forest resources or common water resources, because of their public-goods nature. Programs such as the Rajasthan Watershed Movement in India and the Gal Oya irrigation project in Sri Lanka successfully responded to the needs of small farmers in rainfed areas through social mobilization and a long process of coalition building.

To prevent collective action organizations from strengthening elite dominance and diverting benefits disproportionately to the nonpoor, the organizations should be large enough to defy capture by a few powerful individuals (although not too large to allow for self-monitoring). Even if a group is diverse and heterogeneous, homogeneity of interests should encourage solidarity among the members.

\section{Implementing Programs for the Poor to Advance Social Inclusion}

Increased Use of Partnerships with Civil Society.

Organized groups for the benefit of the poor, like NGOs and civil society groups, are top-down formations that promote, nurture, and help organize associations of poor farmers. External donors often assist these organizations, through government agencies, international voluntary organizations, or NGOs located in donor countries. Examples of the work of these groups include the following:

- supporting the education, organization, and capacity building of farmers, fisherfolk, and indigenous peoples on their rights and entitlements;

- engaging local communities in the management of common property resources;

- replicating, scaling up, and mainstreaming innovative initiatives;

- organizing communities to collectively gain access to credit, technology, and marketing services;

- ensuring direct participation of beneficiaries in gaining access to markets;

- protecting the knowledge systems of indigenous peoples while strengthening the access rights of these peoples to complementary resource management technologies;

- linking up with governments to design propoor laws and regulations; and

- serving as watchdogs over public sector agencies as well as monitoring and evaluating their performance.

Capacity Building to Make the Poor Agents of Change. Organizational capacity building is time consuming but critical to help the rural poor help themselves. Investing in capacity building for a diverse range of organizations allows people to learn how to gain access to assets and services and sharpen their business acumen in the marketplace. Organizational development is context-specific, however, and requires that each training 
program be tailored to fit particular country circumstances. A cursory profile of rural organizations suggests the need for the following competencies by its leaders and members:

- know when and how to use appropriate basic tools (such as accounting, project management, and record keeping);

- have basic knowledge of market instruments (microfinance, rural credit, and marketing);

- understand local policymaking processes, interrelationships with local governments, and the impact of policy on the organization's initiatives;

- cultivate links with external players such as stakeholders, interest groups, market players, and NGOs;

- think in a broad, strategic manner; discern options, trends, symptoms, causes, and effects; see interconnections and linkages;

- respond to challenges and opportunities with innovative yet practical solutions;

- cope well with uncertainty and change; and

- seek out opportunities for continuous learning and organizational improvement.

An important goal of capacity building is guiding the rural organizations to a stage of self-mobilization. With the appropriate skills, the rural poor can undertake initiatives without outside assistance, or they can develop contacts with external institutions for the resources and technical advice they need but retain control over how resources are used.

There is no single model for organizational transformation. NGOs are often the best group to undertake capacity building, although external donors often provide financial assistance. In some instances, the government supplies training and pays costs, as in the case of the agrarian reform communities in the Philippines.

Effective Use of Representation. Rural organizations can gain greater voice and increase their political influence if they form coalitions at higher levels. Representative associations, or networks of these associations drawn from communities and localities, have successfully confronted or conducted business with central and local governments. This strategy has proven successful for rural self-help groups in a number of states in India and in rural Sri Lanka.

\section{Developing Organizations Where They Do Not Exist}

Alone and unorganized, the rural poor face an uneven playing field that limits their access to assets, financial services, technologies, and markets, marginalizing them not only economically but also socially and politically. They become "invisible." New forms of collective organization must be developed to help the rural poor reduce transaction costs and benefit from negotiating experience. One important step in community organizing is social investigation, or the process of gathering data to identify community conditions and investigate community problems. The progress of organizing depends on whether the poor are disconnected by distance, economic groupings, caste, ethnicity, or gender. It also matters whether the poor can afford the time, costs, and risks of political activism. Civil society organizations may be the key institutions in communities struggling with the disadvantage of too little organizational infrastructure. Civil society workers can use their professional skills to make use of the community's assets and combine them with additional resources to build up the local organization.

\section{Developing Programs to Improve Context}

Creating Political Infrastructure for Rural Participation.

Asia's varied political cultures are central to understanding the effectiveness of different approaches to molding a favorable institutional environment for the rural poor because the political context defines, to a significant degree, the depth of participation that can be achieved. Instruments of participation can be used either to enfranchise the rural poor or to control them. Governments sometimes see initiatives that open up institutions to the priorities of poor groups as threatening and are reluctant to lend a helping hand.

What kind of legal or enabling environment is needed for success? Farmers' and fisherfolk organizations are usually successful proponents of change for their members and effective intermediaries when the political and institutional environment includes

- legislation securing freedom of association, encouraging the formation of groups for economic and social activities, and giving them legal recognition; and

- decentralization of political authorities and central technical ministries (agriculture, research, extension) to move them closer to their constituents and share decisionmaking (subsidiarity).

In addition, organizations can press governments to do the following:

- establish appropriate legal, regulatory, and judicial frameworks to register and protect people's resource rights;

- establish independent and accountable bodies with adequate participation by potential beneficiaries;

- ensure women's rights through communal property systems and representation in local decisionmaking bodies;

- reform macroeconomic policies that privilege large-scale farmers;

- develop human capital by investing in rural schools, health facilities, and extension services; and

- create infrastructural assets in particularly disadvantaged areas (if one of the reasons for poverty is lack of access to such assets) to prevent elite capture.

Creating Participatory Research and Development (R\&D) and Solving the "Last Mile" Problem. More decentralized research and extension systems are increasingly using demandled, participatory approaches to targeting and prioritization to make research relevant to farmers' needs. New R\&D methods and tools include participatory technology development and rapid rural appraisals, local farmers' research committees and farmers' field schools, on-farm adaptive research by NGOs, farmer-tofarmer extension systems, participation of farmers and farmers' organizations in the boards of research and extension agencies, and competitive agricultural technology funds. 
The recent explosion in information and communication technologies (ICTs) holds out promise that knowledge can flow rapidly from agricultural research centers to farmers. There is, however, the "last mile" problem to solve: the information highway stops before it reaches the farmer. Little attention has been paid to connectivity at the lowest levels. The key is to empower farmers by connecting them directly to knowledge centers and making sure they can obtain knowledge and decision aids easily.

\section{CONCLUDING REMARKS}

There are no blueprints for institutional transformation: opportunities and constraints are location-specific and empowerment strategies are context-dependent. Institutional arrangements depend on and affect people's relative power (individually and collectively). Rural organizations tend to succeed only when rural folk can manage them autonomously.

Initially, rural organization may need to surmount institutional inertia and bureaucratic self-interest. This situation highlights the importance of continuous motivation and innovation, as well as constant attention and responsiveness to the needs of the rural poor. The goal of empowering the rural poor and their organizations is to improve their ability to exercise access rights. The goal of opening more space for dialogue among rural organizations, civil society organizations, government agencies, and business is to achieve greater coherence in providing the resources to the poor. The greater well-being this approach generates will further stimulate a virtuous circle among strong institutions, good policies, and respectable rural growth and development.
For Further Reading: S. Baas and J. Rouse, Poverty Alleviation: The Role of Rural Institutions and Participation (Rome: Food and Agriculture Organization of the United Nations, 200I); A. de Janvry, “Achieving Success in Rural Development: Tools and Approaches for Implementation of an Integral Approach" (University of California at Berkeley, 2003); Economic and Social Commission for Asia and the Pacific, Rural Development and Poverty in South Asia, Development Papers No. 23 (New York: United Nations, 2003); J. Farrington, D. Carney, C. Ashley, and C. Turton, "Sustainable Livelihoods in Practice: Early Applications of Concepts in Rural Areas" Natural Resource Perspectives (Overseas Development Institute), no. 42 (June 1999); T. George and S. Morin, The Last-Mile Problem in the Information Highway: Improving the Reach of Farmers in Developing Countries (St. Joseph, MI: American Society of Agricultural and Biological Engineers, 2002), www.asabe. org (accessed September 12, 2007); International Fund for Agricultural Development (IFAD), Institutions and the Rural Poor: Building Coalitions for Rural Poverty Reduction (Rome, 200I); IFAD, “Transforming Rural Institutions in Order to Reach the Millennium Development Goals," Roundtable Discussion Paper for the 25th Anniversary Session of IFAD's Governing Council, February 2003; International Land Coalition, "Empowering the Rural Poor through Secure Access to Land," a presentation to the GTZ-IFAD Forum on Institutions-The Key to Development: Building Alliances to Empower the Rural Poor, Berlin, May 20-2I, 2003; J. Roumasset, “Rural Institutions, Agricultural Development, and Pro-Poor Economic Growth," Asian Journal of Agriculture and Development I, no. I (2005): 56-75; N. Uphoff and L. Buck, "Strengthening Rural Local Institutional Capacities for Sustainable Livelihoods and Equitable Development," paper prepared for the Social Development Department of the World Bank, Washington, DC, August 21, 2006.

Eduardo T. Gonzalez (edtgonzalez@yahoo.com) is a professor at the Asian Center, University of the Philippines, and former president of the Development Academy of the Philippines. 
D espite its remarkable development achievements, developing Asia still faces a major poverty challenge. The Asian Development Bank's (ADB's) most recent estimate of poverty revealed that nearly 690 million Asians were living on less than US\$1 a day in 2002. Further, the ADB's estimates of poverty show that the rural poverty rate is higher than the urban poverty rate throughout the region. A large proportion of the population in developing Asia lives in rural areas, suggesting that across the continent the number of rural poor is far larger than the number of urban poor.

The evidence also suggests that a disproportionate fraction of public spending in services goes to the nonpoor. The rural poor have uneven access to critical services, such as education, health, water, sanitation, and electricity. Reducing poverty tends to be more difficult when the poor have inadequate access to basic services. This concern presents policymakers in the development community with some important policy challenges. Development practitioners and researchers have produced substantial evidence identifying specific policies that empower the rural poor and provide them with improved access to services. Decentralization is considered one important governance reform strategy for improving service provision to the poor.

\section{LINKING DECENTRALIZATION WITH SERVICE DELIVERY TO THE RURAL POOR}

Decentralization-the transfer of authority and responsibility for delivery of public services to local governments-has several dimensions (political, administrative, and fiscal) and degrees (deconcentration, delegation, and devolution) (see Box 1 for details). The most common arguments in favor of decentralization are that it promotes more efficient allocation of public resources and creates opportunities for more accountable government. Making expenditure decisions at lower levels of government can raise the efficiency of public resource allocation because local governments are closer to the poor people, and probably more informed about local problems, than higher levels of government. This closeness between resource allocation decisions and their beneficiaries can thus help to correct government failures in service delivery. At the same time, decentralization may facilitate more accountable government by introducing competitive local elections, strengthening political participation, and creating mechanisms to hold politicians accountable between elections.

Theory and evidence suggest that decentralization carries some serious risks. If not thoughtfully designed, decentralization can cause loss of scale economies, generate unnecessary duplications across levels of government, and lead to even greater government failure in delivery of services to the rural poor. Another principal concern with decentralization is the possibility of elite capture of local government, which may reduce government's responsiveness to the needs of the rural poor. Therefore, development practitioners need to rigorously assess these risks by addressing the political
Box I-Decentralization: Dimensions and Degrees

ecentralization involves the transfer of decisionmaking power and responsibility for provision of public goods and services to local governments. Decentralization can have three dimensions:

- Political decentralization transfers decisionmaking power and resources to lower levels of government, encouraging citizens and their elected representatives to participate in policy decisionmaking. Under political decentralization, key local government officials are selected through local elections rather than through central government appointment.

- Administrative decentralization shifts planning and policy implementation responsibility to locally based civil servants who work under the jurisdiction of elected local governments or central government ministries or agencies.

- Fiscal decentralization involves transferring substantial responsibility for generating revenues and allocating expenditures to local governments. Under fiscal decentralization, local governments may have access to intergovernmental transfers and local borrowing.

The extent of decentralization is measured by the degree of local government autonomy from the national government:

- Deconcentration entails shifting the administrative workload from the national government to local offices without changing the rules for authority and control.

- Delegation transfers responsibility for delivery of public goods and services to lower levels of government or other organizations, which act on behalf of the central government.

- Devolution transfers full power and responsibility for delivery of public goods and services to local governments, who have legislative, revenue-raising, and decisionmaking powers.

economy of reform and evaluating the background support and factors affecting the performance of local governments. This assessment should identify appropriate dimensions and degrees of decentralization for different types of public services and match demand-side and supply-side reforms that enable the rural poor to demand and local government to deliver services with countryspecific conditions (Figure 1). 


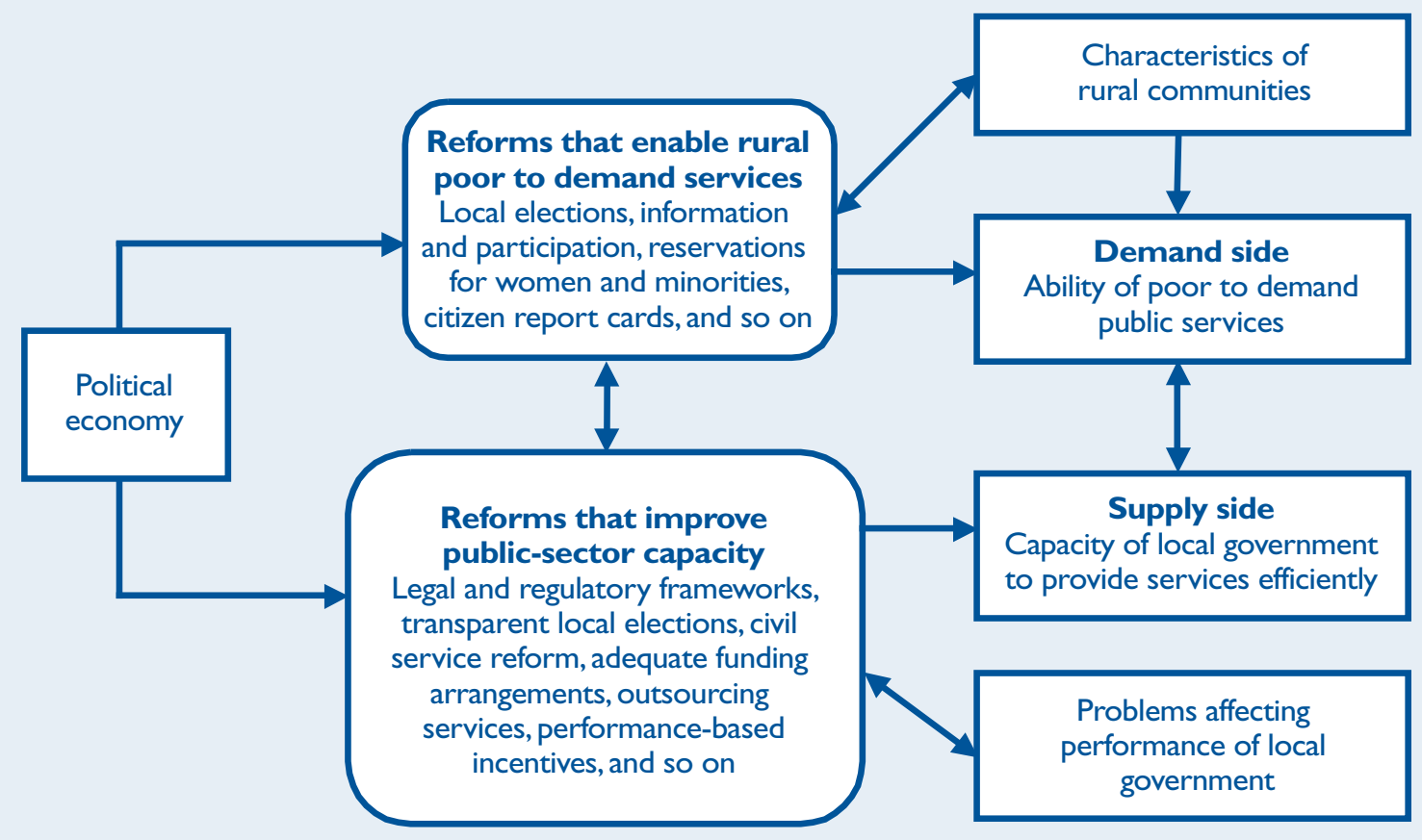

Source:Adapted from World Bank, World Development Report 2008 (New York: Oxford University Press, 2007).

\section{WHEN DECENTRALIZATION CAN PRODUCE BENEFITS IN PRACTICE}

Many developing countries, including many Asian countries from Kyrgyzstan to Indonesia, have experimented with decentralization. The results of decentralization for delivery of public services to the poor have been mixed. Country experiences show that decentralization may create an enabling environment for local governments to efficiently deliver services to the rural poor, but only under specific circumstances. What is currently known-or thought to be known-about these specific circumstances?

\section{Design and Sequencing in Implementation Influence Reform Success}

The literature suggests that design and sequencing of reform measures in the implementation stage affect the outcomes of decentralization. In 2001 Indonesia and Pakistan introduced comparable plans for comprehensive devolution reform, implementing new laws that changed the functions and roles assigned to local government. Reforms in both countries devolved political, fiscal, and administrative authority and responsibility for core public services to district-level governments, largely bypassing the provinces (Table 1). They similarly held local elections for local councils and mayors (by indirect election) and transferred large groups of civil servants to the districts to provide them with the capacity to govern. Both countries followed an approximate sequence of major activities: ensuring macroeconomic stability and control over treasury operations, establishing legal and regulatory frameworks, addressing local capacity weaknesses, and establishing facilitation networks to support and sustain reform.

The evidence suggests that service delivery to poor people in Indonesia has not improved since the country decentralized in 2001. The country still faces low efficiency of public spending, low quality of services, and inequalities in access and outcomes. Inefficiency in education is exemplified by a high rate of teacher absenteeism (19 percent) and a lack of teachers in remote areas despite an overall national surplus. Perhaps these problems existed before the reform, and increased openness has made them more visible. But confusion over the roles and responsibilities of different levels of government have caused significant additional inefficiencies. Effective monitoring and evaluation (M\&E) would have identified those deficiencies and allowed policymakers to make corrections at the implementation stage. Unfortunately, effective M\&E was not embedded in reform design; even available evidence about local capacity was not utilized in designing the decentralization reform.

The impact of decentralization on service delivery in Pakistan has not been thoroughly assessed yet. Available evidence, however, suggests that Pakistan also made inconsistent efforts to fix deficiencies in reform design. The lesson is that successful decentralization requires an embedded M\&tE system to effectively measure and assess results, to find deficiencies in reform design, and to make necessary adjustments during the implementation stage.

\section{Local Government Elections That Take into Account Local Conditions May Improve Rural Service Delivery} The most obvious institution for promoting accountability is elections. Literature on decentralization points to the importance of competitive local elections as an institutional mechanism to enable the rural poor to demand services as well as to improve local government accountability. Through their votes, rural people can send signals to government about their preferences and problems. Moreover, broad electoral participation provides greater legitimacy and authority to local government and its policies. Nevertheless, policymakers should recognize that decentralization and local elections without accompanying changes at the local level to ensure 
Table I-Comparing Decentralization Design and Implementation in Indonesia and Pakistan

\section{Component}

\section{Organizational design}

Supervisory structure and civil society feedback

Legal and regulatory Framework

Local government elections

Local revenue base

Dedicated and rule-based fiscal transfers

Capacity building

Implementation

Local revenue sufficiency

Restructuring of local offices

Performance management and budgeting

Monitoring and evaluation

Pakistan

Top-down and narrow

Few comparative inputs

Direct elections for council/

district nazim elected by council

Yes

Yes

Some emphasis

Weak

Marginal efforts

Superficial interest

Inconsistent

\section{Indonesia}

Less narrow

Comparative inputs

Direct elections for council/

district head elected by council

Yes

No

Strong emphasis

Weak

Marginal efforts

Some interest

Inconsistent

Source:Adapted from G. M. Guess, “Comparative Decentralization Lessons from Pakistan, Indonesia, and the Philippines,” Public Administration Review 65, no. 2 (2005): 217-230.

functioning democratic governance may simply increase the power of local elites rather than enable the rural poor to demand services.

China introduced local elections across tens of thousands of villages in rural areas in the early 1990s and instituted a wealth of other measures to enable villagers to protect their interests. The most important are provisions allowing local protests and media coverage of egregious violations and permitting lawsuits against officials responsible for grievances. The evidence suggests that elected local governments tend to tax rural people less and provide them with higher levels of public services than do local governments with appointed cadres.

Another mechanism for making local governments work for the rural poor is mandated political reservations for disadvantaged groups (women, minorities, and scheduled castes). Reservation policies may have an important impact on disadvantaged groups' representation in local government. In a 2004 study Chattopadhyay and Duflo examined the policy consequences of mandated representation of women in India, where one-third of village council head positions are randomly reserved for women. Their results suggest that mandated reservation affects policy choices in ways that appear to better reflect women's preferences. In West Bengal women's major concerns are drinking water and roads, and these two areas receive more public investments under village council headships reserved for women. Likewise, in Rajasthan, women are more concerned about drinking water than men but less about roads, and under female village council heads, there are more investments in water and less investments in roads.

\section{Policy Coherence Is Important}

The evidence suggests that decentralization might be effective in improving service delivery to the rural poor only if other policy changes are implemented simultaneously and the reform does not contradict other programs and policies undertaken by government. One important pitfall associated with decentralization is that existing inequality and lack of credible political competition allow local elites to capture government. In this kind of environment, decentralization might be effective only if pre-existing inequalities are addressed simultaneously and appropriately. For example, in West Bengal decentralization reforms have been linked to comprehensive and successful land reform and provisions for the rights of women and other less-powerful groups. This cohesive and participatory reform process improved information flow and created awareness among the rural poor, enabling them to demand services. The power of the traditional rural elite was diminished as a consequence of both regular local elections and successful land reform. Rigorous evaluations have shown that access to water and sanitation, the provision of agricultural input kits, and credit to the rural poor improved significantly.

\section{Improving Information Matters}

One of the important problems in developing countries in general, and in rural areas in particular, is that policymakers as well as ordinary citizens have limited access to information. In this kind of environment, increasing the amount of information available may help. E-government-the use by government agencies of information technologies-can affect decentralization by improving government's interactions with citizens and service providers and enhancing intragovernmental and intergovernmental exchange. Thus, local governments can function more effectively and productively by digitizing existing government processes and thereby improve service delivery.

The transfer of primary school teachers, a critical public policy issue in South Asia, significantly affects service delivery to rural people. Because demand for transfers is significantly higher than available opportunities, bad governance and influence play important roles in the decisionmaking. Transfer orders often contradict each other, teachers are disgruntled, and the needs of poor people are often sacrificed. In two Indian states-Karnataka and Madhya Pradesh-governments implemented a computer-aided system that identifies surplus posts and teachers as well as schools with teacher shortages, publishes a database of all openings, and helps to make a decision. This citizen-centric e-government innovation has improved information and introduced transparency, openness, fairness, and rationalization into government decisionmaking. 
Other evidence shows that e-government can improve land administration. Karnataka computerized more than 20 million records of landownership for 6.7 million farmers. Introducing e-government helped modernize the entire process of keeping records of rights tenancy and crops by eliminating the delays, harassment, and bribery that had been widespread. Now farmers can obtain a printed copy of an online land record for Rs. 15 (US\$0.32) at computerized land record kiosks in more than 140 offices around the state.

\section{Community-Driven Development Initiatives Can Help to Create Local Capacity}

The literature and field experience suggest that communitydriven development (CDD) can empower both local governments and the rural poor by promoting greater civic participation, voice, and accountability in local governance, by delivering cost-effective services to the rural poor, and by informing and formulating necessary corrections to the decentralization process. Since the mid-1990s, the World Bank and other donors have been using CDD in Kyrgyzstan to improve the delivery of social and infrastructure services to the rural poor.

During the country's transition, the collapse of most stateowned enterprises and the dramatic decline in public resources caused a sharp deterioration of most social and economic services, especially in rural areas, which are home to nearly two-thirds of the country's population. The government introduced a policy of gradual decentralization and looked to international donors for help in generating community-level capacity and commitment to resolve local problems. International donors provided both financial and technical assistance for CDD activities as well as structural and governance reforms. For example, the World Bank's Village Investment Project (VIP) helped improve governance and capacity at the village level and strengthened the delivery of basic services.

These CDD activities helped the government of Kyrgyzstan establish functioning rural community organizations and improved access to basic social and economic infrastructure services such as safe drinking water, health facilities, schools, irrigation, and roads. Now local self-government is a right guaranteed by the Constitution, and decentralization is an integral part of the political and economic transformation and the overall development strategy of Kyrgyzstan. There are 487 local self-government bodies, and the majority of local government heads are elected. According to the new rules, local governments are entitled to have their own budgets and make resource allocation decisions. It is expected that the new system will make local governments more accountable for managing their budgets as they make decisions about revenues and expenditures. The new system also assumes intergovernmental fiscal linkages and revenue-sharing arrangements. It remains to be seen whether decentralization will bring about any real improvements in access to and quality of services for the rural poor, but CDD efforts have invigorated the public debate, created local government capacity, and enabled the rural poor to demand services.

\section{CONCLUSION}

Even if the Millennium Development Goal for poverty and hunger is achieved, millions of the world's poor people, especially in rural areas, will be left behind, and the challenge of providing access to public services for the rural poor will remain. The importance of well-designed and-sequenced decentralization measures to improve local government capacity and enable the rural poor to demand services will increase. A number of factors can help make decentralization more effective in delivering services to the rural poor. These factors include M\&E systems embedded in reform packages; measures that address pre-existing local conditions and inequalities; improvements in information sharing between government, service providers, and rural people; and CDD initiatives. It is also important that national governments and donors support policies that increase the accountability and transparency of local governments.

For Further Reading: ADB (Asian Development Bank), Key Indicators 2004: Poverty in Asia: Measurement, Estimates, and Prospects (Manila, 2004); ADB, U.K. Department for International Development (DFID), and World Bank, Devolution in Pakistan: An Assessment and Recommendations for Action, Research Report (Manila, London, and Washington, DC, 2005); P. Bardhan and D. Mookherjee, eds., Decentralization and Local Governance in Developing Countries: A Comparative Perspective (Boston: MIT Press, 2006); P. Bardhan and D. Mookherjee, "Pro-Poor Targeting and Accountability of Local Governments in West Bengal," Journal of Development Economics 79, no. 2 (2006): 303-327; R. Birner and N. Palaniswamy, "Public Administration Reform and Rural Service Provision: A Comparison of India and China" in S. Fan and L. Zhang, eds., Poverty Reduction Strategy in the New Millennium: Emerging Issues, Experiences and Lessons (Beijing: China Financial and Economic Publishing House, forthcoming); G. M. Guess, "Comparative Decentralization Lessons from Pakistan, Indonesia, and the Philippines," Public Administration Review 65, no. 2 (2005): 217-230; J. Jütting, E. Corsi, C. Kauffmann, I. Mcdonnell, H. Osterrieder, N. Pinaud, and L. Wegner, "What Makes Decentralization in Developing Countries ProPoor?" The European Journal of Development Research 17, no. 4 (2005): 626-648; K. B. C. Saxena, "Towards Excellence in EGovernance," International Journal of Public Sector Management I8, no. 6 (2005): 498-5I3; S. Wong and S. Guggenheim, "Community-Driven Development: Decentralization's Accountability Challenge," in East Asia Decentralizes: Making Local Government Work (Washington, DC: World Bank, 2005); World Bank, World Development Report 2004: Making Services Work for Poor People (New York: Oxford University Press, 2003); World Bank, Making Services Work for the Poor in Indonesia: Focusing on Achieving Results on the Ground (Washington, DC, and Jakarta, Indonesia, 2006); World Bank, World Development Report 2008 (New York: Oxford University Press, 2007); J. S. L. Yong and S. Sachdeva, "India: e-Progress in the States," in J. S. L. Yong, ed., Enabling Public Service Innovation in the 2Ist Century: E-Government in Asia (Singapore: Times Edition, 2003); X. Zhang, S. Fan, L. Zhang, and J. Huang, "Local Governance and Public Goods Provision in Rural China," Journal of Public Economics 88, no. 12 (2004): 2857-287I.

Kamiljon Akramov (k.akramov@cgiar.org) is a postdoctoral fellow in the Development Strategy and Governance Division of the International Food Policy Research Institute (IFPRI). The author would like to thank Regina Birner, Ruth Vargas Hill, Nurul Islam, and Rajul Pandya-Lorch for their valuable comments and suggestions.

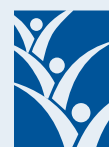

International Food Policy Research Institute 2033 K Street, N.W. • Washington, D.C. 20006-1002 • U.S.A. Phone: +I-202-862-5600 • Fax: +I-202-467-4439•Email: ifpri@cgiar.org 
$\mathbf{P}$ ublic investments in developing countries have contributed significantly to agricultural growth and rural poverty reduction in rural areas, and to urban poverty reduction through growth in the national economy and lower food prices. Without such investments, agricultural and national economic growth would have been much slower, and many more rural and urban people in developing countries would be poor. Yet, despite these successes, the poor still number about one billion in these countries, and many still face severe government budget constraints. Thus, public resources need to be targeted more effectively to the sectors and regions that can generate the largest economic growth and poverty reduction. This brief presents a synthesis and review of several case studies conducted by IFPRI and its national collaborators to quantify the effects of government spending on both growth and poverty reduction in Asian countries representing different stages of economic development and, hence, the need for different spending priorities.

\section{GOVERNMENT SPENDING IN ASIA}

Over the last two decades of the 20th century, total government spending in Asian developing countries based on a data set for Bangladesh, China, India, Indonesia, South Korea, Malaysia, Myanmar, Nepal, Philippines, Sri Lanka, and Thailand grew rapidly. Expenditures increased from $\$ 500$ billion in 1980 to $\$ 871$ billion in 1990 (in 2000 international dollars) -an annual growth rate of 5.7 percent. In the 1990s, governments further increased their spending power by 9.1 percent per year, such that total government expenditures reached $\$ 2,084$ billion in 2000, and grew to $\$ 2,921$ billion in 2004. This represents a significant acceleration in public spending growth.

Equally important is the composition of government expenditures, which reflects government spending priorities. Developing-country education spending in Asia was the largest among all government expenditures in the region, accounting for 12 percent in 2004. It is not surprising that Asia has the highest quality of human capital. Defense and agriculture spending ranked second and third, accounting for 8 and 7 percent, respectively, in 2004, falling from 18 and 15 percent, respectively, in 1980. Other expenditures (which include government spending in fuel and energy, mining, manufacturing and construction, and general administration) increased from 35 percent in 1980 to 63 percent in 2004. The large and increasing share of these expenditures may have competed with more productive spending, such as in agriculture, education, and infrastructure.

Agriculture is the largest sector in many developing countries in terms of their shares of GDP and employment. More importantly, the majority of the world's poor live in rural areas and depend on agriculture for their livelihoods. Therefore, agricultural expenditure is one of the most important government instruments for promoting economic growth and alleviating poverty.
Agricultural expenditures in Asia more than doubled in the past two decades, with an annual growth rate of 4.2 percent. Compared with developed countries, agricultural spending as a percentage of agricultural GDP is extremely low in developing countries. In developed countries, the share is usually more than 20 percent, while in developing countries it averages less than 10 percent. For Asia, the share remained constant at 8.5-10 percent over this timeframe. South Korea allocates close to half of its agricultural GDP to the agricultural sector. It is followed by China and Thailand, which spent 11 percent of agricultural GDP on agriculture. For many countries, the spending allocation-whether in terms of shares of agricultural GDP or the total national budget-have fallen over time. The decline is particularly sharp in Bangladesh, Sri Lanka, Nepal, Indonesia, and Myanmar. This will have important implications for future productivity growth in agriculture in these countries and for poverty reduction.

\section{PUBLIC SPENDING AFFECTS POVERTYTHROUGH MULTIPLE CHANNELS}

Public investment affects rural poverty through many channels.

For example, public investment in agricultural research, rural education, and infrastructure increases agricultural productivity, which directly increases farmers' incomes and reduces rural poverty. Indirect impacts come from higher agricultural wages and improved nonfarm employment opportunities induced by growth in agricultural productivity. Increased agricultural output from rural investment often leads to lower food prices, again helping the poor indirectly because they are often net buyers of food grains. Redistribution of land caused by higher agricultural growth also affects rural poverty. Public investments in rural education, health, and infrastructure directly promote rural wage increases, nonfarm employment, and migration, thereby reducing rural poverty, but they also have further indirect effects in each of these areas by increasing productivity. For example, improved access to infrastructure will assist in the establishment of small, rural nonfarm businesses such as foodprocessing and marketing enterprises, electronics repair shops, and transportation- and trade-related enterprises. Improved infrastructure will also support higher volumes of sales transactions in areas like farm and industrial products, restaurants, and other service-oriented businesses.

Investments in rural sectors not only contribute to growth, employment, and wages in rural areas, but also to the development of the national economy by providing labor, human and physical capital, cheaper food, and markets for urban industrial and service development. Growth in the national economy reduces poverty in both rural and urban sectors. Understanding these different effects provides useful policy insights for improving the effectiveness of national poverty reduction strategies. In particular, an understanding of these effects enables public investment to be used to strengthen weak links in poverty reduction channels and, thus, to allocate public 
resources more efficiently. More efficient targeting has become even more crucial as many developing countries have committed to achieving poverty reduction targets of the Millennium Development Goals, despite limited public resources.

\section{THE IMPACT OF PUBLIC SPENDING IN INDIA}

Using state-level data spanning 1970 to 1993, the India study clearly shows that additional government expenditure on roads has the largest poverty-reducing impact, as well as a significant impact on productivity growth (Table 1). For every 1 million rupees spent on rural roads, 124 poor people could be lifted above the poverty linethe largest rate of poverty reduction among all types of investment. Furthermore, 1 rupee invested in rural roads would generate more than 5 rupees in returns from agricultural production, which is the second-largest production growth effect after agricultural research and development (RED). Additional government spending on agricultural $R \& D$ and extension has the largest impact on production growth, with a cost-benefit ratio of 13; it also leads to large rural poverty-reduction benefits, second only to rural road investment. Additional government spending on education has the third-largest impact in reducing rural poverty, largely because of the increases in nonfarm employment and rural wages that it induces. Finally, public investment in irrigation has an impact on agricultural productivity similar to that of education investments and only a small impact in reducing rural poverty.

Another study found that, for every type of investment, the highest marginal impact on agricultural production and poverty alleviation occurs in rainfed lands, while irrigated areas rank second or last. Moreover, many types of investments in low-potential rainfed lands yield some of the highest production returns, and all investments except education have some of the most favorable impacts on poverty. These results strongly suggest that more investment should be channeled into less-favored areas.

\section{THE IMPACT OF PUBLIC SPENDING IN CHINA}

The Chinese case studies indicate that government expenditure on education had the largest impact on reducing rural poverty and regional inequality and had significant impact on production growth

Table I-Returns to Agricultural Research in India, State-Level Analysis, 1993

\begin{tabular}{lcc}
\multicolumn{1}{c}{ Sector } & $\begin{array}{c}\text { Returns } \\
\text { in Rupee }\end{array}$ & $\begin{array}{c}\text { Numbers of } \\
\text { Poor Reduced } \\
\text { per Million } \\
\text { Rupees }\end{array}$ \\
\hline R\&D & 13.45 & 84.5 \\
Irrigation & 1.36 & 9.7 \\
Roads & 5.31 & 123.8 \\
Education & 1.39 & 41.0 \\
Power & 0.26 & 3.8 \\
Soil and water conservation & 0.96 & 22.6 \\
Health & 0.84 & 25.5 \\
Anti-poverty programs & 1.09 & 17.8 \\
\hline
\end{tabular}

Source: Calculated by authors from S. Fan, P. Hazell, and S. Thorat, "Government Spending, Agricultural Growth, and Poverty in Rural India," American Journal of Agricultural Economics (Vol. 82, No. 4, 2000).

(Table 2). Increased rural nonfarm employment was responsible for much of this poverty- and inequality-reducing effect. Government spending on agricultural R\&D had the largest impact on agricultural production growth. The benefits of agricultural production growth also trickled down to the rural poor, with the poverty-reduction effect per unit of additional agricultural R\&D investment ranking second after investment in rural education. Government spending on rural infrastructure (roads, electricity, and telecommunications) had a substantial impact on poverty and inequality, mainly through improved opportunities for nonfarm employment and increased rural wages. Investments in irrigation had only a modest impact on agricultural production growth and an even smaller impact on rural poverty and inequality.

For all types of government spending, the poverty-reducing returns to investments were highest in the less-developed western region, while returns from agricultural production growth were the highest in the more developed central region for most types of spending. Furthermore, investments in the western region led to the greatest reductions in regional inequality for all types of government spending, while investments in either coastal or central regions exacerbated large regional inequalities. Another study found

Table 2-Returns to Public Investment in China, 2000

Investment

Returns to total rural GDP
R\&D
Irrigation
Roads
Education
Electricity
Telephone

Returns to agricultural GDP $R \& D$ Irrigation

Roads

Education

Electricity

Telephone

Returns to nonfarm GDP

Roads
Education
Electricity
Telephone

Returns to poverty reduction

R\&D
Irrigation
Roads
Education
Electricity
Telephone
Poverty loan

Source: S. Fan, L. Zhang, and X. Zhang, "Investment, Reforms, and Poverty in Rural China," Economic Development and Cultural Change (Vol. 52, No. 2, 2004). 
that low-grade (mostly rural) roads have cost-benefit ratios for national GDP that are about four times larger than the cost-benefit ratios for high-grade, mostly urban, roads. Even in terms of urban GDP, the cost-benefit ratios for low-grade roads are much greater than for high-grade roads. In terms of agricultural GDP, high-grade roads have no statistically significant impact, while low-grade roads are not only significant, but also generate 1.57 yuan of agricultural GDP for every yuan invested. Investment in low-grade roads also generates high returns in rural nonfarm GDP.

Every yuan invested in low-grade roads yields more than 5 yuan of rural nonfarm GDP. Equally important in terms of poverty reduction, low-grade roads raise far higher numbers of rural and urban poor above the poverty line per yuan invested than do highgrade roads.

\section{THE IMPACT OF PUBLIC SPENDING IN VIETNAM}

The results from Vietnam reveal that government investment in education has the largest poverty-reducing impact, followed by roads and agricultural R\&D (Table 3 ), while investment in agricultural R\&D has the largest return to agricultural growth, followed by roads. Investment in irrigation has the smallest impact on both agricultural growth and poverty reduction. The large poverty impacts resulting from investment in education and roads are derived from improved nonfarm employment opportunities, which accounted for 89 percent of the total education impact on poverty. The remaining gains

Table 3-Returns to Public Investment in Vietnam, 2000

\begin{tabular}{|c|c|c|c|}
\hline Region & Irrigation & Roads & Education \\
\hline & \multicolumn{3}{|c|}{ Dong per dong spending } \\
\hline Northern uplands & 0.21 & 1.87 & 0.95 \\
\hline Red River delta & 0.40 & 3.26 & 2.08 \\
\hline Central north & 0.22 & 3.27 & 1.01 \\
\hline Central coast & 0.21 & 2.44 & 1.23 \\
\hline Highlands & 0.28 & 3.09 & 1.97 \\
\hline Southeast & 1.33 & 3.30 & 4.66 \\
\hline Mekong River delta & 0.37 & 3.40 & 2.08 \\
\hline Vietnam total & 0.42 & 3.01 & 2.06 \\
\hline \multirow[t]{2}{*}{ Total agricultural R\&D } & & 12.22 & \\
\hline & \multicolumn{3}{|c|}{ Numbers of poor reduced per billion dong } \\
\hline Northern uplands & 12.03 & 153.04 & 65.60 \\
\hline Red River delta & 7.93 & 91.38 & 49.40 \\
\hline Central north & 14.90 & 311.57 & 81.28 \\
\hline Central coast & 12.99 & 215.58 & 92.31 \\
\hline Highlands & 8.37 & 130.54 & 70.14 \\
\hline Southeast & 27.85 & 98.64 & 117.64 \\
\hline Mekong River delta & 5.68 & 74.14 & 38.24 \\
\hline Vietnam total & 12.93 & 132.34 & 76.40 \\
\hline Total agricultural R\&D & & 338.96 & \\
\hline
\end{tabular}

Source: S. Fan, L. Zhang, and X. Zhang, “Investment, Reforms, and Poverty in Rural China," Economic Development and Cultural Change (Vol. 52, No. 2, 2004). resulted from improved agricultural production. For roads, improved nonfarm opportunities accounted for 67 percent of the total effect of road investment.

\section{THE IMPACT OF PUBLIC SPENDING INTHAILAND}

The Thailand case study found that additional government spending on agricultural R\&D improves agricultural productivity the most and has the second-largest impact in reducing rural poverty (Table 4). Investments in rural electrification have the largest impact on rural poverty and the second-largest impact on growth. These two investments dominate all others. Road expenditure has the third-largest impact in reducing rural poverty, but only a modest and statistically insignificant impact on agricultural productivity. Government spending on rural education has only the fourth-largest impact on poverty, but a significant economic impact through improved agricultural productivity. Irrigation investment has the smallest impact both in reducing rural poverty and in improving agricultural productivity. Disaggregating the investments shows that additional investments in the northeast-especially in electricity and roads-contribute more to reducing poverty than do investments in other regions. Since the growth impacts of many investments are also greater in the northeast than in other regions, there is no evident trade-off between investments for growth and investments for poverty reduction.

\section{CONCLUSIONS AND IMPLICATIONS FOR SPENDING STRATEGY}

Increasing public rural investment significantly is difficult-if not unlikely-so countries must use their public investment resources

Table 4-Returns to Public Investment in Rural Thailand, 1999

Investment Northeast North Central South Thailand Cost-benefit ratio (bhat/bhat)

Agricultural

$\begin{array}{lccccc}\text { R\&D } & \text { n.a } & \text { n.a. } & \text { n.a. } & \text { n.a. } & 12.62 \\ \text { Irrigation } & 0.76 & \text { I.II } & 0.55 & 0.62 & 0.7 \mathrm{I} \\ \text { Roads } & \mathrm{I} .23 & \mathrm{I} .23 & 0.44 & \mathrm{I} .24 & 0.86 \\ \text { Education } & \mathrm{I} .26 & 2.92 & 2.89 & 2.5 \mathrm{I} & 2.12 \\ \text { Electricity } & 8.66 & 8.04 & 2.59 & 5.48 & 4.89 \\ \text { Phone } & \text { n.s. } & \text { n.s } & \text { n.s } & \text { n.s } & \text { n.s }\end{array}$

Agricultural

$\begin{array}{lllll}\text { R\&D n.a n.a n.a } & \text { n.a } 138.10\end{array}$

$\begin{array}{llllll}\text { Irrigation } & 21.05 & 5.22 & \text { I.74 } & 4.53 & 7.69\end{array}$

$\begin{array}{llllll}\text { Roads } & 483.39 & 82.71 & 19.48 & 130.12 & 126.25\end{array}$

$\begin{array}{llllll}\text { Education } & 34.74 & 13.71 & 9.08 & 18.53 & 22.75\end{array}$

$\begin{array}{llllll}\text { Electricity } & 1,253.02 & 198.57 & 42.79 & 211.99 & 276.07\end{array}$

$\begin{array}{lllll}\text { Phone n.s n.s n.s n.s } & \text { n.s }\end{array}$

Source: S. Fan, S. Jitsuchon, and N. Methakunnavut, The Importance of Public Investment for Reducing Rural Poverty in Middle-Income Countries:The Case of Thailand, DSGD Discussion Paper No. 7 (Washington, DC: IFPRI, 2004).

Notes: n.a. indicates not available; n.s. indicates statistically insignificant. 
more efficiently. This requires improved targeting of investments to achieve growth and poverty-alleviation goals, as well as improved efficiency within the agencies that provide public goods and services. Reliable information on the marginal effects of various types of government spending is crucial for governments to be able to make sound investment decisions. Despite the countries' vast differences in economic systems, natural resource endowments, socioeconomic conditions, and size, these case studies offer some important lessons:

1. Agricultural research, education, and rural infrastructure are the three most effective types of public spending for promoting agricultural growth and reducing poverty.

2. Evidence from China indicates that it is often the low-cost types of infrastructure that may have highest payoffs in terms of growth and poverty reduction per unit of investment. Rural road investment not only contributes to rural growth and poverty reduction, but also to urban growth and poverty reduction.

3. Regional analysis conducted for China, India, Thailand, and Vietnam suggests that more investments in many lessdeveloped areas not only offer the largest poverty reduction per unit of spending, but also lead to the highest economic returns.

4. Government spending on anti-poverty programs generally has only a small impact in reducing poverty, mainly due to inefficient targeting and misuse of the funds. Although many governments have realized the seriousness of the problem, it is essential to improve the targeting of funds to the poor, or otherwise use the investments to improve rural education and infrastructure, which promote long-term growth and hence a long-term solution to reducing poverty.

5. Government spending on irrigation played an important role in promoting agricultural growth and reducing poverty in the past, but today this type of spending has smaller marginal poverty and growth returns for many Asian countries. Instead of increasing investment in irrigation, the efficiency of the current public irrigation system should be improved by reforming public institutions and governance.

The case studies also indicate that different spending priorities are needed during different stages of development; "one-sizefits-all" strategies do not work. During the first phase, strategies should focus on reducing widespread poverty through broad-based economic growth that reaches rural areas. In subsequent phases, more direct attention should be focused on lagging sectors and regions, as well as on poverty at the community and household levels, in order to reduce the poverty and income inequalities that arise and persist despite reform.

Many Asian countries, including Bangladesh, Laos, Myanmar, Nepal, and Pakistan, are still in the first phase of development. Investments to support economic growth are vital to efforts to reduce their mass poverty. In these countries governments have the central responsibility of forging a well-sequenced, coherent growth strategy, while at the same time determining which public investments are required. Public investment in infrastructure and agriculture are the main areas in need of attention.

Countries such as China, India, Vietnam, and Thailand have successfully completed the first phase of poverty reduction and now need to begin to address regional inequities and poverty issues at the household level. China has traditionally favored a sectoral and regional targeting approach (such as employment programs) to deal with rising inequalities but has recently expanded to more household- and community-targeted programs. India, in contrast, has concentrated on targeting specific sections of the population and has recently expanded employment programs, too. India's experience shows that the use of a variety of targeted programs directed to specific sections of the poor can help improve targeting compared with the broader income- or area-based approaches.

For Further Reading: S. Fan, L. Zhang and X. Zhang, "Investment, Reforms, and Poverty in Rural China," Economic Development and Cultural Change (Vol. 52, No. 2, 2004); S. Fan, X. Zhang, and N. Rao, Public Expenditure, Growth, and Poverty Reduction in Rural Uganda, DSG Discussion Paper No. 4 (Washington, DC: IFPRI, 2004); S. Fan, P. Hazell, and S. Thorat, "Government Spending, Agricultural Growth, and Poverty in Rural India," American Journal of Agricultural Economics 82, no. 4 (2000); S. Fan, P. Hazell, and T. Haque, "Targeting Public Investments by Agroecological Zone to Achieve Growth and Poverty Alleviation Goals in Rural India," Food Policy 25, no. 4 (2000); S. Fan and C. Chan-Kang, Road Development, Economic Growth, and Poverty Reduction in China, Research Report No. I38 (Washington, DC: IFPRI, 2005).

Shenggen Fan (s.fan@cgiar.org), Joanna Brzeska (j.brzeska@cgiar.org), and Ghada Shields (g.shields@cgiar.org) are division director, research analyst, and consultant, respectively, in the Development Strategy and Governance Division of the International Food Policy Research Institute. This brief is based on a 2020 Focus Brief published by IFPRI in 2007 and originally prepared for a policy consultation process coordinated by IFPRI on the World's Poor and Hungry People. 


\section{Download or Order All IFPRI 2020Vision Focus Briefs}

\section{http://www.ifpri.org/pubs/catalog.htm\#focus}

14: Bioenergy and Agriculture: Promises and Challenges (I 2 briefs)

Edited by Peter Hazell and R. K. Pachauri

13: Understanding the Links between Agriculture and Health (I 6 briefs)

Edited by Corinna Hawkes and Marie T. Ruel

12: Building on Successes in African Agriculture (10 briefs)

Edited by Steven Haggblade

I I: Collective Action and Property Rights for Sustainable Development (I6 briefs)

Edited by Ruth S. Meinzen-Dick and Monica Di Gregorio

10: Food Safety in Food Security and Food Trade (I 7 briefs)

Edited by Laurian Unnevehr

9: Overcoming Water Scarcity and Quality Constraints (I 4 briefs)

Edited by Ruth S. Meinzen-Dick and MarkW. Rosegrant

8: Shaping Globalization for Poverty Alleviation and Food Security (I 3 briefs)

Edited by Eugenio Díaz-Bonilla and Sherman Robinson

7: Appropriate Technology for Sustainable Food Security (9 briefs)

Edited by Per Pinstrup-Andersen

6: Empowering Women to Achieve Food Security (I 2 briefs)

Edited by Agnes R. Quisumbing and Ruth S. Meinzen-Dick

5: Health and Nutrition: Emerging and Reemerging Issues in Developing Countries (I I briefs)

Edited by Rafael Flores and Stuart Gillespie

4: Promoting Sustainable Development in Less-Favored Areas (9 briefs)

Edited by John Pender and Peter Hazell

3: Achieving Urban Food and Nutrition Security in the Developing World (IO briefs)

Edited by J. L. Garrett and M.T. Ruel

2: Biotechnology for Developing-Country Agriculture: Problems and Opportunities (I 0 briefs) Edited by Gabrielle J. Persley

I: Getting Ready for the Millennium Round Trade Negotiations (9 briefs)

Edited by Eugenio Díaz-Bonilla and Sherman Robinson 


\section{REDUCING POVERTY AND HUNGER IN ASIA The Role of Agricultural and Rural Development}

\section{Edited by Nurul Islam}

I. Agricultural and Rural Development for Reducing Poverty and Hunger in Asia: Past Performance and Priorities for the Future - Nurul Islam and Joachim von Braun

2. Poverty in Asia and the Transition to High-Priced Food Staples • C. Peter Timmer

3. Asia's Poorest and Hungry:Trends and Characteristics • Akhter U Ahmed, Ruth V. Hill, Doris M. Wiesmann, and Lisa C. Smith

4. Economic Exclusion and Poverty in Asia:The Example of Castes in India - Sukhadeo Thorat

5. Women's Status and the Changing Nature of Rural Livelihoods in Asia • Agnes R. Quisumbing

6. Agriculture in Asia: Challenges and Opportunities - MarkW. Rosegrant, Claudia Ringler,Timothy B. Sulser, Siwa Msangi, Tingju Zhu, Rowena Valmonte-Santos, and Stanley Wood

7. Asian Food Market Transformation: Policy Challenges to Promote Competitiveness with Inclusiveness • Ashok Gulati and Thomas Reardon

8. Changing Sources of Household Income and Poverty Reduction in Rural Asia, 1985-2004 - Keijiro Otsuka and Jonna P. Estudillo

9. How and When Road Investments Encourage Inclusive Growth: Learning from the Asian Development Bank's Experience • Hemamala Hettige

10. Strategies for Developing and Disseminating Improved Rice Technologies for the Poor - Robert Zeigler

II. Climate Change in the Context of Asia: Pro-Poor Adaptation, Risk Management, and Mitigation Strategies - Gary Yohe, lan Burton, Saleemul Huq, and Mark W. Rosegrant

12. Risks Faced by Rural Households and Private-Sector Insurance Initiatives in India • D. Sattaiah

13. Developing Rural Institutions That Strengthen the Voice of the Rural Poor • Eduardo T. Gonzalez

14. Decentralization and Public Service Delivery to the Rural Poor • Kamiljon T.Akramov

15. Investment Priorities for Economic Growth and Poverty Reduction in Asia - Shenggen Fan, Joanna Brzeska, and Ghada Shields

Copyright @ 2008 International Food Policy Research Institute. All rights reserved. For permission to republish, contact ifpri-copyright@cgiar.org.

International Food Policy Research Institute • $2033 \mathrm{~K}$ Street, NW Washington, DC 20006-1002 USA

Phone: + I-202-862-5600 - Skype: IFPRIhomeoffice Fax: + I-202-467-4439• Email: ifpri@cgiar.org

IFPRI $^{\oplus}$ www.ifpri.org

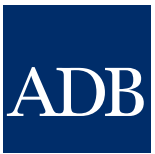

Postal Address: P.O. Box $789 \cdot 0980$ Manila, Philippines Street Address: 6 ADB Avenue - Mandaluyong City 1550, Philippines Tel.: + 6326324444 (connecting all Depts./Offices) Fax: + 6326362444 www.adb.org 